LAWRENCE LIVERMORE N A T IO N A L LABORATORY
THE EFFECT OF SULFATE ANIONS ON CREVICE CORROSION IN ALLOY 22

Gabriel O. Ilevbare

August 27, 2004 
This document was prepared as an account of work sponsored by an agency of the United States Government. Neither the United States Government nor the University of California nor any of their employees, makes any warranty, express or implied, or assumes any legal liability or responsibility for the accuracy, completeness, or usefulness of any information, apparatus, product, or process disclosed, or represents that its use would not infringe privately owned rights. Reference herein to any specific commercial product, process, or service by trade name, trademark, manufacturer, or otherwise, does not necessarily constitute or imply its endorsement, recommendation, or favoring by the United States Government or the University of California. The views and opinions of authors expressed herein do not necessarily state or reflect those of the United States Government or the University of California, and shall not be used for advertising or product endorsement purposes.

This work was performed under the auspices of the U.S. Department of Energy by University of California, Lawrence Livermore National Laboratory under Contract W-7405-Eng-48. 


\title{
THE EFFECT OF SULFATE ANIONS ON CREVICE CORROSION IN ALLOY 22
}

\author{
G.O. Ilevbare \\ Lawrence Livermore National Laboratory \\ 7000 East Avenue, Livermore, California 94550
}

\begin{abstract}
The electrochemical behavior of Alloy 22 was studied in $4 \mathrm{M} \mathrm{NaCl}$, and $4 \mathrm{M} \mathrm{NaCl}$ with sulfate additions of 0.4 and $0.04 \mathrm{M}$ between 45 and $105{ }^{\circ} \mathrm{C}$ using Multiple Crevice Assembly (MCA) specimens. The susceptibility to localized corrosion was found to decrease in the presence of sulfate ions in solution.
\end{abstract}

Keywords: Alloy 22, crevice corrosion, inhibition, corrosion potential, breakdown potential, repassivation potential, cyclic polarization, sulfate, chloride, temperature.

\section{INTRODUCTION}

Alloy 22 (UNS number N06022) is a nickel alloy rich in chromium and molybdenum. It possesses a high degree of corrosion resistance. Compared with other nickel alloys, Alloy 22 exhibits a lower general corrosion rate under most conditions and has better localized corrosion 
resistance in most environments [1-8]. For this reason, Alloy 22 is used in a wide variety of industrial applications.

While the effect of $\mathrm{SO}_{4}{ }^{2-}$ on localized corrosion has been extensively characterized for stainless steels and some nickel alloys, relatively little data in this area of study is available for Alloy 22. However, valuable insight into how Alloy 22 might behave in $\mathrm{SO}_{4}{ }^{2-}$ containing environments might be acquired from studies performed on stainless steels (SS) and other nickel (Ni) alloys. It has been found that sulfate ions $\left(\mathrm{SO}_{4}{ }^{2-}\right)$ have the ability to mitigate several forms of localized corrosion including pitting corrosion, crevice corrosion, and stress corrosion cracking in chloride $\left(\mathrm{Cl}^{-}\right)$environments in stainless steels and Ni alloys, [9-22]. However, some authors have also found that $\mathrm{SO}_{4}{ }^{2-}$ could also act as a promoter of localized corrosion under certain environmental conditions in some stainless steels and Ni alloys [16, 17, 23, 24].

In a study of various grades of stainless steels including AISI 304, 316, 317L, 321, 15-7PH, C and F, Man and Gabe $[19,20]$ found that greater ennoblement of the pitting potential occurred among alloys with a higher molybdenum (Mo) content. Although ennoblement of the pitting potential increased with increase in concentration of $\mathrm{SO}_{4}{ }^{2-}$ in solution, significant ennoblement did not always occur (compared with other anions) when appreciable amounts of $\mathrm{SO}_{4}{ }^{2-}$ was present in solution. For example, only a $400 \mathrm{mV}$ improvement in the pitting potential could be achieved in a solution of $10 \% \mathrm{SO}_{4}{ }^{2-}$ and $3 \% \mathrm{Cl}^{-}\left(\mathrm{SO}_{4}{ }^{2-} / \mathrm{Cl}^{-}\right.$ratio of 3.3), compared with a $400-800$ $\mathrm{mV}$ improvement with nitrate $\left(\mathrm{NO}_{3}^{-}\right)$and hydroxyl $\left(\mathrm{OH}^{-}\right)[19,20]$. Gabe and Mann $[19,20]$ showed that compared with $\mathrm{NO}_{3}{ }^{-}$and $\mathrm{OH}^{-} ; \mathrm{SO}_{4}{ }^{2-}$ was not as efficient an inhibitor. In certain cases, they even found carbonate to be more effective inhibitor than $\mathrm{SO}_{4}{ }^{2-}$. 
Studies carried out in $\mathrm{Cl}^{-}$solutions with Inconel 600 showed that $\mathrm{SO}_{4}{ }^{2-}$ was an effective inhibitor of pitting corrosion and stress corrosion cracking [15,18]. Chang and Yang [15] found that in Inconel 600 , over a temperature range of $25-70{ }^{\circ} \mathrm{C}$, in solutions with chloride concentrations

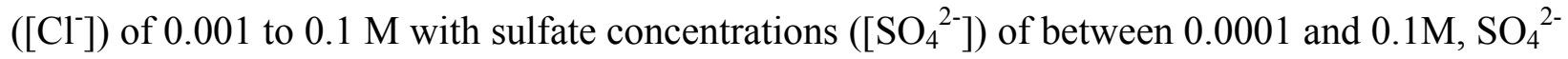
was generally found to increase the pitting and repassivation potentials. They also found that there was a less expensive pitting attack in polarized specimens of Inconel 600 [15]. The pit sizes and density were also found to decrease with increase in $\left[\mathrm{SO}_{4}{ }^{2-}\right]$. The interruption of growth or continued propagation of cracks in Inconel 600 in the presence of $\mathrm{SO}_{4}{ }^{2-}$ in a $\mathrm{Cl}^{-}$ environment at $250{ }^{\circ} \mathrm{C}$ led Ashour [18] to conclude that the solution at progressing crack tips was made less aggressive by the presence of $\mathrm{SO}_{4}{ }^{2-}$. It was observed that $\mathrm{SO}_{4}{ }^{2-}$ seemed to change the morphology of attack of the crack surface from intergranular to transgranular mode of failure. The intergranular crack growth rate was thus hindered with increase in $\left[\mathrm{SO}_{4}{ }^{2-}\right]$. The stress intensity factor $(\mathrm{K})$ also increased with increasing $\left[\mathrm{SO}_{4}{ }^{2-}\right]$. In the presence of $\mathrm{SO}_{4}{ }^{2-}$, cracks did not propagate under free load at the corrosion potential on Alloy 600. $\mathrm{SO}_{4}{ }^{2-}$ was also thought to hinder the dissolution of alloy 600 by adsorbing on to the active sites of the fracture surfaces, thus preventing continued dissolution by $\mathrm{Cl}^{-}$probably by the formation of a $\mathrm{Cr}$ oxide layer, which is stable at high temperature [18].

Under certain conditions, $\mathrm{SO}_{4}{ }^{2-}$ might only be effective in inhibiting localized corrosion on stainless steels and $\mathrm{Ni}$ alloys within certain ranges of concentration (or $\left[\mathrm{SO}_{4}{ }^{2-}\right] /\left[\mathrm{Cl}^{-}\right]$ratio) and applied potential. In the study of the effect of $\mathrm{SO}_{4}{ }^{2-}$ on the initiation and propagation of metastable pits, Pistorius and Burstein [9] found that $\mathrm{SO}_{4}{ }^{2-}$ had an inhibitory effect on nucleation 
of pits at low potential (between -0.4 and +0.2 VSCE), but inhibition was lost at higher potential ${ }^{\mathrm{a}}$. Where inhibition was effective, $\mathrm{SO}_{4}{ }^{2-}$ lowered the growth rate of already formed metastable pits across the potential range tested. $\mathrm{SO}_{4}{ }^{2-}$ also reduced the pit stability product $\mathrm{ir}^{\mathrm{b}}$, by lowering the solubility of the metal cations formed in the pit.

Also in stainless steels, repassivation potentials decreased by about $50 \mathrm{mV}$ (from $\sim 50$ to $\sim 0 \mathrm{mV}$ ), and pits grew in size from 150 to 500 microns in 304 stainless steel when increasing the amount of $\mathrm{SO}_{4}{ }^{2-}$ from 0 to $300 \mathrm{mg} / 1$, in experiments carried out in solutions with [Cl-] of $300 \mathrm{mg} / 1$ at 55 ${ }^{\circ} \mathrm{C}$ [17]. These drops in potential were worse when thosisulfate $\left(\mathrm{S}_{2} \mathrm{O}_{3}{ }^{2-}\right)$ was added into solution. Although Chan and $\mathrm{Yu}$ [15] found that Inconel 600 was immune to pitting when the ratio of $\mathrm{SO}_{4}{ }^{2-}: \mathrm{Cl}^{-}$was above 1 , pitting was found to be more severe in dilute chloride solutions $(<0.001$ $\mathrm{M})$ with small additions $\mathrm{SO}_{4}{ }^{2-}\left(\left[\mathrm{SO}_{4}{ }^{2-}\right] /\left[\mathrm{Cl}^{-}\right] \leq 0.01\right)$ than when no $\mathrm{SO}_{4}{ }^{2-}$ was present in solution (i.e., lower pitting potentials). Bogaerts and Van Haute [12] observed in their investigations on various steels and $\mathrm{Ni}$ - alloys at temperatures up to $175^{\circ} \mathrm{C}$ that in the absence of a strongly passivating compound like chromium $(\mathrm{Cr})$, the inhibitive potential of $\mathrm{SO}_{4}{ }^{2-}$ could be lost as concentration (of $\mathrm{SO}_{4}{ }^{2-}$ ) increased, with a resultant acceleration of localized corrosion.

In other studies, the presence of $\mathrm{SO}_{4}{ }^{2-}$ has been known to induce localized corrosion in Ni alloys. Cragnolino and Shidhar [23] found that $\mathrm{SO}_{4}{ }^{2-}$ was a weak promoter of localized corrosion on $\mathrm{Ni}$ alloy 825 in high $\mathrm{Cl}^{-}$-containing environments. Yang observed that in Inconel $600, \mathrm{SO}_{4}{ }^{2-}$ induced crevice corrosion in experiments carried out at $316{ }^{\circ} \mathrm{C}[16,24]$. Pits occurred under the crevice formers as well as on the freely exposed surface. It was found that the higher the acidity,

\footnotetext{
${ }^{a}$ Solution used: $1 \mathrm{M} \mathrm{NaCl}+0.1 \mathrm{M} \mathrm{H}_{2} \mathrm{SO}_{4}$. Solution $\mathrm{pH}=0.7$. Solution temperature: $16 \pm 2{ }^{\circ} \mathrm{C}$.

$\mathrm{b}$ "ir" is the product of the current density and radius of the propagating it. Is a measure of the aggressiveness of the pit anolyte.
} 
the easier it was to initiate crevices in the presence of $\mathrm{SO}_{4}{ }^{2-}$. At $\mathrm{pH} 2^{\mathrm{c}}$ only $100 \mathrm{ppm}$ of $\mathrm{SO}_{4}{ }^{2-}$ was required to initiate crevice corrosion. At a pH of between 2 and 4, more than 15,000 ppm $\mathrm{SO}_{4}{ }^{2-}$ was required to initiate crevice corrosion, while at neutral $\mathrm{pH}$ no crevice corrosion occurred.

The foregoing suggests that the issue of inhibition and the kinetics of pit growth in stainless steels and $\mathrm{Ni}$ - alloys might not be a simple function of $\left[\mathrm{SO}_{4}{ }^{2-}\right] /\left[\mathrm{Cl}^{-}\right]$ratio. It also shows that there is no consensus as to the action of $\mathrm{SO}_{4}{ }^{2-}$ on localized corrosion. Subtleties in the alloy composition and environmental conditions might cause major changes in the inhibitive efficacy of $\mathrm{SO}_{4}{ }^{2-}$ with regard to localized corrosion.

Presently, there is interest in the use of Alloy 22 as a corrosion resistant material in underground storage facilities where it might come into contact with $\mathrm{Cl}^{-}$-containing ground waters with an abundant $\mathrm{SO}_{4}{ }^{2-}$ content [25-27]. It is therefore important to understand the behavior of Alloy 22 in $\mathrm{SO}_{4}{ }^{2-}$ bearing $\mathrm{Cl}^{-}$.

The effect of $\mathrm{SO}_{4}{ }^{2-}$ ions on crevice breakdown and repassivation potentials of Alloy 22 was studied to establish whether $\mathrm{SO}_{4}{ }^{2-}$ inhibits localized breakdown. Emphasis is placed on reporting the observation from the experiments in detail. A comprehensive treatment of the possible mechanism(s) of $\mathrm{SO}_{4}{ }^{2-}$ of inhibition is beyond the scope of this paper. Experiments were carried out on wrought Alloy 22 in $4 \mathrm{M} \mathrm{NaCl}, 4 \mathrm{M} \mathrm{NaCl}+0.4 \mathrm{M} \mathrm{Na}_{2} \mathrm{SO}_{4}$, and $4 \mathrm{M} \mathrm{NaCl}+0.04 \mathrm{M}$ $\mathrm{Na}_{2} \mathrm{SO}_{4}$ using a multiple crevice assembly (MCA) specimen configuration (Figure 1). This configuration was optimized for the study of crevice corrosion as it provides 24 potential crevice ${ }^{\mathrm{c}} \mathrm{pH}$ values as measured at $25^{\circ} \mathrm{C}$. 
generation sites on a surface area of less than $10 \mathrm{~cm}^{2}$. The temperature range of study was between 45 and $105^{\circ} \mathrm{C}\left( \pm 2{ }^{\circ} \mathrm{C}\right)$.

\section{EXPERIMENTAL PROCEDURE}

Alloy 22 (N06022) specimens were fabricated from $\sim 2 \mathrm{~mm}$ thick wrought plate into Multiple Crevice Assembly (MCA) specimens. The chemical composition of the Alloy 22 plates used for fabrication appears in Table 1 as documented by the supplier. The composition is consistent with ASTM-B 575 (for plates/sheets) standard [28, 29]. The MCA specimens look like lollipops (Figure 1). The design was optimized for crevice corrosion studies so that most of the working surface was covered by the ceramic crevice former. The working surfaces of the MCA specimens were finished with 600-grit silicon carbide ( $\mathrm{SiC}$ ) paper. The edge (surface 90 degrees in angle to the working surface) of the specimens was finished also with 600 -grit $\mathrm{SiC}$ paper after first grinding with 100 and then 240 -grit $\mathrm{SiC}$ paper. All the grinding was carried out wet. After grinding, the specimens were degreased first with hexane, then with acetone and followed by methanol. The rest of the MCA consisted of titanium (Ti) grade 2 nuts, bolts and washers, as well as ceramic crevice formers with multiple ridges (also referred to as teeth). The bolts were polytetrafluoroethylene (PTFE) wrapped to prevent these hardware components from coming into electrical contact with the specimen. Each crevice former had a total of 12 ridges (or teeth) on it, creating 12 different potential crevice sites on each face of the specimen, and a total of 24 potential sites in each assembly (Figure 1). The assembly was tightened to a torque of $70 \mathrm{in}-\mathrm{lb}$. PTFE tape inserts were placed between the ceramic crevice former and the MCA specimen prior 
to tightening. This was done to fill in the micro voids created by the micro-rough surfaces of the specimen and the ceramic crevice former, and to increase the reproducibility of the tight crevices in all specimens. The total surface area of the MCA specimen immersed in the electrolyte was $7.43 \mathrm{~cm}^{2}$. This surface area included the area under the 24 ridges of the crevice formers, which had a combined surface area of $1.6 \mathrm{~cm}^{2}$. In current density estimations, the surface area of 7.43 $\mathrm{cm}^{2}$ was used for calculations.

A three-electrode glass cell with a capacity of $1000 \mathrm{~cm}^{3}$ was used for experimentation. The volume of electrolyte in the cell was $\sim 900 \mathrm{~cm}^{3}$. A saturated silver/silver chloride (SSC) $(\mathrm{Ag} / \mathrm{AgCl})$ electrode was the reference electrode $(\mathrm{RE})$. The $\mathrm{RE}$ was maintained near room temperature by mounting it to the end of a water-cooled Luggin probe. The temperature of the water pumped through the cooling jacket of the Luggin probe was between 5 and $12{ }^{\circ} \mathrm{C}$. Thermal liquid junction calculations showed that potential variation caused by this phenomenon was in the order of a few $\mathrm{mV}(\sim 10 \mathrm{mV}$ maximum $)$. Also, according to Macdonald et al., a high $\mathrm{KCl}$ concentration in the reference electrode tends to suppress thermal liquid junction potentials across the boundary between the high and low temperature solutions [30]. Liquid junction potential variations were therefore ignored in further analyses. The counter electrode was made of a $40 \mathrm{~cm}^{2}$ platinum (Pt) foil. The temperature of the electrolyte was maintained with an oilfilled heating bath. The specimen was immersed into the cell immediately after the grinding process when the electrolyte reached the desired temperature. Electrolyte temperature readings were taken before and after the experiment with a thermocouple. Electrochemical measurements were carried out with a potentiostat. The corrosion (open circuit) potential $\left(\mathrm{E}_{\text {corr }}\right)$ was monitored for 24 hours, which allowed $\mathrm{E}_{\text {corr }}$ to settle considerably. This was followed by polarization 
resistance measurements, and then by cyclic potentiodynamic polarization measurements immediately afterwards. Scans at $0.1667 \mathrm{mVs}^{-1}\left(600 \mathrm{mVh}^{-1}\right)$ between -20 and $+20 \mathrm{mV}$ relative to the $\mathrm{E}_{\text {corr }}$ were carried out for polarization resistance measurements. Corrosion rates were calculated from the values derived from these polarization resistance measurements. Cyclic polarization was started approximately $100 \mathrm{mV}$ below $\mathrm{E}_{\text {corr }}$, and continued until the current density from the specimen reached a maximum of up to $30 \mathrm{mAcm}^{-2}$, or $1.3 \mathrm{~V}$ (SSC) before reversal of the scan. The sweep rate in the forward and reverse directions was $0.1667 \mathrm{mVs}^{-1}$. The electrolytes used included $4 \mathrm{M} \mathrm{NaCl}, 4 \mathrm{M} \mathrm{NaCl}+0.04 \mathrm{M} \mathrm{Na}_{2} \mathrm{SO}_{4}$ and $4 \mathrm{M} \mathrm{NaCl}+0.4 \mathrm{M}$ $\mathrm{Na}_{2} \mathrm{SO}_{4}$, with $\mathrm{pH}$ values of $6.17,6.20$ and 7.19 respectively at room temperature. These solutions represent pure $\mathrm{Cl}^{-}$, and $\left[\mathrm{Cl}^{-}\right] /\left[\mathrm{SO}_{4}{ }^{2-}\right]$ ratios of $100: 1$ and $10: 1$ respectively. All electrolytes were deaerated with nitrogen gas $\left(\mathrm{N}_{2}\right) . \mathrm{N}_{2}$ was bubbled through the electrolytes for at least one hour before and throughout the experiments at a rate of $\sim 100 \mathrm{cc}$ per minute. Experiments were carried out in these electrolytes at temperatures between 45 and $105{ }^{\circ} \mathrm{C}$. All electrolytes were prepared using certified American Chemical Society (ACS) reagent grade chemicals.

\section{EXPERIMENTAL RESULTS}




\section{The Corrosion Potential ( $\left.\mathrm{E}_{\mathrm{corr}}\right)$}

The corrosion potential $\left(\mathrm{E}_{\text {corr }}\right)$ of Alloy 22 decreased with time at all temperatures in the electrolytes tested over the 24-hour monitoring period. Usually, when the samples were introduced into the electrolyte, the open circuit potential initially increased briefly, and then decreased with time in all electrolytes tested. Figure 2 shows representative curves of Alloy 22 during a 24-hour open circuit potential monitoring period in all the electrolytes tested. The temperature during data acquisition in Figure 2 was $75{ }^{\circ} \mathrm{C}$. Figure 3 shows a summary of the average $\mathrm{E}_{\text {corr }}$ values between $45{ }^{\circ} \mathrm{C}$ and $105{ }^{\circ} \mathrm{C}$ for Alloy 22 in $4 \mathrm{M} \mathrm{NaCl}, 4 \mathrm{M} \mathrm{NaCl}+0.04 \mathrm{M}$ $\mathrm{Na}_{2} \mathrm{SO}_{4}$ and $4 \mathrm{M} \mathrm{NaCl}+0.4 \mathrm{M} \mathrm{Na}_{2} \mathrm{SO}_{4}$. $\mathrm{E}_{\text {corr }}$ was measured at the end of the 24-hour immersion period in solution. These values are the averages of at least 4 repeats, except for $\mathrm{NaCl}$ values at 60 and $90{ }^{\circ} \mathrm{C}$ which are from single values. The average values of $\mathrm{E}_{\text {corr }}$ were lowest in pure $4 \mathrm{M}$ $\mathrm{NaCl}$, except at $105{ }^{\circ} \mathrm{C}$ where they were highest compared with the $\mathrm{SO}_{4}{ }^{2-}$-bearing electrolytes. $\mathrm{E}_{\text {corr }}$ values in $4 \mathrm{M} \mathrm{NaCl}+0.04 \mathrm{M} \mathrm{Na}_{2} \mathrm{SO}_{4}$ were generally higher than in $4 \mathrm{M} \mathrm{NaCl}$, and were highest in $4 \mathrm{M} \mathrm{NaCl}+0.4 \mathrm{M} \mathrm{Na}_{2} \mathrm{SO}_{4}$. In the $\mathrm{SO}_{4}{ }^{2-}$-bearing solutions $\mathrm{E}_{\text {corr }}$ generally decreased with increase in temperature (Figure 3) although slight increases in the average value of $\mathrm{E}_{\text {corr }}$ occurred at $105{ }^{\circ} \mathrm{C}$. The difference in the mean values of the $\mathrm{SO}_{4}{ }^{2-}$ containing solutions at each temperature was within $100 \mathrm{mV}$. In pure $\mathrm{Cl}^{-} \mathrm{E}_{\text {corr }}$ also tends to generally decrease with temperature up till $90{ }^{\circ} \mathrm{C}$. There is a significant increase in $\mathrm{E}_{\text {corr }}$ at $105^{\circ} \mathrm{C}$. The $\mathrm{E}_{\text {corr }}$ values of Alloy 22 in the three electrolytes fell within a $200 \mathrm{mV}$ range and shows that there were no significant effects of sulfate on the 24-hour $\mathrm{E}_{\text {corr }}$ values of Alloy 22 under these conditions.

\section{Corrosion Rate}

Corrosion rates were calculated from polarization resistance values obtained from short scans 
$(-20$ to $+20 \mathrm{mV})$ relative to $\mathrm{E}_{\text {corr }}$ according to the ASTM G 59 method [31]. Upon completion of the scans, liner fits were generated between the potentials of -10 and $+10 \mathrm{mV}$ relative to $\mathrm{E}_{\text {corr. }} \mathrm{A}$ value of $\pm 0.12 \mathrm{~V} /$ decade was assumed for the Tafel constants $\beta_{\mathrm{a}}$ and $\beta_{\mathrm{c}}$ for the anodic and cathodic curves respectively. Thus, the values obtained from the calculations are approximations of the corrosion rates. Corrosion rates were calculated from the following expression:

$$
C R=k \frac{i_{c o r r}}{\rho} E W
$$

Where $\boldsymbol{C} \boldsymbol{R}$ is the passive corrosion rate given in microns per year, $\boldsymbol{k}$ is a unit conversion factor to microns per year $\left(3.27 \times 10^{6} \mu \mathrm{m} \cdot \mathrm{g} \cdot \mathrm{A}^{-1} \cdot \mathrm{cm}^{-1} \cdot \mathrm{yr}^{-1}\right), \mathrm{i}_{\text {corr }}$ is the corrosion current density; $\boldsymbol{E} \boldsymbol{W}$ is the equivalent weight of Alloy 22 (23.38), assuming an equivalent dissolution of major alloying elements as $\mathrm{Ni}^{2+}, \mathrm{Cr}^{3+}, \mathrm{Mo}^{6+}, \mathrm{Fe}^{2+}$ and $\mathrm{W}^{6+}$; and $\rho$ is the density of Alloy $22\left(8.69 \mathrm{~g} . \mathrm{cm}^{-3}\right)$ [32].

These corrosion rates represent metal dissolution (or loss) under passive conditions at potentials close to open circuit conditions. The average corrosion rates calculated from polarization resistance data showed that the values were between 0.09 and $2.90 \mu \mathrm{m} /$ year Figure 4. Generally, the corrosion rates increased with temperature in all the electrolytes (Figure 4a). While the corrosion rates in the $\mathrm{SO}_{4}{ }^{2-}$-bearing electrolytes showed a consistent increase in rates with temperature, the pure $\mathrm{Cl}^{-}$electrolyte did not. Except at $45^{\circ} \mathrm{C}$, the average corrosion rate of Alloy 22 at subsequent temperatures was consistently higher in $4 \mathrm{M} \mathrm{NaCl}+0.04 \mathrm{M} \mathrm{Na}_{2} \mathrm{SO}_{4}$ compared with in $4 \mathrm{M} \mathrm{NaCl}+0.4 \mathrm{M} \mathrm{Na}_{2} \mathrm{SO}_{4}$ (Figure 4a). In the $\mathrm{SO}_{4}{ }^{2-}$-bearing electrolytes, Alloy 22 showed a steep increase in corrosion rates between 75 and $90{ }^{\circ} \mathrm{C}$. In $4 \mathrm{M} \mathrm{NaCl}+0.4 \mathrm{M} \mathrm{Na}_{2} \mathrm{SO}_{4}$ the average corrosion rates were similar between 45 and $75{ }^{\circ} \mathrm{C}$, followed by an appreciable increase thereafter (Figures $4 \mathrm{a}$ and $4 \mathrm{~b}$ ). In general, the higher the $\mathrm{SO}_{4}{ }^{2-}$ concentration, the lower 
the corrosion rate, especially at temperatures above $75^{\circ} \mathrm{C}$. At lower temperatures, the corrosion rates were indistinguishable. Thus, $\mathrm{SO}_{4}{ }^{2-}$ ions may promote passivation and decrease corrosion rate.

\section{Cyclic Potentiodyanamic Polarization (CPP)}

Figure 5 shows representative polarization curves for the MCA specimens in $4 \mathrm{M} \mathrm{NaCl}, 4 \mathrm{M}$ $\mathrm{NaCl}+0.04 \mathrm{M} \mathrm{Na}_{2} \mathrm{SO}_{4}$ and $4 \mathrm{M} \mathrm{NaCl}+0.4 \mathrm{M} \mathrm{Na}_{2} \mathrm{SO}_{4}$ at $45{ }^{\circ} \mathrm{C}$. Similarly shaped curves as shown in Figure 5a were observed in all three electrolytes. Three regions characterize this type of curve. Region "a" is described by a dip (or sometimes a short plateau) in the current density just after the corrosion potential. After the region "a", there is a rise in the current density into a plateau (region "b"). This is the passive region. After region " $b$ " there is another inflection in the curve resulting in a region "c", an area of reduced rate of current density increase, which is nearly independent of potential increase. The end of region " $\mathrm{c}$ " is marked by a rapid increase in current density. The shape of the curve in Figure $5 \mathrm{~b}$ was observed in $4 \mathrm{M} \mathrm{NaCl}$ and $4 \mathrm{M} \mathrm{NaCl}+$ $0.04 \mathrm{M} \mathrm{Na}_{2} \mathrm{SO}_{4}$ only. It was observed in $50 \%$ (2 of 4 ) of the polarization curves from $4 \mathrm{M} \mathrm{NaCl}$, and in $25 \%$ (1 of 4 ) of the curves from $4 \mathrm{M} \mathrm{NaCl}+0.04 \mathrm{M} \mathrm{Na}_{2} \mathrm{SO}_{4}$. The others were similar to Figure 5a. Figure 5b possesses regions corresponding to $\mathrm{a}, \mathrm{b}$ and $\mathrm{c}$ in Figure 5a. The difference between this curve (Figure 5b) and the one shown in Figure 5a is that the passive current density (anodic region) on the reverse sweep does not fall as fast in Figure 5b. Also, there is a small hystereses created by the reverse sweep crossing the forward sweep before the net current finally falls at the corrosion potential on the reverse scan. The curve in Figure 5c was observed only in $4 \mathrm{M} \mathrm{NaCl}+0.4 \mathrm{M} \mathrm{Na}_{2} \mathrm{SO}_{4}$. Unlike Figures 5a and 5b there are no regions "a" and "c", but instead, an extended region " $b$ " on the forward sweep of the curve. The current density on the 
reverse scan remains nearly parallel to the forward scan, and stays within 0.5 of a decade until the current density changes from net anodic to net cathodic.

Figures 6, 7 and 8 are SEM micrographs of Alloy 22 in $4 \mathrm{M} \mathrm{NaCl}, 4 \mathrm{M} \mathrm{NaCl}+0.04 \mathrm{M} \mathrm{Na}_{2} \mathrm{SO}_{4}$ and $4 \mathrm{M} \mathrm{NaCl}+0.4 \mathrm{M} \mathrm{Na}_{2} \mathrm{SO}_{4}$ respectively at $45{ }^{\circ} \mathrm{C}$. Localized attack due to crevice corrosion was observed on these specimens in spite of the fact that little or no hystereses were observed in the polarization curves. The presence of a hysteresis loop is usually indicative of localized attack. The localized attack that occurred in Figures 6-8 was not substantial enough to register as hystereses loops in Figure 5. The most severe damage occurred on the specimen polarized in 4 $\mathrm{M} \mathrm{NaCl}$ (Figure 6), while the least amount of damage occurred on the specimen polarized in $4 \mathrm{M}$ $\mathrm{NaCl}+0.4 \mathrm{M} \mathrm{Na}_{2} \mathrm{SO}_{4}$. At $45^{\circ} \mathrm{C}$ localized damage (crevice corrosion) initiated underneath the crevice teeth, close to the edge of the crevice former, and then developed towards the center of the crevice former teeth. As a result, the most severe damage was located at the edge of the crevice teeth, in the area closest to the electrolyte bulk. All the localized attack that occurred at this temperature was confined to underneath the crevice teeth, where a barrier to diffusion was maintained. At $45^{\circ} \mathrm{C}$ localized damage occurred under the crevice former as little pits. The grind lines introduced during specimen preparation were favored sites for pits initiation. These small individual pits then coalesced to form narrow and shallow trenches underneath these crevice formers (Figures $6 \mathrm{c}, 7 \mathrm{~b}$ and $7 \mathrm{c}$ ). Figures 6,7 and 8 show that $\mathrm{SO}_{4}{ }^{2-}$ mitigated the development of crevice corrosion. The abundant dissolution that occurred outside the crevice former on the boldly exposed surfaces (Figures 6a, 7a and 8a) was due to transpassive dissolution at high potentials. 
Representative polarization curves for the MCA specimens in $4 \mathrm{M} \mathrm{NaCl}, 4 \mathrm{M} \mathrm{NaCl}+0.04 \mathrm{M}$ $\mathrm{Na}_{2} \mathrm{SO}_{4}$ and $4 \mathrm{M} \mathrm{NaCl}+0.4 \mathrm{M} \mathrm{Na}_{2} \mathrm{SO}_{4}$ at $60{ }^{\circ} \mathrm{C}$ are shown in Figures $9 \mathrm{a}, 9 \mathrm{~b}$ and $9 \mathrm{c}$ respectively. Figure $9 \mathrm{~d}$ shows an additional polarization curve of Alloy 22 in $4 \mathrm{M} \mathrm{NaCl}+0.4 \mathrm{M} \mathrm{Na}_{2} \mathrm{SO}_{4}$. Apart from slight differences in the anodic portion of the curve just after the corrosion potential, the forward sweeps of the polarization curves of Alloy 22 observed in Figures 9a, 9b and 9c are similar. The shape of the anodic portion of these curves is also similar to those observed at $45^{\circ} \mathrm{C}$ (Figure 5). The major differences in these curves lie in the shape of the reverse sweep of the curve. The size of the hystereses loops generated in the polarization curves decreased as the concentration of $\mathrm{SO}_{4}{ }^{2-}$ increased (Figure $9 \mathrm{a}, 9 \mathrm{~b}$ and $9 \mathrm{c}$ ). The loops generated in $4 \mathrm{M} \mathrm{NaCl}$ were larger than those observed in $4 \mathrm{M} \mathrm{NaCl}+0.04 \mathrm{M} \mathrm{Na}_{2} \mathrm{SO}_{4}$. In most of the polarization curves generated from $4 \mathrm{M} \mathrm{NaCl}+0.4 \mathrm{M} \mathrm{Na}_{2} \mathrm{SO}_{4}$ at $60{ }^{\circ} \mathrm{C}$ (Figure 9c), no loops were observed, and the polarization curves looked like those observed at $45^{\circ} \mathrm{C}$ (Figure 5a). When a loop was observed, it was very small (Figure 9d).

SEM micrographs in Figures 10, 11 and 12 show that more damage occurred at $60{ }^{\circ} \mathrm{C}$ compared with at $45^{\circ} \mathrm{C}$ in the electrolytes tested. At $60{ }^{\circ} \mathrm{C}$ more of the individual pits under the crevice teeth had coalesced to form trenches in $4 \mathrm{M} \mathrm{NaCl}$ compared with the $4 \mathrm{M} \mathrm{NaCl}$ solutions with sulfate additions. In $4 \mathrm{M} \mathrm{NaCl}$ it could be observed that in some instances localized damage had proceeded from underneath the crevice former to outside of the crevice former on the boldly exposed surface (Figure 10a). This implies that conditions were aggressive enough to facilitate the continued growth of crevices without the benefit of the barrier to diffusion provided by the crevice former. 
The degree of corrosion damage per unit area also reduced in the presence of $\mathrm{SO}_{4}{ }^{2-}$. Discrete individual pits still occurred along the grind lines in the presence of $\mathrm{SO}_{4}{ }^{2-}$ and are visible in Figures 11 and 12. Furthermore, the footprint of the localized damage was still largely confined to underneath the crevice former in the presence of $\mathrm{SO}_{4}{ }^{2-}$ (Figures 11a and 12a). This is different from observation in $4 \mathrm{M} \mathrm{NaCl}$ where the growth proceeded outside the crevice teeth. This shows that $\mathrm{SO}_{4}{ }^{2-}$ mitigated crevice corrosion.

Figures 13a, 13b and 13c show representative polarization curves in $4 \mathrm{M} \mathrm{NaCl}$ at 75, 90 and 105 ${ }^{\circ} \mathrm{C}$ respectively. The polarization curves of Alloy 22 at these temperatures had similar shapes and characteristics. The presence of $\mathrm{SO}_{4}{ }^{2-}$ did not change the general shape of these curves, which were similar to those in pure $\mathrm{NaCl}$ at their respective temperatures. The curves had primary and secondary current plateau regions in the forward sweep. The current density in the secondary current plateau region $\left(\sim 2 \times 10^{-4} \mathrm{Acm}^{-2}\right)$ was up to 3 decades higher than that of the primary plateau region $\left(\sim 2 \times 10^{-7} \mathrm{Acm}^{-2}\right)$. While the primary plateau region represents a passive current region, the current density in the secondary plateau may perhaps be too high for the material to maintain any reasonable degree of passivity. The length of the passive region (primary plateau) shortened with increase in temperature. This is consistent with a reduction in crevice breakdown potential as temperature increased. The current densities in the passive region at $105^{\circ} \mathrm{C}$ in all three solutions were slightly higher (one to one and a half decades higher) than at 75 and $90^{\circ} \mathrm{C}$ (Figures 13a and 13b). The secondary plateau probably represents diffusionlimited dissolution since the current density remained constant as potential increased. The current density in this second plateau was at times as low as $0.025 \mathrm{mAcm}^{-2}$ at $75^{\circ} \mathrm{C}$ (Figure 13a) to as high as $2.0 \mathrm{mAcm}^{-2}$ at $105^{\circ} \mathrm{C}$ (Figure 13c). All curves at 75,90 and $105^{\circ} \mathrm{C}$ displayed 
prominent hysteresis loops. These are delayed hystereses loop, typical of crevice corrosion, which nucleate and grow over a range of potentials

Figures 14, 15 and 16 are SEM microcgraphs of Alloy 22 tested in the three electrolytes at $75^{\circ} \mathrm{C}$. They show that the presence of $\mathrm{SO}_{4}{ }^{2-}$ mitigated the development of crevices that formed on the specimens. In $4 \mathrm{M} \mathrm{NaCl}$ at $75{ }^{\circ} \mathrm{C}$ (Figure 14), dissolution was more severe than at $60{ }^{\circ} \mathrm{C}$. The most damaged portion of the specimen was the region at the periphery of the crevice teeth closest to the bulk electrolyte. This is consistent with observations at 45 and $60{ }^{\circ} \mathrm{C}$. All the pits in this area had coalesced into large trenches. Just beyond this peripheral damage zone, smaller localized events in form of pits yet to coalesced into trenches are observable (Figure 14d). Beyond this band of small pits, further into the crevice, another band (or area) of larger pits exists (Figure 14d). The pits in this third band are angular in shape and might represent a stage of development of crevice dissolution that is between the small pit stage and the well-developed large trenches. While these three distinct bands with varying degree of damage were observed at lower temperature, the best examples were observed on specimens tested at $75{ }^{\circ} \mathrm{C}$. At $45{ }^{\circ} \mathrm{C}$ pits of varying sizes would populate these bands instead of trenches and pits as observed at $75^{\circ} \mathrm{C}$. At $45^{\circ} \mathrm{C}$ the outermost band (closest to the electrolyte) would be populated by the largest pits at the most advanced stage of crevice corrosion. The relative amount of damage observed in the presence of $\mathrm{SO}_{4}{ }^{2-}$ (Figures 15 and 16) was much less than in pure $\mathrm{Cl}^{-}$(Figure 14). These images imply that although the presence of sulfate does not prevent crevice corrosion under the tested conditions, it clearly retards its growth and development at $75^{\circ} \mathrm{C}$. 
Figures 17, 18 and 19 show SEM micrographs of Alloy 22 in $4 \mathrm{M} \mathrm{NaCl}, 4 \mathrm{M} \mathrm{NaCl}+0.04 \mathrm{M}$ $\mathrm{Na}_{2} \mathrm{SO}_{4}$ and $4 \mathrm{M} \mathrm{NaCl}+0.4 \mathrm{M} \mathrm{Na}_{2} \mathrm{SO}_{4}$ respectively at $90{ }^{\circ} \mathrm{C}$. At $90^{\circ} \mathrm{C}$, dissolution by crevice corrosion is considerable, and the corrosion mitigating effect of $\mathrm{SO}_{4}{ }^{2-}$ although still observable, appears to be much less than at lower temperatures. Dissolution occurs both under the crevice former and on the boldly exposed surface adjacent to the crevice teeth in all the three solutions. In $4 \mathrm{M} \mathrm{NaCl}$ (Figure 17) "concentric" trenches are observable in the lower portion of both crevice teeth shown. At $105^{\circ} \mathrm{C}$ corrosion mitigation is only readily observable in the presence of $0.4 \mathrm{M} \mathrm{Na}_{2} \mathrm{SO}_{4}$ (Figure 20). The amount of damage on the specimens in the presence of $0.04 \mathrm{M}$ $\mathrm{Na}_{2} \mathrm{SO}_{4}$ is comparable to damage observed on specimens exposed to $4 \mathrm{M} \mathrm{NaCl}$. "Concentric" trenches are easily observable on the specimens exposed to all three electrolytes (Figure 20). The dissolution or attack morphology of the crevices formed on Alloy 22 at $105{ }^{\circ} \mathrm{C}$ is very similar to that observed at $90{ }^{\circ} \mathrm{C}$ except that it is more severe at $105{ }^{\circ} \mathrm{C}$. Generally, although mitigation of crevice corrosion appears to be diminished at 90 and $105{ }^{\circ} \mathrm{C}$, at no time was it observed that $\mathrm{SO}_{4}{ }^{2-}$ made the electrolyte more aggressive.

\section{The Breakdown Potential $\left(\mathrm{E}_{\underline{b}}\right)^{\mathrm{d}}$}

Figure 21 shows a summary of the breakdown potentials $\left(\mathrm{E}_{\mathrm{b}}\right)$ for Alloy 22 as a function of temperature between 45 to $105{ }^{\circ} \mathrm{C}$. Where mean values were plotted, they were the averages of at least two values. Data points that are not mean values are easily recognizable by the absence of error bars. The error bars where present are the standard deviations of the distribution. Two methods were used to determine $\mathrm{E}_{\mathrm{b}}$. In one method (Method 1), $\mathrm{E}_{\mathrm{b}}$ (denoted by $\mathrm{E}_{\mathrm{b} 1}$ ) was the potential at which the current reached a threshold current density of $2 \times 10^{-5} \mathrm{Acm}^{-2}\left(20 \mu \mathrm{Acm}^{-2}\right)$.

\footnotetext{
${ }^{d}$ The crevice breakdown potential, $E_{b}$, as utilized here is used to denote the potential(s) at which the breakdown of the passive film occurs by localized attack due to crevice corrosion.
} 
In the second method (Method 2) $\mathrm{E}_{\mathrm{b}}\left(\mathrm{E}_{\mathrm{b} 2}\right)$ was the potential at which a permanent rise in current density from the passive region commenced. $\mathrm{E}_{\mathrm{b} 2}$ was selected by determining (on the polarization curve) where the point of inflection that denoted the change (or transition) from a passive state to local (or transpassive) breakdown occurred. Figure 21 shows that the values realized from Method $1\left(\mathrm{E}_{\mathrm{b} 1}\right)$ are higher than those realized from Method $2\left(\mathrm{E}_{\mathrm{b} 2}\right)$.

Figure 21 shows that the breakdown potential $\mathrm{E}_{\mathrm{b}}$ decreased with increase in temperature. The difference between $E_{b 1}$ and $E_{b 2}$ also decreased as temperature increased. Both $E_{b 1}$ and $E_{b 2}$ values show that the improvement in $\mathrm{E}_{\mathrm{b}}$ was at best $100-150 \mathrm{mV}$ between $4 \mathrm{M} \mathrm{NaCl}$ and $4 \mathrm{M} \mathrm{NaCl}$ with $0.4 \mathrm{M} \mathrm{SO}_{4}{ }^{2-}$ additions. Any increases in the values of $\mathrm{E}_{\mathrm{b}}$ as a result of the presence of $0.04 \mathrm{M}$ $\mathrm{SO}_{4}{ }^{2-}$ in solution were much lower. The $\mathrm{E}_{\mathrm{b}}$ values suggest that at best there were only slight improvements to $\mathrm{E}_{\mathrm{b}}$ with $0.4 \mathrm{M} \mathrm{SO}_{4}{ }^{2-}$ and weak improvement, if any, with $0.04 \mathrm{M} \mathrm{SO}_{4}{ }^{2}$. Nonetheless, SEM photos showed that there was appreciable mitigation of dissolution on the specimens in the presence of $\mathrm{SO}_{4}{ }^{2-}$ (Figures 6-8, 10-12 and 14-16). These improvements are more easily observed between 45 and $60{ }^{\circ} \mathrm{C}$.

\section{The Repassivation Potential ( $\left.\mathrm{E}_{\mathrm{r}}\right)$}

Two methods were also used to obtain the values of $E_{\mathrm{r}}$. In the first method (Method 1, denoted by $\left.\mathrm{E}_{\mathrm{r} 1}\right), \mathrm{E}_{\mathrm{r}}$ was the potential that coincided with a current density of $1 \times 10^{-6} \mathrm{Acm}^{-2}$ on the reverse scan of the polarization curve. In the second method (Method 2, denoted by $\mathrm{E}_{\mathrm{r} 2}$ ), $\mathrm{E}_{\mathrm{r}}$ was the potential where the reverse scan of the polarization curve intersected the forward scan. Approximately half of the experiment had a reverse threshold current of $5 \mathrm{mAcm}^{-2}$ and the other

half had a reverse current density of $30 \mathrm{mAcm}^{-2}$. The aim of this exercise was to determine 
whether the magnitude at which the current density was reversed, or more specifically, the amount of charge passed after breakdown occurred affected $\mathrm{E}_{\mathrm{r}}$.

Figures 22 and 23 show $\mathrm{E}_{\mathrm{r} 1}$ and $\mathrm{E}_{\mathrm{r} 2}$ values respectively as a function of temperature in the three electrolytes used. Figures $22 \mathrm{a}, 22 \mathrm{~b}$ and $22 \mathrm{c}$ show $\mathrm{E}_{\mathrm{r} 1}$ while Figures $23 \mathrm{a}, 23 \mathrm{~b}$ and $23 \mathrm{c}$ show $\mathrm{E}_{\mathrm{r} 2}$ values in $4 \mathrm{M} \mathrm{NaCl}, 4 \mathrm{M} \mathrm{NaCl}+0.04 \mathrm{M} \mathrm{Na}_{2} \mathrm{SO}_{4}$ and $4 \mathrm{M} \mathrm{NaCl}+0.4 \mathrm{M} \mathrm{Na}_{2} \mathrm{SO}_{4}$ respectively. The data in Figures 22 and 23 include three sets of values. One set of data points show the mean values of $E_{\mathrm{r}}$ from specimens polarized to a maximum current density of $5 \mathrm{mAcm}^{-2}$ (before reversal of potential scan), another shows $\mathrm{E}_{\mathrm{r}}$ values from specimens polarized to a maximum current density of $30 \mathrm{mAcm}^{-2}$, and the third set (labeled "All" in the legend box) shows $\mathrm{E}_{\mathrm{r}}$ mean values calculated from all the polarization curves (with maximum current densities of 5 and $\left.30 \mathrm{mAcm}^{-2}\right)$.

Generally, the $\mathrm{E}_{\mathrm{r}}$ decreased as temperature increased regardless of the method used for analyses (Figures 22 and 23). Figure 22 shows that $\mathrm{E}_{\mathrm{r} 1}$ was not significantly affected by the amount of charge passed before the potential scan was reversed. In $4 \mathrm{M} \mathrm{NaCl}$ (Figure 22a), there is complete agreement of $E_{r 1}$ values at every temperature. All the values in Figure 22c (with $0.4 \mathrm{M}$ $\mathrm{Na}_{2} \mathrm{SO}_{4}$ ) also show very good agreement. Mean values of $\mathrm{E}_{\mathrm{r} 1}$ are higher at 45 and $105{ }^{\circ} \mathrm{C}$ for the $30 \mathrm{mAcm}^{-2}$ curves in the presence $0.04 \mathrm{M} \mathrm{Na}_{2} \mathrm{SO}_{4}$ (Figure 22b).

Not all the curves produced hysteresis. This accounts for the missing data points in Figure 23, except in Figure 23c, where all the specimens at $105{ }^{\circ} \mathrm{C}$ were polarized to a maximum of $30 \mathrm{mAcm}^{-2}$. Thus, there was no data for specimens polarized to a maximum current density of 
$5 \mathrm{mAcm}^{-2}$. As shown in Figure 22, generally, $\mathrm{E}_{\mathrm{r} 2}$ taken from the $30 \mathrm{mAcm}^{-2}$ curves were higher when compared with those taken from the $5 \mathrm{mAcm}^{-2}$ curves in all the solutions tested. Nonetheless, these differences were usually very small. Another interesting observation was that the $\mathrm{E}_{\mathrm{r} 2}$ taken from the $30 \mathrm{mAcm}^{-2}$ curves were higher at $105^{\circ} \mathrm{C}$ when compared with at $90^{\circ} \mathrm{C}$ in all test solutions.

Figures 24 and 25 are the summaries for $\mathrm{E}_{\mathrm{r} 1}$ and $\mathrm{E}_{\mathrm{r} 2}$ values respectively for the solutions tested. The mean values of $E_{\mathrm{rl}}$ combine all the values from the 5 and $30 \mathrm{mAcm}^{-2}$ polarization curves. These figures suggest that $\mathrm{SO}_{4}{ }^{2-}$ additions do not affect $\mathrm{E}_{\mathrm{r}}$ values at $75{ }^{\circ} \mathrm{C}$ and above. $\mathrm{E}_{\mathrm{r} 1}$ and $\mathrm{E}_{\mathrm{r} 2}$ values coincide at 75,90 and $105^{\circ} \mathrm{C}$ (Figure 26). However $\mathrm{E}_{\mathrm{r} 1}$ values are higher than $\mathrm{E}_{\mathrm{r} 2}$ values at 45 and $60{ }^{\circ} \mathrm{C}$ (Figure 24). The only temperature where sulfate $\mathrm{SO}_{4}{ }^{2-}$ affected $\mathrm{E}_{\mathrm{r}}$ was at $60^{\circ} \mathrm{C}$ (Figures 24 and 25). At $60{ }^{\circ} \mathrm{C} \mathrm{E}_{\mathrm{r} 1}$ values increased as sulfate concentration increased (Figure 24). This trend is reversed in Figure 25 at $60{ }^{\circ} \mathrm{C}$. However is should be noted that 3 of the 4 values at $60{ }^{\circ} \mathrm{C}$ with $0.4 \mathrm{M} \mathrm{SO}_{4}{ }^{2-}$ additions did not register any hysteresis, suggesting that there was some inhibition of localized corrosion. Hence, this solitary value might not be representative of the $\mathrm{E}_{\mathrm{r}}$ values of $0.4 \mathrm{M} \mathrm{SO}_{4}{ }^{2-}$ additions to $4 \mathrm{M} \mathrm{NaCl}$. When hysteresis is not present in the polarization curve, $\mathrm{E}_{\mathrm{r} 1}$ is a better tool than $\mathrm{E}_{\mathrm{r} 2}$ for comparing repassivation potentials.

\section{DISCUSSION}

The concentration of $\mathrm{Cl}^{-}$in the electrolytes used in these experiments far exceeds that of the 
$\mathrm{SO}_{4}{ }^{2-}$. This implies that $\mathrm{Cl}^{-}$was still the predominant anion in the electrolytes, and it is not expected that mechanisms of crevice initiation and indeed repassivation will be significantly altered by the presence of $\mathrm{SO}_{4}{ }^{2-}$. Although the $\mathrm{SO}_{4}{ }^{2-}$ concentrations employed in this work are in some cases less than (with regard to $\left[\mathrm{SO}_{4}{ }^{2-}\right] /\left[\mathrm{Cl}^{-}\right]$ratios) what is expected to be present in the aqueous environments in some proposed underground storage facilities where Alloy 22 may be utilized [25-27]. The level of inhibition provided by $\mathrm{SO}_{4}{ }^{2-}$ in such environments is expected to be higher than observed in this work since it is reasonable to expect that the degree of inhibition by $\mathrm{SO}_{4}{ }^{2-}$ will probably increase with increase in concentration. The $\left[\mathrm{Cl}^{-}\right] /\left[\mathrm{SO}_{4}{ }^{2-}\right]$ ratio in these underground aqueous environments is expected to be about 1:1 or lower [25-27].

The error bars for the average values describing the behavior of Alloy 22 in $\mathrm{SO}_{4}{ }^{2-}$-containing $\mathrm{Cl}^{-}$ electrolytes (Figure $3\left(\mathrm{E}_{\mathrm{corr}}\right)$, Figure 4 (corrosion rate), and Figures 21-26 $\left(\mathrm{E}_{\mathrm{b}}\right.$ and $\left.\mathrm{E}_{\mathrm{r}}\right)$ ) overlap significantly. In statistical terms overlapping error bars suggest that mean values for which the error bars overlap cannot be distinguished with confidence. When error bars overlap, it would be expected that data points from the data sets for the different electrolytes/environments would alternate above and below one another in a random manner on the graphs, signifying that the mean values are indeed indistinguishable. However, in Figures 3, 4 and 21-26 the graph shows that in many cases one set of mean values ${ }^{\mathrm{e}}$ representing a particular environment or condition are consistently higher (or lower) compared with the other set(s) of values in the graph. This implies that these mean values are indeed different despite the overlapping error bars. A larger number of repeat experiments in each data set would likely result in the separation of the error bars. Recall, only a maximum of 4 repeats were carried out at each condition in this work. Nonetheless, the overlapping error bars, as well as the close proximity of the mean values in

${ }^{\mathrm{e}}$ Corrosion rate, repassivation potential $\left(\mathrm{E}_{\mathrm{r}}\right)$, crevice breakdown potential $\left(\mathrm{E}_{\mathrm{b}}\right)$ 
Figures 3, 4, and 21-26 show that the differences in the parameters of interest are small, and indicate that $\mathrm{SO}_{4}{ }^{2-}$ in the concentrations used did not change the measured parameters significantly in many instances.

\section{The Corrosion Potential ( $\mathrm{E}_{\text {corr }}$ ) and Corrosion Rate (CR)}

In the presence of $0.4 \mathrm{M} \mathrm{SO}_{4}{ }^{2-}$ the higher $\mathrm{E}_{\text {corr }}$ values of Alloy 22 coupled with lower corrosion rates (CR) indicates that passivity is slightly more stable on Alloy 22 compared with at lower $\left[\mathrm{SO}_{4}{ }^{2-}\right](0.04 \mathrm{M})$ (Figures 3 and 4$)$. This implies that $\mathrm{SO}_{4}{ }^{2-}$ was able to improve the integrity of the oxide film and mitigate passive dissolution at the higher concentration. The reasons for the highly scattered nature of the $\mathrm{CR}$ data for Alloy 22 in pure $4 \mathrm{M} \mathrm{NaCl}$ compared with the $\mathrm{SO}_{4}{ }^{2-}-$ bearing solutions are unknown. Sulfate appears to reduce the nature of the scatter of the corrosion rate data. From the similarity of the $\mathrm{E}_{\text {corr }}$ values of Alloy 22 in the $4 \mathrm{M} \mathrm{NaCl}$ and $4 \mathrm{M}$ $\mathrm{NaCl}$ with $0.04 \mathrm{M} \mathrm{Na}_{2} \mathrm{SO}_{4}$, it would have been expected that the $\mathrm{CR}$ values would display a comparable similarity had the reduction in the CR been due solely to an improvement in the oxide film. However, from the higher values posted at 75 and $105{ }^{\circ} \mathrm{C}$ in $4 \mathrm{M} \mathrm{NaCl}$ compared with when $0.04 \mathrm{M} \mathrm{SO}_{4}{ }^{2-}$ was present, it would suggest that the rate of dissolution of Alloy 22 was actually reduced by the presence of $\mathrm{SO}_{4}{ }^{2-}$ even at the lower concentration. This is consistent with the mitigation of dissolution at higher potentials shown in SEM micrographs (Figures 6-8, 10-12, and 14-16), as well as from the $\mathrm{E}_{\mathrm{b}}$ values shown in Figure 21.

\section{The Breakdown Potential $\left(\mathrm{E}_{\mathrm{b}}\right)$}

Figures 7,8 , and 9 show that the absence of a hysteresis loop in the polarization curve is not always confirmation that localized corrosion did not occur on a specimen. A possible reason for 
the lack of hysteresis in the polarization curves despite localized damage might be due to the fact that the damage, which occurred on the specimens at $45^{\circ} \mathrm{C}$, was not extensive. Thus, the amount of current coming from the localized damage was small, and not very significant compared with current coming from the rest of the specimen especially at high potentials where transpassive dissolution of the boldly exposed surface, and oxygen evolution might start dominating the contribution to the total current emanating from the specimen. Consequently, these current contributions overshadowed the current contributions due to crevice corrosion activity. This suggestion is supported by the fact the hysteresis loops tended to get more prominent as the level of aggression of the environment increased. This is exemplified by the polarization curves of Alloy 22 at $60{ }^{\circ} \mathrm{C}$ (Figure 9). Note that the localized damage sustained by Alloy 22 at $45{ }^{\circ} \mathrm{C}$ was made up of small and shallow pits, probably initiated at high potential.

A discussion about the mechanism of attack or corrosion mitigation is beyond the scope of this paper. However, the following things are apparent from the data presented: 1) the damage is initiated as small pits within the crevice area, and these pits then enlarge to form trenches. 2) These localized events tend to partition themselves into 3 distinct zones with different rates of development under the crevice former teeth. Further work is required to fully understand this phenomenon in Alloy 22. 3) At the lower temperatures of 45 and $60{ }^{\circ} \mathrm{C}$, where the aggressiveness of the environment is mild to moderate compared with the higher temperatures of 75 through $105{ }^{\circ} \mathrm{C}$, localized dissolution of Alloy 22 tends to be confined to underneath the crevice former. In these moderately aggressive environments, the resultant pits and crevices (Figures 6-8) are too shallow to create a sufficient barrier to diffusion to allow for growth on the boldly exposed surface. 4) Under-teeth corrosion damage is less severe when $\mathrm{SO}_{4}{ }^{2-}$ is present 
(see Figures 6-8, 10-12 and 14-16). This implies that less dissolution occurred in the presence of $\mathrm{SO}_{4}{ }^{2-}$. This is also consistent with the ability of $\mathrm{SO}_{4}{ }^{2-}$ to prevent or delay the progressive dissolution of a crevice to such an extent that the growth becomes self sustaining without requiring an additional barrier to diffusion in the form of the ceramic crevice former (Figures 1416). This suggests that the mechanism of action of $\mathrm{SO}_{4}{ }^{2-}$ might include an ability to prevent or delay the formation of the critical crevice solution required to facilitate the self-sustaining growth of such crevices. This is consistent with the finding of Pistorius and Burstein [9] who found that in SS304, the pit stability product "ir", and hence the amount of dissolution in corrosion pits was lower in the presence of $\mathrm{SO}_{4}{ }^{2-}$. It is reasonable to assume that the presence of $\mathrm{SO}_{4}{ }^{2-}$ dilutes the crevice anolyte by preventing the required concentration of $\mathrm{Cl}^{-}$ions from building up within the pits and crevices thus reducing the aggressiveness of the environment in Alloy 22 .

The difference between the two methods used to measure the breakdown potential $\mathrm{E}_{\mathrm{b}}$, lies in the physical meaning of what the measured values represent. When Method 1 is typically employed; the primary aim is usually not the accurate determination of the point of commencement of localized breakdown (although possible), but rather, the establishment of a good and uniform basis for comparing the susceptibility of specimens/environment combinations to localized breakdown. The threshold current chosen for this sort of analyses is usually high enough to ensure that by the attainment of the chosen current density, localized corrosion would have commenced. In Method 2 however, the primary aim is the accurate determination of the potential at which localized corrosion starts, although this might be challenging on occasion. Thus, while Method 1 simply measures or compares the voltage corresponding to a pre-selected 
current or current density value representing an already growing localized event, Method 2 aims at using the current or current density signals to determine as accurately as possible where the growth of localized event(s) started. This is one reason why the $\mathrm{E}_{\mathrm{b}}$ values from Method 1 are higher than those from Method 2. Method 1 is more reproducible and more objective than Method 2. The $\mathrm{E}_{\mathrm{b}}$ values from Method 2 are more affected operator influence and hence less objective than Method 1. Further, the acuity or sharpness of the turning or inflection point in the polarization curve affects the ability to select $E_{b}$ when Method 2 is used. A sharper and more abrupt increase in current or current density from the passive region (indicating breakdown) would be easier to select compared with if the turning point in the curve, and rise in current or current density, is gentler.

These methods of determining $E_{b}$ from the polarization curves clearly affect not only the magnitude of values realized from such analyses, but also affect the temperature dependence (slopes) of the data obtained (Figure 21). The data in Figure 21 also shows that both methods are sensitive to the level of aggression of the environments. In Figure 21, it is seen that $\mathrm{E}_{\mathrm{b} 1}$ and $\mathrm{E}_{\mathrm{b} 2}$ measurements converge towards higher temperature where environmental conditions are more aggressive. The reason for this is that at lower temperatures which correspond to less aggressive environments, it is difficult to separate the current due to localized breakdown from that of transpassive dissolution, when localized corrosion is mild. The tendency under such mild conditions is that the current threshold value chosen in Method 1 represents a current from localized and transpassive dissolution. In Method $2\left(\mathrm{E}_{\mathrm{b} 2}\right)$, where an effort was made to separate the currents due to localized corrosion from transpassive dissolution currents, it is observed that a consistent improvement of $\mathrm{E}_{\mathrm{b}}$ by the presence of $\mathrm{SO}_{4}{ }^{2-}$ can be observed (especially at $0.4 \mathrm{M}$ 
levels) from 45 through $105{ }^{\circ} \mathrm{C}$ (Figure 21). The data presented in Figure 21 correlates to the damage sustained by the specimen in SEM photographs as see in Figures 6-8, 10-12 and 14-20. However, while these figures show that $\mathrm{SO}_{4}{ }^{2-}$ mitigated localized corrosion, they also reveal that temperature (in the range considered) is a stronger factor than $\left[\mathrm{SO}_{4}{ }^{2-}\right]$ in determining the amount of damage sustained by the specimen. At 45 and $60{ }^{\circ} \mathrm{C}, \mathrm{E}_{\mathrm{b} 1}$ values show no improvement between the $4 \mathrm{M} \mathrm{NaCl}$ and $4 \mathrm{M} \mathrm{NaCl}$ with $0.4 \mathrm{M} \mathrm{SO}_{4}{ }^{2-}$ additions, while $\mathrm{E}_{\mathrm{b} 2}$ values show some improvement at these two temperatures. The reason why no improvements are seen in $E_{b 1}$ values might be due to the fact that transpassive corrosion currents dominate the signals at these two temperatures at the threshold current density chosen for analyses. It should be noted that a small amount of localized corrosion occurred at these temperatures (Figures 6-8 and 10-12).

\section{The Repassivation Potential $\left(\mathrm{E}_{\mathrm{r}}\right)$}

The possibility of the lack of hysteresis formation, and hence a lack of an intersection of the forward and the reverse sweeps of the polarization curve even after the occurrence of localized corrosion made it necessary to consider a method of analyses that does not rely on the aforementioned features. For this reason, data analysis was carried out with the two methods chosen (which yielded $E_{r 1}$ and $E_{r 2}$ ), facilitating the comparison of both. As with the $E_{b}$ values, the physical meanings of the measured potential values representing $E_{r}$ from these two methods vary. With the $E_{r 1}$ values (Method 1), the threshold value typically chosen for the analyses is one that is low enough to ensure that no local corrosion sites still survive. The value chosen is one that is typically close enough; often lower in magnitude (of current or current density) than the passive current (or current density) of the metal or alloy in the forward sweep. Thus, the primary objective is the establishment of a good and consistent basis for comparing the ability of 
metals to repassivate after local breakdown has occurred. With Method 1, it is not essential that a hysteresis loop is visible, neither is there the need for the forward and reverse sweeps of a polarization curve to intersect. The basis for the method by which $\mathrm{E}_{\mathrm{r} 2}$ (Method 2) values were generated assumes that a drop in current density to the previous passive current density level (of the forward sweep) implies that the metal has re-attained passivity, and assumes that the point of intersection of the forward and reverse scans on a polarization curve represents the reacquisition of passivity by the previously locally active metal. The primary goal in this case is to derive $\mathrm{E}_{\mathrm{r}}$ values that are as close as possible to the exact point of repassivation. An obvious limitation of using Method 2 to generate $\mathrm{E}_{\mathrm{r} 2}$ is that it cannot be used where the forward and reverse scans do not intersect in the passive region of the anodic portion of the curve as found in $5 \mathrm{M} \mathrm{LiCl} \mathrm{[3].} \mathrm{It}$ is therefore not conducive for situations where repassivation of a localized event(s) is primarily due to a change in net current from anodic to cathodic, rather than a dilution of the crevice anolyte to a concentration where localized corrosion can no longer be supported despite the presence of a net anodic current. Other issues with the accuracy of $E_{r}$ may arise if the point of intersection of the forward and reverse sweeps is difficult to establish for any reason. However, no such difficulty was encountered in this work since all the intersection points were easy to delineate when they occurred.

Figures 22 and 23 show that in $\mathrm{E}_{\mathrm{r} 1}$ measurements, there is in general no difference in the values of $E_{r}$ regardless of the amount of charge passed before reversing the polarization scan. However, in $\mathrm{E}_{\mathrm{r} 2}$ analyses, the mean values were generally higher with increase in the amount of charge passed. The conclusion reached about charge not interfering with the $\mathrm{E}_{\mathrm{r} 1}$ measurements are consistent with the results of Kehler et al. where the same threshold value of $1 \times 10^{-6} \mathrm{Acm}^{-2}$ was 
used in estimating the repassivation potentials of Alloy 22 in $5 \mathrm{M} \mathrm{LiCl} \mathrm{[3].}$

Although the differences between in $\mathrm{E}_{\mathrm{r} 2}$ values from the 5 and $30 \mathrm{mAcm}^{-2}$ apex were usually not significant, it is not immediately clear why higher average $\mathrm{E}_{\mathrm{r} 2}$ values were realized from the 30 $\mathrm{mAcm}^{-2}$ curves compared with the $5 \mathrm{mAcm}^{-2}$ ones (Figure 23). With more charge passed, and hence more dissolution taking place at $30 \mathrm{mAcm}^{-2}$ compared with $5 \mathrm{mAcm}^{-2}$, it would have been expected that in the event of any difference in $E_{r}$, the $E_{r}$ for the $30 \mathrm{mAcm}^{-2}$ curves would be lower since it was thought that a lower potential (hence more time) might be required to shut down the growth of larger and deeper crevices compared with smaller and shallower ones. Clearly, this is not the case.

Sulfate appears to have no effect on $\mathrm{E}_{\mathrm{r}}$ at $45{ }^{\circ} \mathrm{C}$. This might be partially due to the limited localized corrosion that occurred at elevated potentials at this temperature (Figures 24 and 25). Transpassive dissolution dominated the currents emanating from the specimens $45^{\circ} \mathrm{C}$. From Figure 24 and 25, it can be seen that the beneficial effect of $\mathrm{SO}_{4}{ }^{2-}$ to repassivation was observed at $60{ }^{\circ} \mathrm{C}$. At $60{ }^{\circ} \mathrm{C}$, Figure 24 shows that when $0.4 \mathrm{M} \mathrm{SO}_{4}{ }^{2-}$ was added to solution, $\mathrm{E}_{\mathrm{r}}$ increased by more than $600 \mathrm{mV}$. An increase of over $300 \mathrm{mV}$ is attained with $0.04 \mathrm{M} \mathrm{SO}_{4}{ }^{2-}$ in solution. By $75^{\circ} \mathrm{C}$ any beneficial effect of $\mathrm{SO}_{4}{ }^{2-}$ on $\mathrm{E}_{\mathrm{r}}$ had been all but completely lost. This implies that once a certain level of aggressiveness (concentration or composition of the crevice solution) has been attained, the repassivation potential becomes independent of temperature and $\mathrm{SO}_{4}{ }^{2-}$ concentration within the range tested. 
$E_{r 1}$ values being higher than $E_{r 2}$ values is likely due to the fact the mean values posted are a contribution from curves which had hystereses loops, and those which did not. The size of the loop increase as the electrolyte becomes more aggressive at $60{ }^{\circ} \mathrm{C}$ (Figure 9), and a lack of a loop is common at $45{ }^{\circ} \mathrm{C} . \mathrm{E}_{\mathrm{r} 2}$ values include data only from curves that had hysteresis loops. Thus, $\mathrm{E}_{\mathrm{r} 1}$ values are likely to have values in them that come from curves where transpassive dissolution, rather than localized breakdown predominated. This argument is supported by the fact that by $75{ }^{\circ} \mathrm{C}$, the values for $\mathrm{E}_{\mathrm{r} 1}$ and $\mathrm{E}_{\mathrm{r} 2}$ are similar (Figure 26). At $75{ }^{\circ} \mathrm{C}$ and above, currents due to localized corrosion dominate all the currents emanating from the specimens. The convergence of $\mathrm{E}_{\mathrm{r} 1}$ and $\mathrm{E}_{\mathrm{r} 2}$ data for all the electrolytes at $75{ }^{\circ} \mathrm{C}$ also implies that as the environment becomes more aggressive, any differences between $\mathrm{E}_{\mathrm{r} 1}$ and $\mathrm{E}_{\mathrm{r} 2}$ diminish to an insignificant minimum. This is supported by earlier work carried out in $10 \mathrm{M} \mathrm{Cl}^{-}$between 45 and $120{ }^{\circ} \mathrm{C}$, which showed that in this highly concentrated $\mathrm{Cl}^{-}$solution, there was virtually no difference between $\mathrm{E}_{\mathrm{r} 1}$ and $\mathrm{E}_{\mathrm{r} 2}$ values between 45 and $120{ }^{\circ} \mathrm{C}$ [33]. Either of the two methods can thus be used without fear of compromising the accuracy of the repassivation potentials measured in aggressive environments where localized corrosion currents predominate. However, in some cases, it might be prudent to use Method 1 (which yields) $\mathrm{E}_{\mathrm{r} 1}$ since it is always available.

\section{CONCLUSIONS}


1. Alloy 22 was susceptible to crevice corrosion in $4 \mathrm{M} \mathrm{NaCl}, 4 \mathrm{M} \mathrm{NaCl}+0.04 \mathrm{M}$ $\mathrm{Na}_{2} \mathrm{SO}_{4}$ and $4 \mathrm{M} \mathrm{NaCl}+0.4 \mathrm{M} \mathrm{Na}_{2} \mathrm{SO}_{4}$ between 45 and $105^{\circ} \mathrm{C}$ under anodic polarization conditions.

2. The presence of $\mathrm{SO}_{4}{ }^{2-}$ increased the resistance of Alloy 22 to crevice corrosion. The higher the $\mathrm{SO}_{4}{ }^{2-}$ concentration, the higher the degree of corrosion inhibition. Better improvement was observed at the higher $0.4 \mathrm{M} \mathrm{SO}_{4}{ }^{2-}$ concentration compared with the lower $0.04 \mathrm{M}$ concentration of $\mathrm{SO}_{4}{ }^{2-}$.

3. The presence of $\mathrm{SO}_{4}{ }^{2-}$ increased the breakdown potentials at all the temperatures tested, and increased the repassivation potentials at $60{ }^{\circ} \mathrm{C}$. There was no improvement of the repassivation potentials by $\mathrm{SO}_{4}{ }^{2-}$ at $75{ }^{\circ} \mathrm{C}$ and above.

4. Localized damage under the crevice former was initiated as small pits, and these pits then enlarged and coalesced to form trenches.

5. The presence of $\mathrm{SO}_{4}{ }^{2-}$ reduced the sizes of the pits under the crevice former.

6. As the level of aggression of the environment increased, crevice corrosion tended to proceed away from the crevice formers towards the crevice free area.

\section{Acknowledgements}

The Department of Energy Office of Civilian Radioactive Waste Management (OCRWM) sponsored this work. This work was done under the auspices of the U.S. Department of Energy (DOE) by the University of California, Lawrence Livermore National Laboratory (LLNL) under contract No. W-7405-Eng-48. This work is supported by the DOE Office of Repository 
Development, LLNL. Technical discussions with R.B. Rebak are appreciated. SEM done with the assistance of Lana L. Wong is also appreciated.

\section{REFERENCES}

1. G.O. Ilevbare T. Lian and J.C. Farmer, Environmental Considerations in the Studies of Corrosion Resistant Alloys for High-Level Radioactive Waste Containment Paper No. 02539 , Corrosion 2002, NACE.

2. G.O. Ilevbare, Electrochemical Behavior of Alloy 22 in $5 \mathrm{M} \mathrm{CaCl}_{2}$, Transportation Storage, and Disposal of Radioactive Materials, PVP-Vol. 449, p.55, 2002. American Society of Mechanical Engineers (ASME), New York, USA.

3. B. A. Kehler, G.O. Ilevbare and J.R. Scully Corrosion, 57, p. 1042, 2001.

4. B. A. Kehler, G. O. Ilevbare and J. R. Scully Corrosion 2001, Crevice Corrosion Behavior, of Ni-Cr-Mo Alloys: Comparison of Alloys 625 and 22, NACE Topical Research Symposium, p.30, March 2001.

5. Haynes International, Inc., Product Brochure H-2019E, Haynes International Inc. Kokomo, IN, p.22, 1997.

6. J. C. Farmer, D. McCright, G.E. Gdowski, F. Fang, T. Summers, P. Bedrossian, J. Horn, T. Lian, J. Estill, A. Lingenfelter, and W. Halsey, General and Localized Corrosion of Outer Barrier of High-Level Waste Container in Yucca Mountain, May 2000. Preprint UCRL-JC-138890, Lawrence Livermore National Laboratory, Technical Information Department Digital Library. 
7. K.A. Gruss, G.A. Cragnolino, D.S. Dunn and N.Sridhar, Corrosion '98, Paper No. $149,1998$.

8. S.J. Lukezich, The Corrosion Behavior of Ni-Base High Performance Alloys in Simulated Repository Environments, MS Thesis, The Ohio State University 1989.

9. P.C. Pistorius and G.T. Burstein, Corrosion Science, 33, (1992): p.1885

10. H.P. Leckie and H.H. Uhlig, J. Electrochem. Soc., 113, (1966): p.1262

11. H. Yashiro and K. Tanno, Corrosion Science, 31, (1990): p.485

12. W.F. Bogaerts and A.A. Van Haute, Corrosion Science, 25, (1985): p.1149

13. I.L. Rozenfeld and I.S. Danilov Corrosion Science, 7, (1967): p.129

14. Z. Ahmed Corrosion, 33, (1977): p.161

15. M-Y. Chang and G-P. Yu, Journal of Materials Science, 202, (1993): p.145

16. I-J. Yang, Corrosion Science 33, (1992): p.25

17. T. Laitinen, Corrosion Science, 42, (2000): p.421

18. E.A. Ashour, Journal of Materials Science, 36, (2001): p.685

19. H.C. Man and D.R. Gabe, Corrosion Science, 21, (1981): p.323

20. H.C. Man and D.R. Gabe, Corrosion Science, 21, (1981): p.713

21. Z. Szklarska-Smialowska, Corrosion Science, 11, (1971): p.209

22. Z. Szklarska-Smialowska, Corrosion Science, 12, (1972): p.527

23. G.A. Cragnolino and N. Shridhar, Corrosion, 47, (1991): p.464

24. I-J. Yang, Materials Chemistry and Physics, 49, (1997): p.50

25. J. Harrar, J. Carley, W. Isherwood and E. Rabeer, in Report of the Committee to Review The Use of J-13 Well-water in the Nevada Nuclear Waste Storage 
Investigations, UCID-21876, Lawrence Livermore National Laboratory, January 1990.

26. F. Wang, G.E. Gdowski, J. Estill, S. Gordon, S. Doughty, K. King and D. McCright, Corrosion'98, 1998 Paper No. 161.

27. N.D. Rosenberg, G.E. Gdowski, and K. G. Knauss, Applied Geochemistry, 16, (2001): p.1231.

28. ASTM B574, Annual Book of ASTM Standards, Nonferrous Metal Products, Volume 02.04, American Society of Testing and Materials, West Conshohocken, PA (2000).

29. ASTM B575, Annual Book of ASTM Standards, Nonferrous Metal Products, Volume 02.04, American Society of Testing and Materials, West Conshohocken, PA (2000).

30. D.D. Macdonald, A.C. Scott, and P. Wentrcek, J. Electrochem. Soc., 126, (1978): p.908

31. ASTM G59, ASTM Standards, Wear and Erosion; Metal Corrosion, Volume 03.02, American Society of Testing and Materials, West Conshohocken, PA (2001).

32. ASTM G 102, ASTM Standards, Wear and Erosion; Metal Corrosion, Volume 03.02, American Society of Testing and Materials, West Conshohocken, PA (2001).

33. G.O.Ilevbare, The Effect of Welding on the Breakdown and Repassivation Potentials of Alloy 22 in $5 \mathrm{M} \mathrm{CaCl}_{2}$, UCRL-JC-155209, University of California Records Library, Lawrence Livermore National Laboratory. 
Table 1. Chemical composition of Alloy 22 (UNS No. N06022) given in weight percent.

\begin{tabular}{|c|c|c|}
\hline Element & $\begin{array}{c}\text { Actual } \\
\text { Composition } \\
\text { Heat \# } 2277-5-3203\end{array}$ & $\begin{array}{c}\text { ASTM } \\
\text { Requirements } \\
\text { ASTM B575- } \\
\text { Sheets }\end{array}$ \\
\hline Cr & 22.00 & $20.0-22.5$ \\
\hline Mo & 14.10 & $12.5-14.5$ \\
\hline Fe & 4.50 & $2.0-6.0$ \\
\hline W & 2.70 & $2.5-3.5$ \\
\hline Co & 1.30 & $0.0-2.5$ \\
\hline Mn & 0.31 & $0.00-0.50$ \\
\hline $\mathbf{V}$ & 0.16 & $0.00-0.35$ \\
\hline Mn & 0.31 & $0.00-0.50$ \\
\hline $\mathbf{P}$ & 0.01 & $0.00-0.02$ \\
\hline $\mathbf{S}$ & $<0.01$ & $0.00-0.02$ \\
\hline $\mathbf{C}$ & 0.003 & $0.000-0.015$ \\
\hline $\mathbf{N i}$ & Bal. & Bal. \\
\hline
\end{tabular}

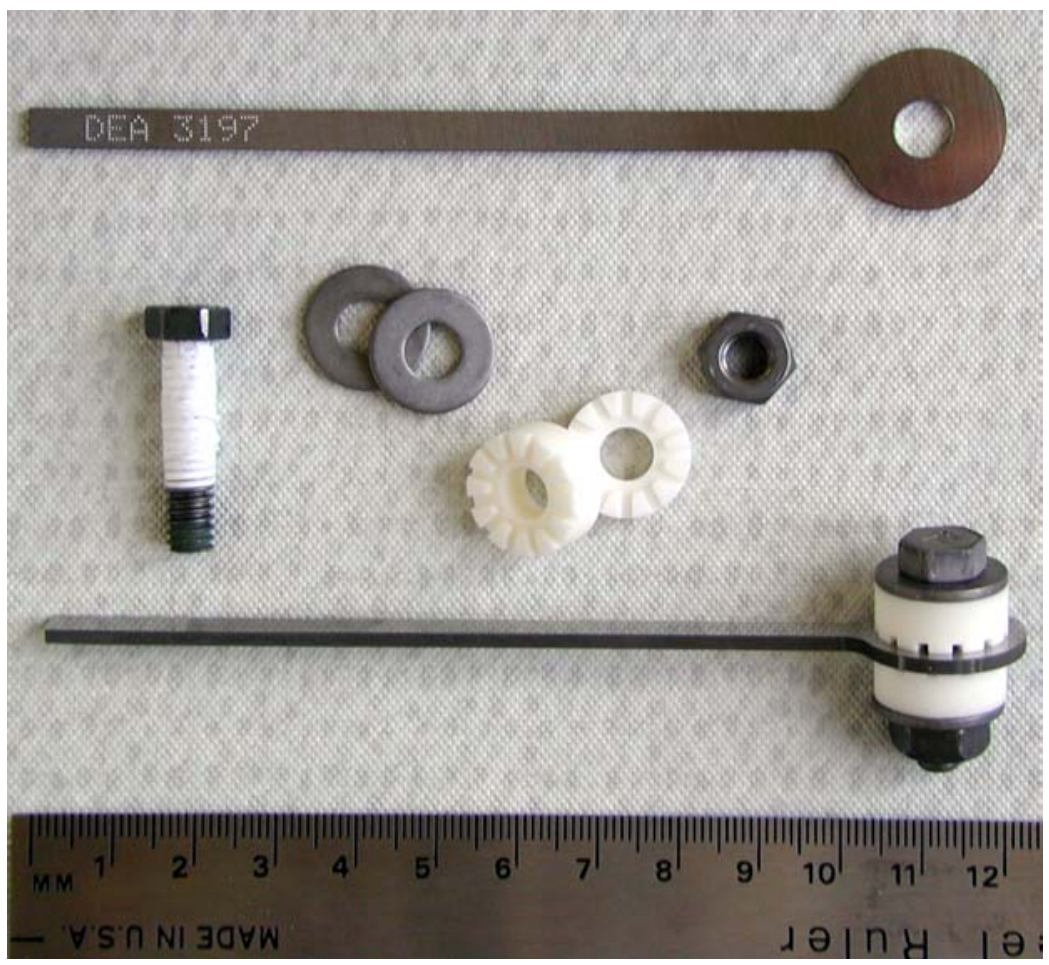

Figure 1: Multiple Crevice Assembly (MCA), bottom. It shows the lollipop-like specimen (top), titanium grade two bolt (Teflon wrapped for electrical insulation), washers, nuts and ceramic washers. 


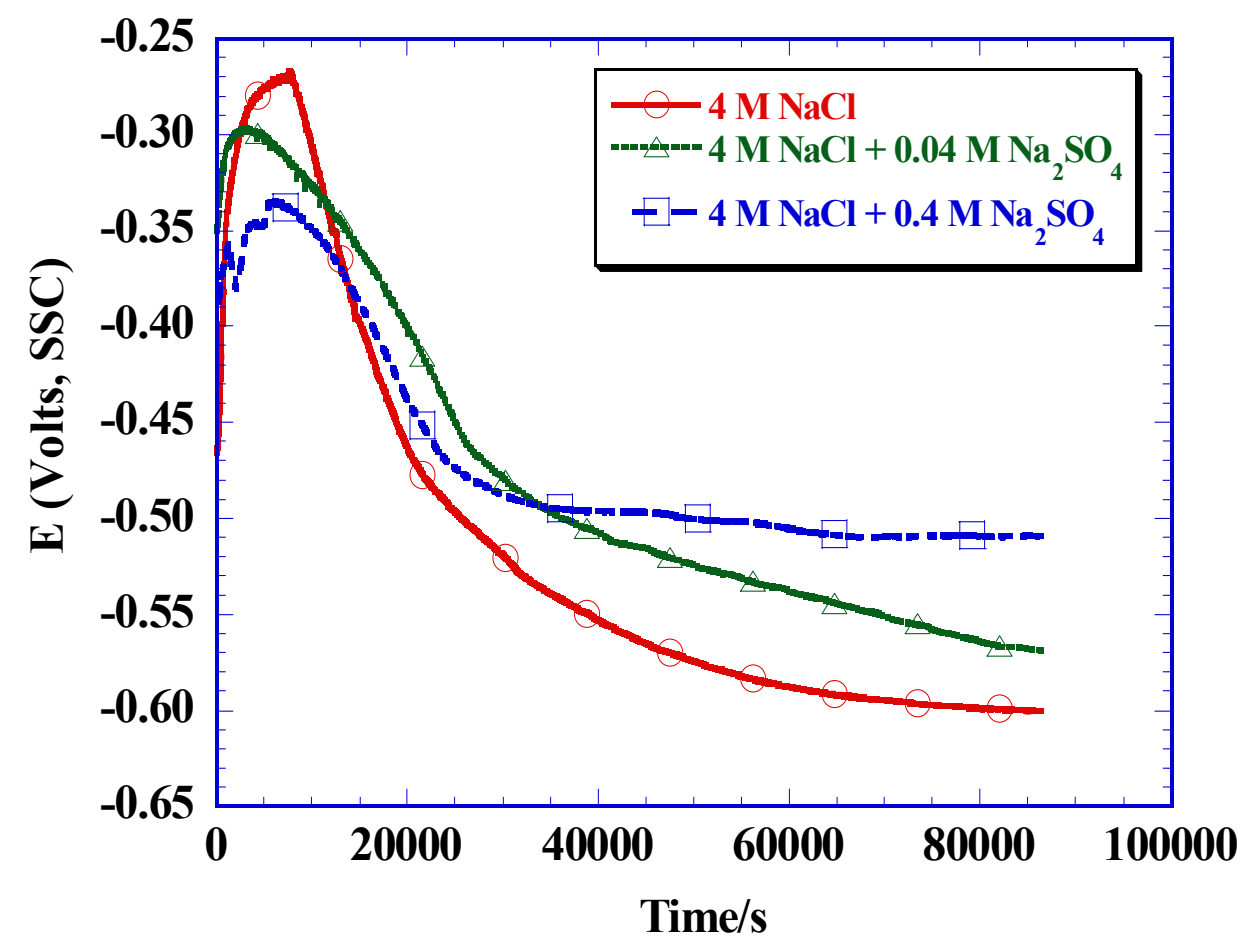

Figure 2: 24-hour open circuit potential of Alloy 22 in $4 \mathrm{M} \mathrm{NaCl}, 4 \mathrm{M} \mathrm{NaCl}+0.4 \mathrm{M} \mathrm{Na}_{2} \mathrm{SO}_{4}$ and $4 \mathrm{M} \mathrm{NaCl}+0.04 \mathrm{M} \mathrm{Na}_{2} \mathrm{SO}_{4}$ at $75^{\circ} \mathrm{C}$.

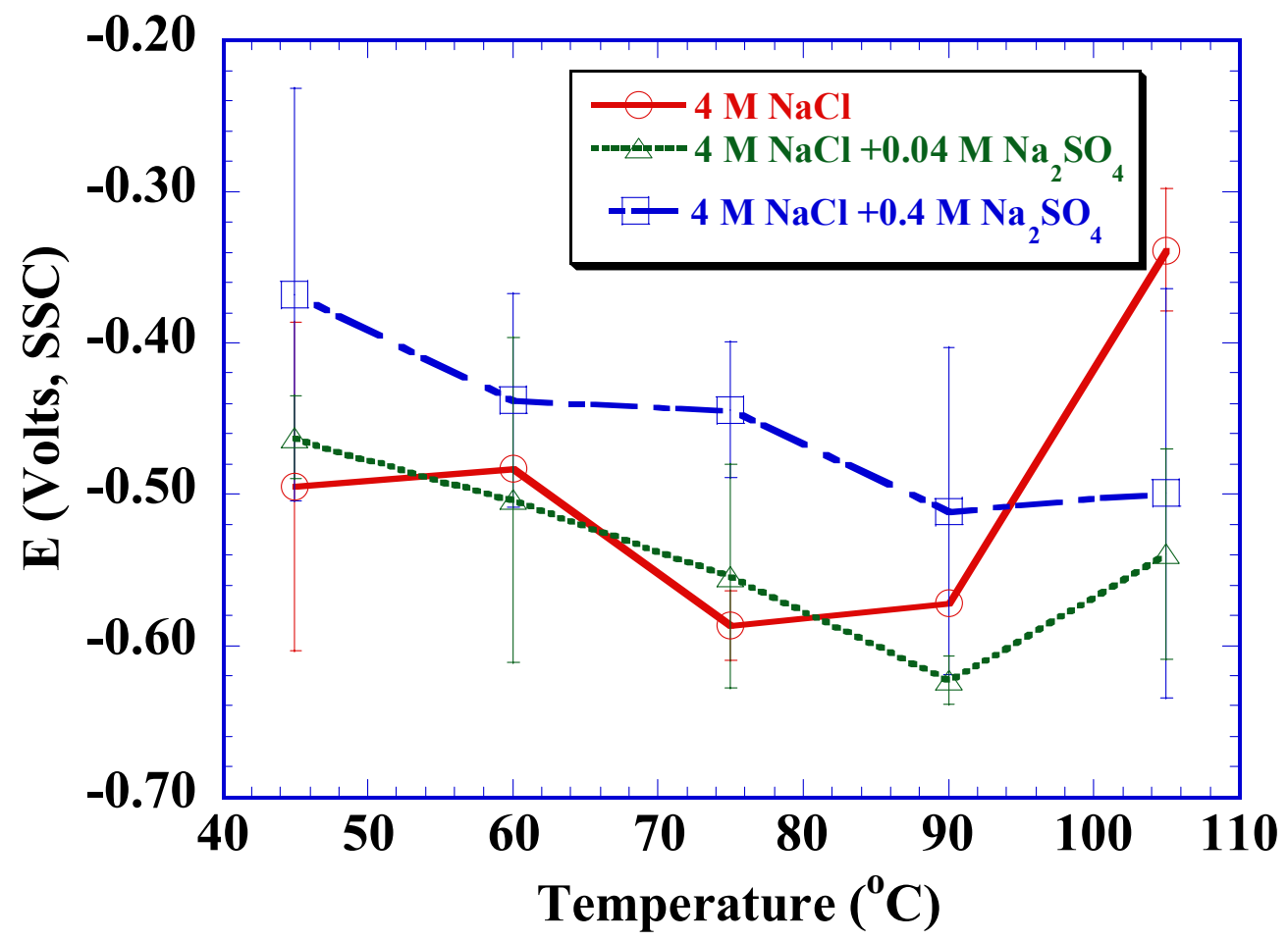

Figure 3: $\mathrm{E}_{\text {corr }}$ of MCA Alloy 22 specimens as a function of temperature in $4 \mathrm{M} \mathrm{NaCl}, 4 \mathrm{M} \mathrm{NaCl}$ $+0.4 \mathrm{M} \mathrm{Na}_{2} \mathrm{SO}_{4}$ and $4 \mathrm{M} \mathrm{NaCl}+0.04 \mathrm{M} \mathrm{Na}_{2} \mathrm{SO}_{4}$. $\mathrm{E}_{\text {corr }}$ was measured after 24 hour of immersion in solution. 


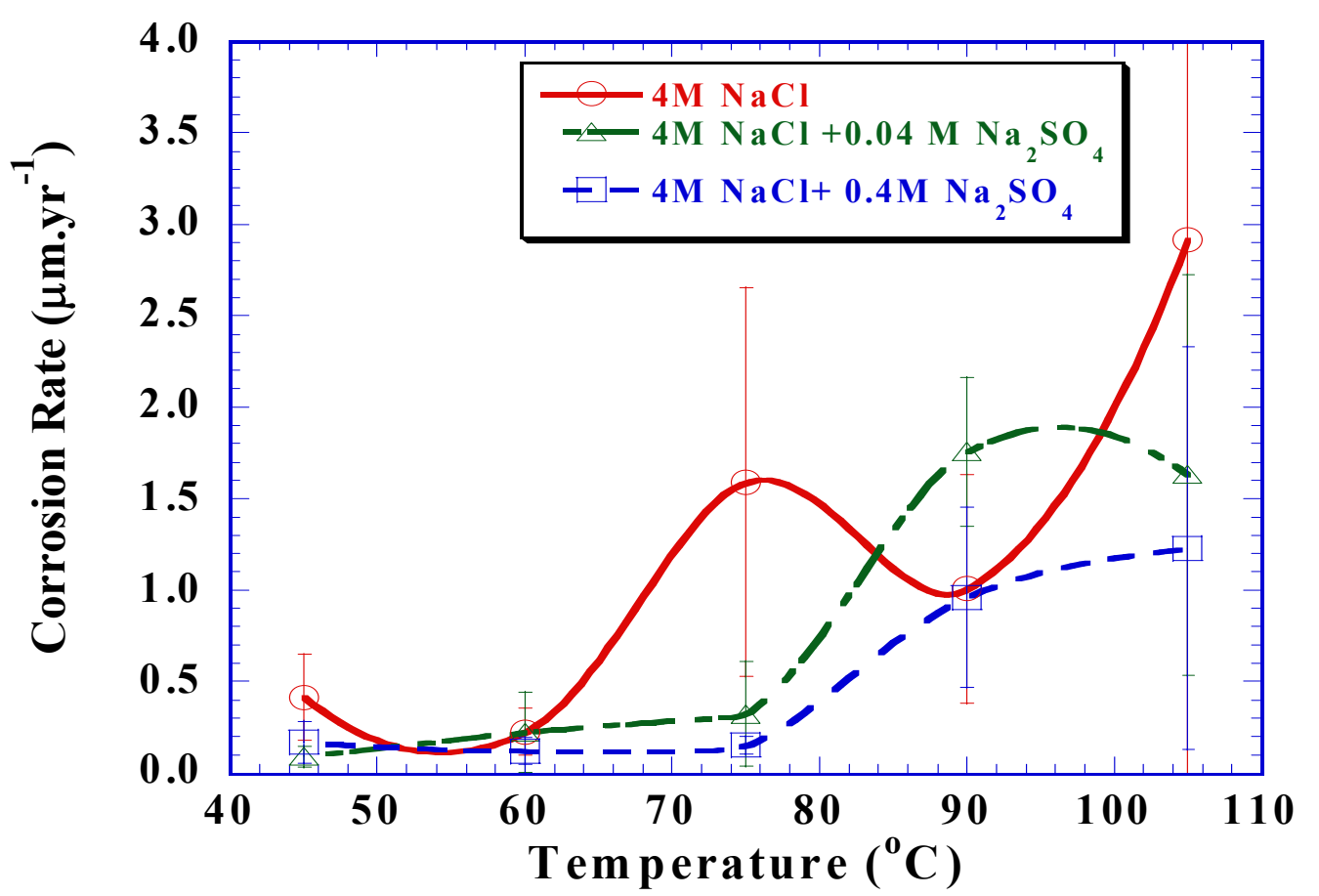

Figure 4a: Corrosion rates of Alloy 22 ( $\mu \mathrm{m}$ per year) as a function of temperature in $4 \mathrm{M} \mathrm{NaCl}$, $4 \mathrm{M} \mathrm{NaCl}+0.4 \mathrm{M} \mathrm{Na}_{2} \mathrm{SO}_{4}$ and $4 \mathrm{M} \mathrm{NaCl}+0.04 \mathrm{M} \mathrm{Na}_{2} \mathrm{SO}_{4}$.

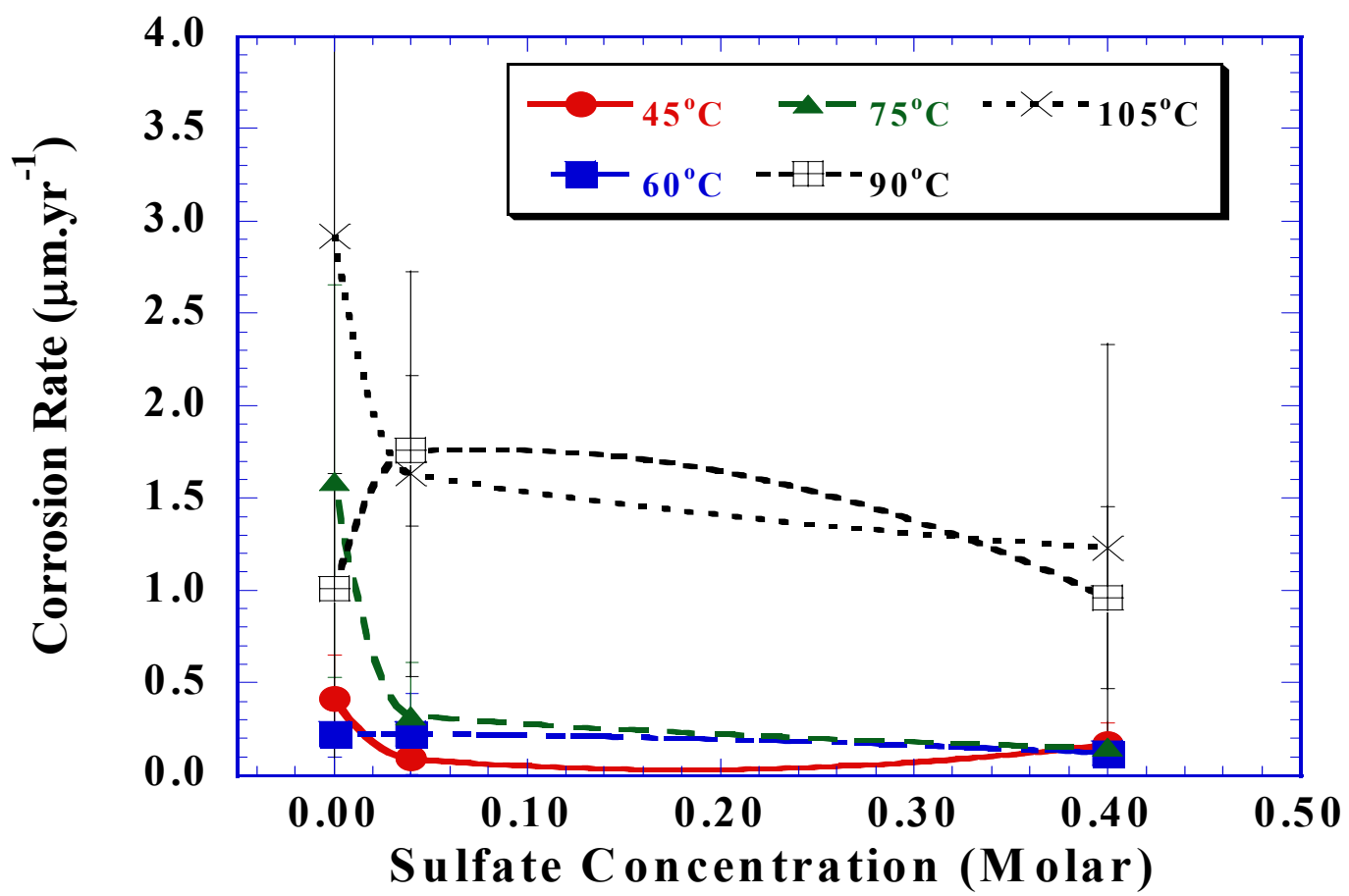

Figure 4b: Corrosion rates of Alloy 22 ( $\mu \mathrm{m}$ per year) as a function of sulfate concentration in 4 $\mathrm{M} \mathrm{NaCl}, 4 \mathrm{M} \mathrm{NaCl}+0.04 \mathrm{M} \mathrm{Na}_{2} \mathrm{SO}_{4}$ and $4 \mathrm{M} \mathrm{NaCl}+0.4 \mathrm{M} \mathrm{Na}_{2} \mathrm{SO}_{4}$. 


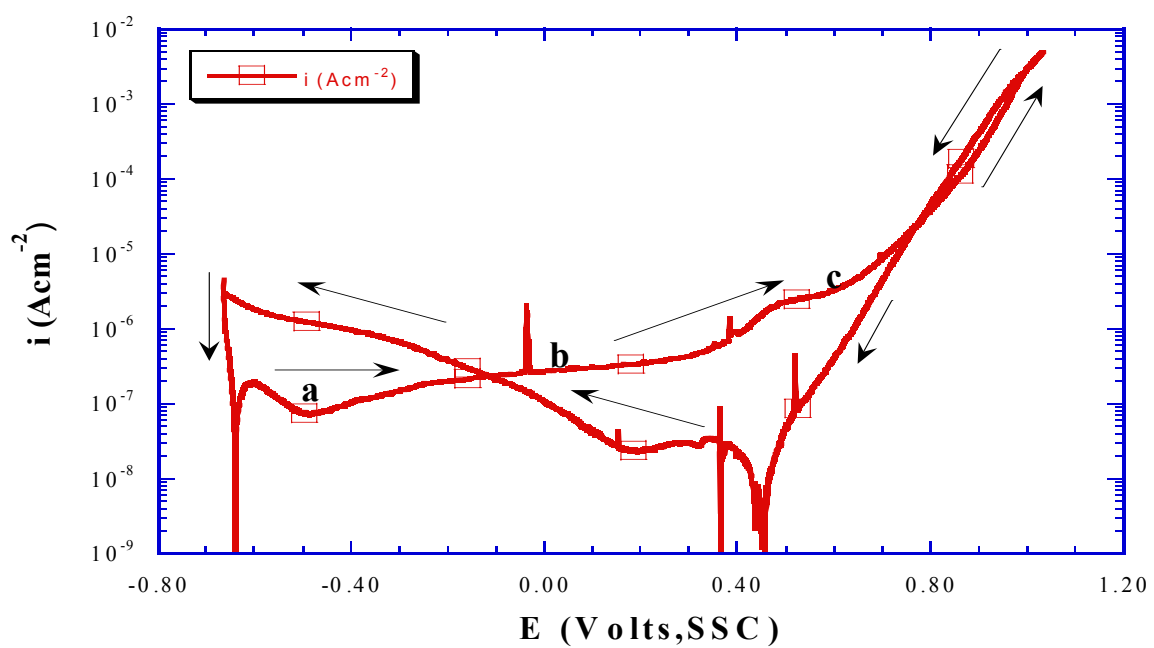

Figure 5a: $4 \mathrm{M} \mathrm{NaCl}$

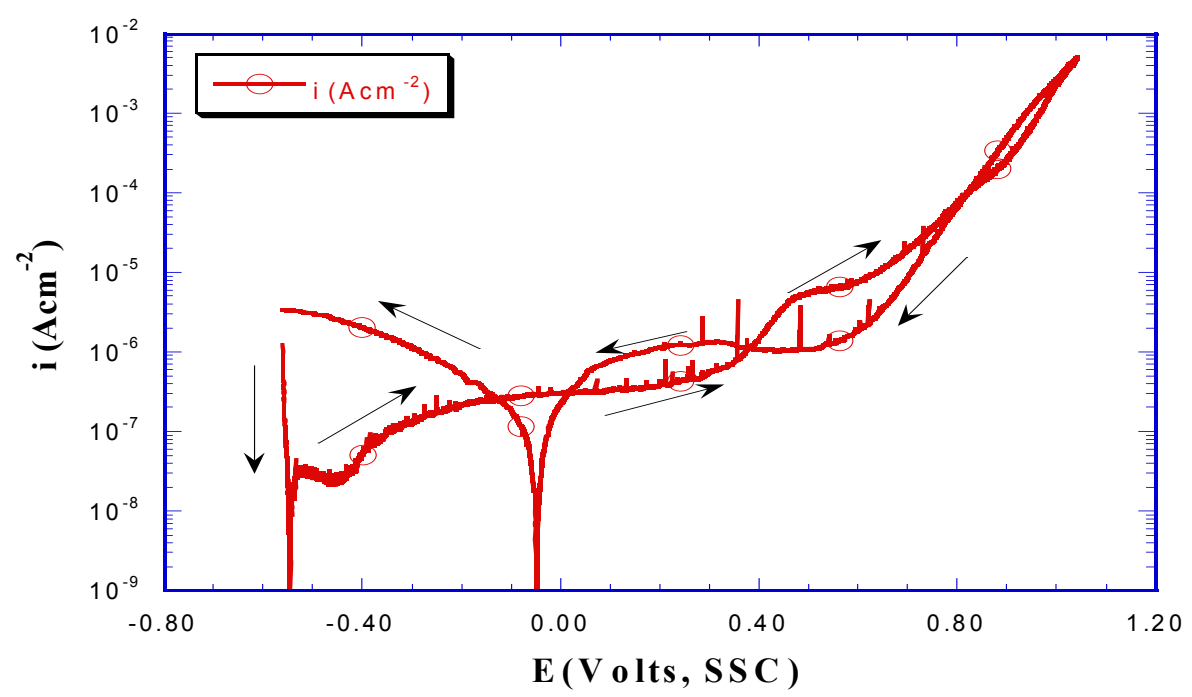

Figure 5b: $4 \mathrm{M} \mathrm{NaCl}+0.04 \mathrm{M} \mathrm{Na}_{2} \mathrm{SO}_{4}$

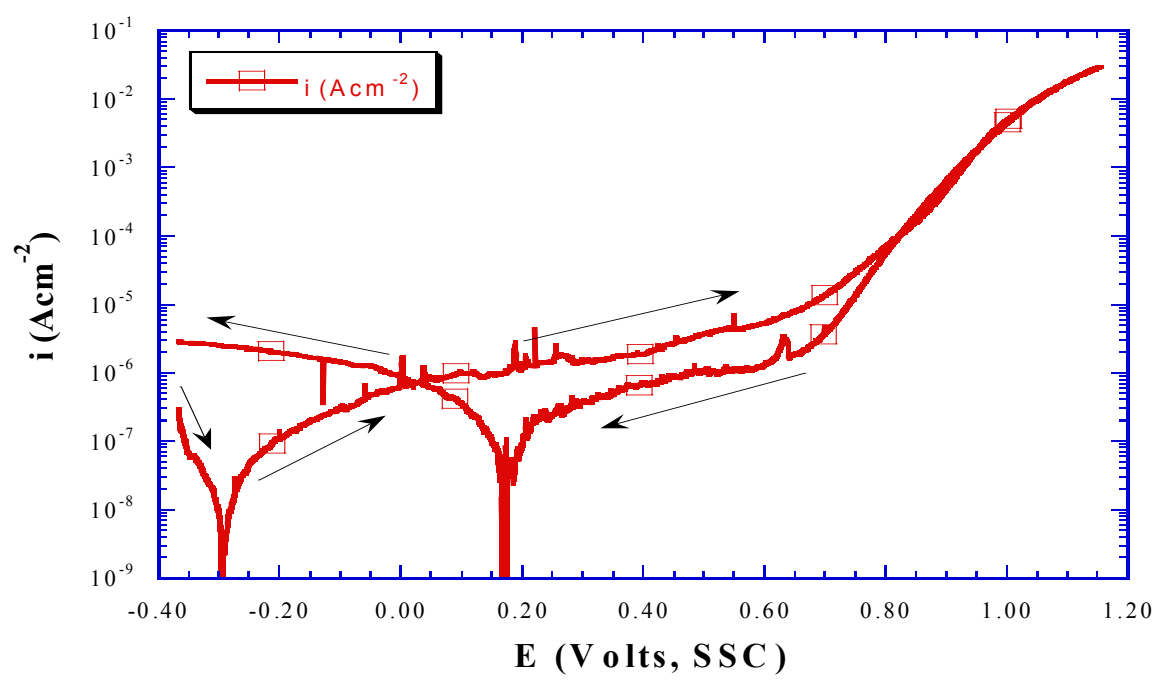

Figure $5 \mathrm{c}: 4 \mathrm{M} \mathrm{NaCl}+0.4 \mathrm{M} \mathrm{Na}_{2} \mathrm{SO}_{4}$
Figure 5: Polarization curves of Alloy 22 at 45 ${ }^{\circ} \mathrm{C}$. The Polarization curves represent the shapes of the curves generated from all three electrolytes, namely: $4 \mathrm{M}$ $\mathrm{NaCl}, 4 \mathrm{M} \mathrm{NaCl}+0.04 \mathrm{M}$ $\mathrm{Na}_{2} \mathrm{SO}_{4}+$ and $4 \mathrm{M} \mathrm{NaCl}$ $+0.4 \mathrm{M} \mathrm{Na}_{2} \mathrm{SO}_{4}$ ) tested at $45^{\circ} \mathrm{C}$. Sweep rate was $0.1667 \mathrm{mVs}^{-1}$. 


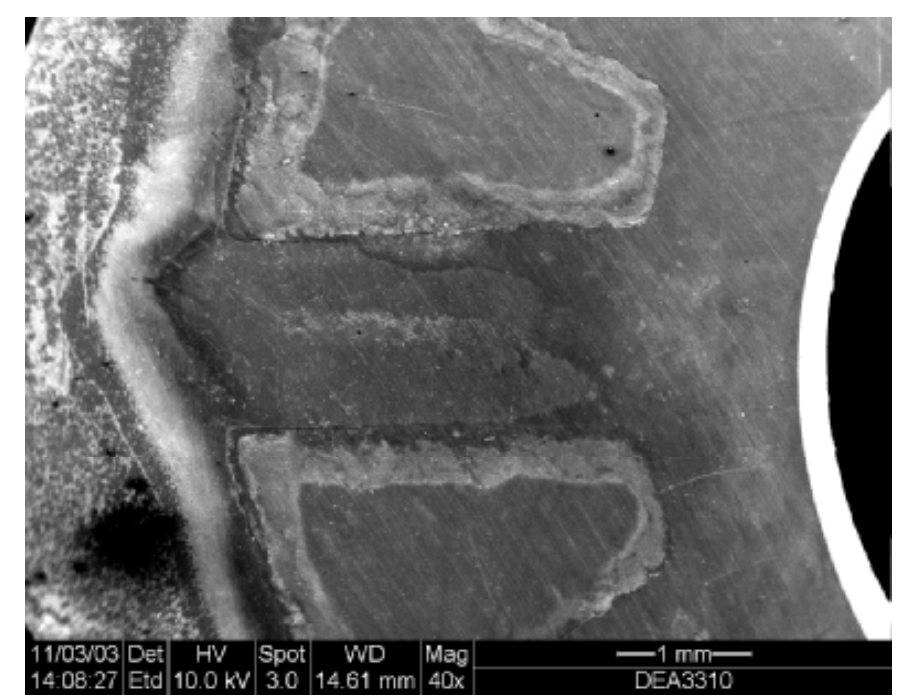

FIGURE 6a: Magnification- x40

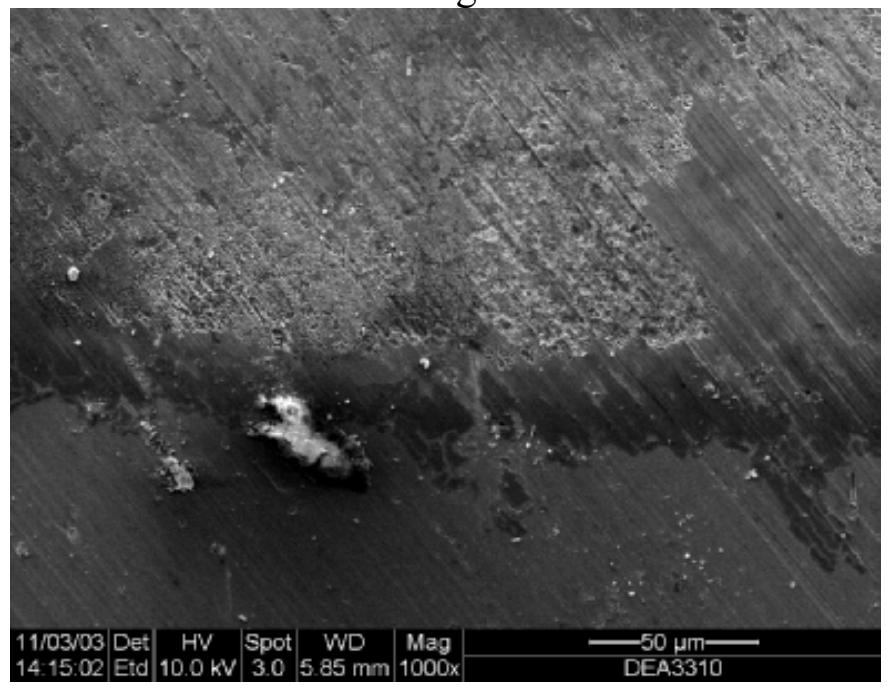

FIGURE 6b: Magnification-x1000

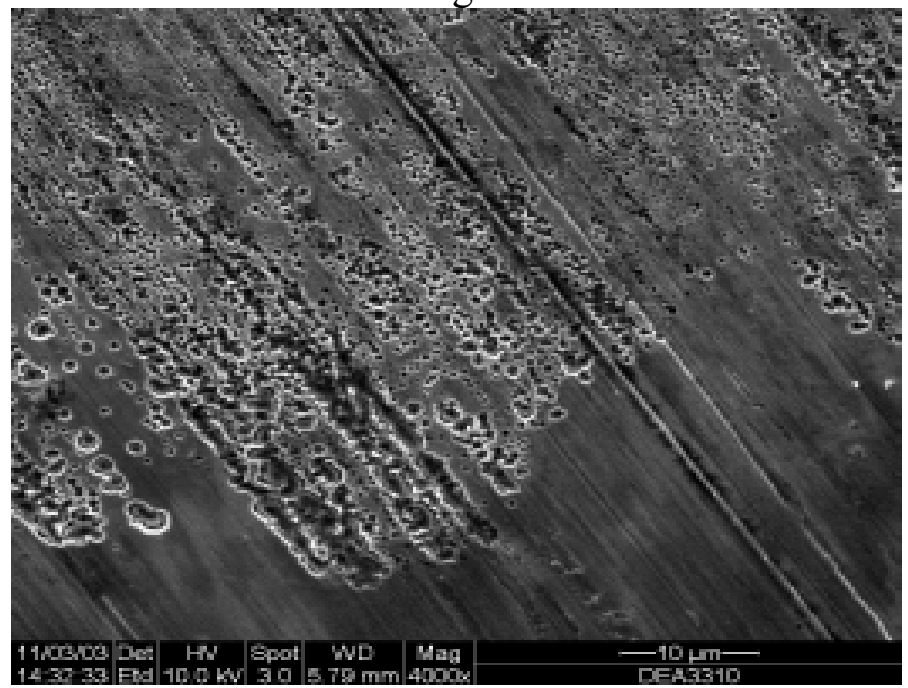

FIGURE 6c: Magnification- $\mathrm{x} 4000$
Figure 6: SEM images of Alloy 22 after cyclic polarization in $4 \mathrm{M} \mathrm{NaCl}$ at $45^{\circ} \mathrm{C}$, at a sweep rate of $0.1667 \mathrm{mVs}^{-1}$. Maximum potential attained during polarization on this specimen was about $1.2 \mathrm{~V}$ (SSC). 


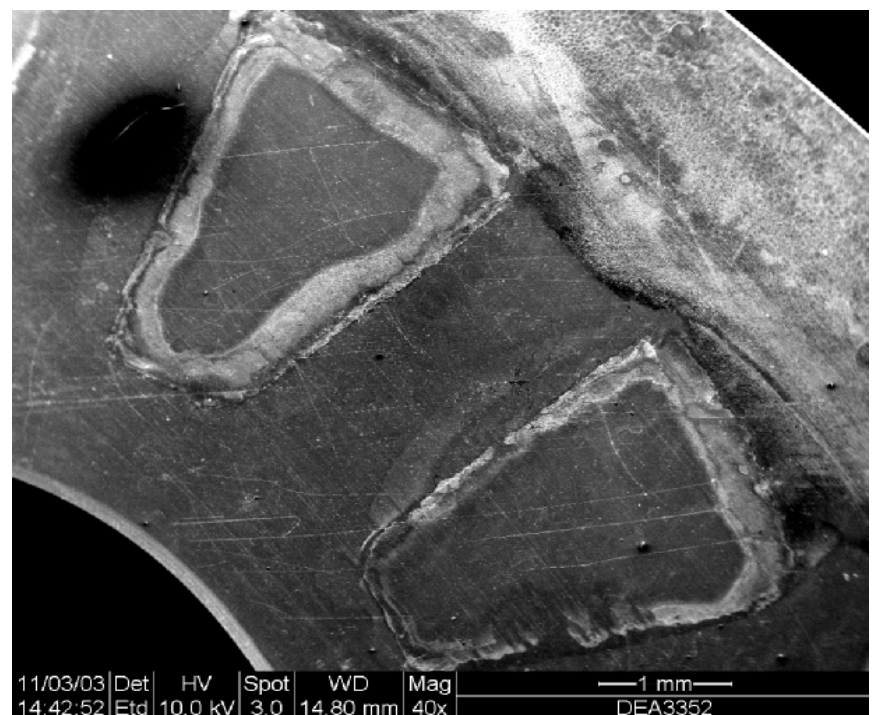

Figure 7a: Magnification- $x 40$

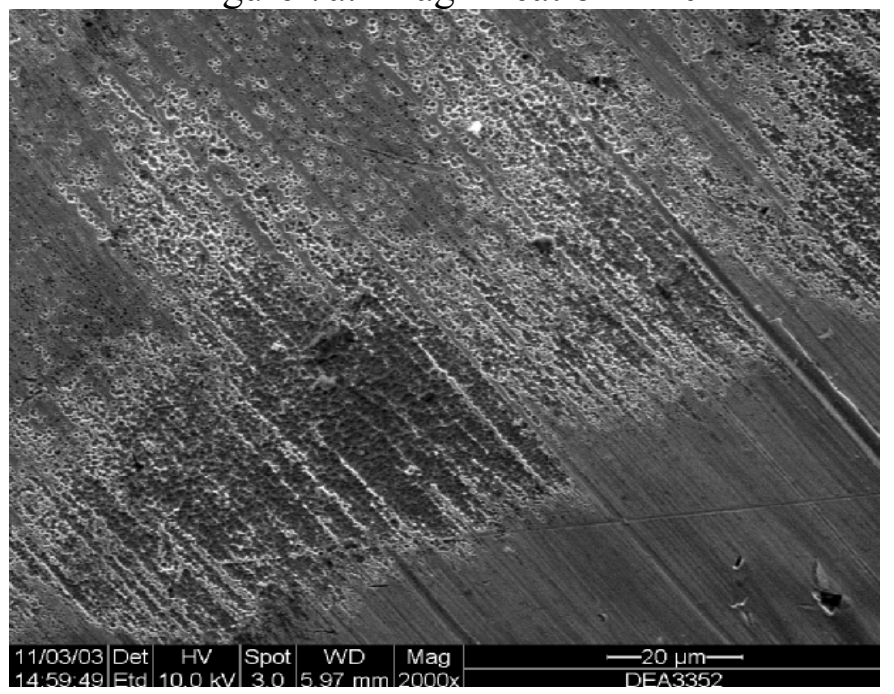

Figure 7b: Magnification-x2000

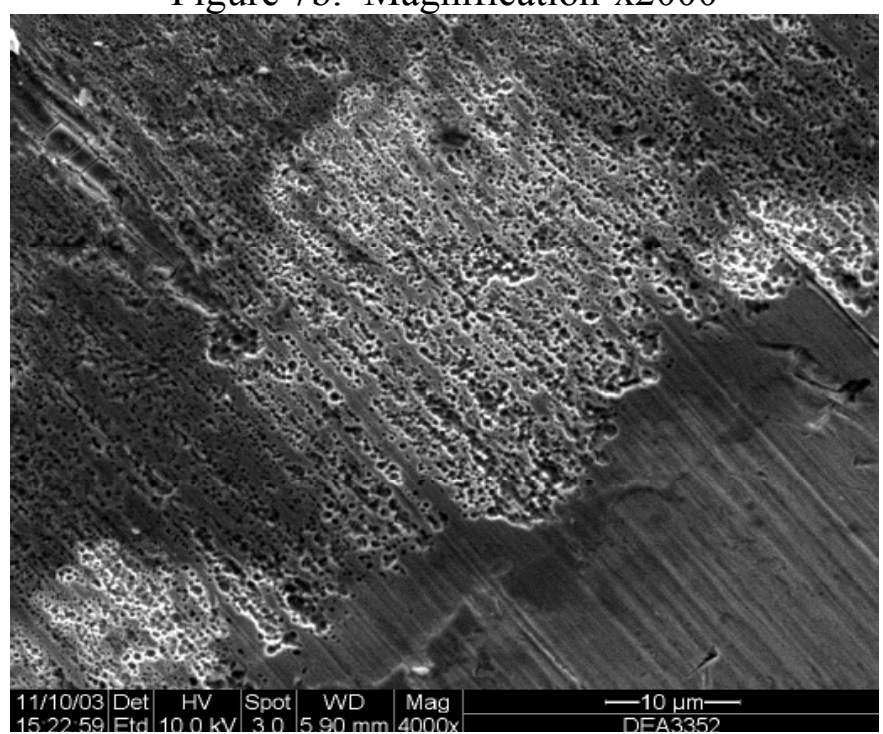

Figure 7c: Magnification- $\mathrm{x} 4000$
Figure 7: SEM images of Alloy 22 after cyclic polarization in $4 \mathrm{M} \mathrm{NaCl}+0.04 \mathrm{M}$ $\mathrm{Na}_{2} \mathrm{SO}_{4}$ at $45^{\circ} \mathrm{C}$, at a sweep rate of 0.1667 $\mathrm{mVs}^{-1}$. Maximum potential attained during polarization on this specimen was about $1.1 \mathrm{~V}$ (SSC). 


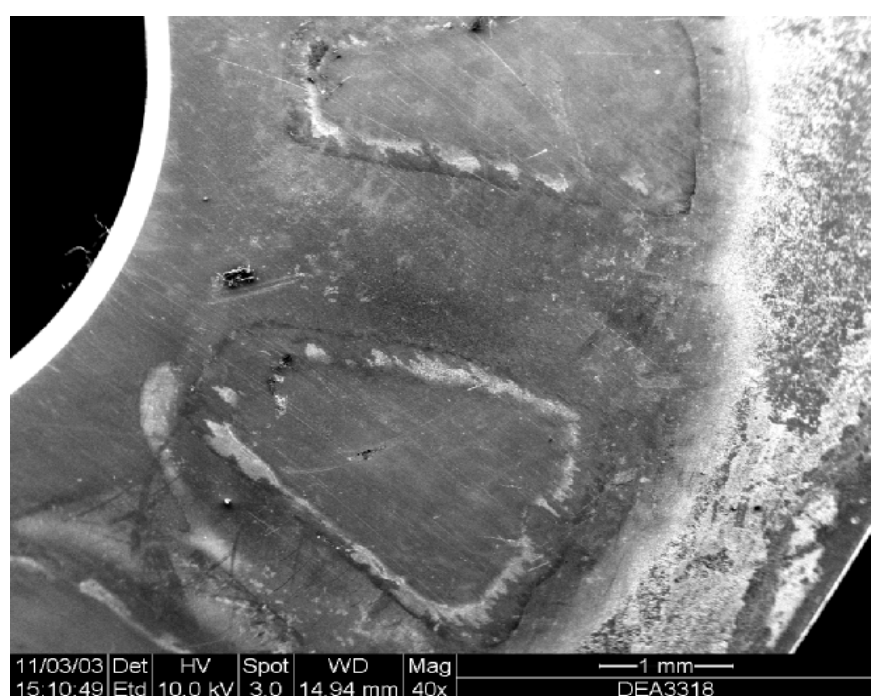

Figure 8a: Magnification- $\mathrm{x} 40$

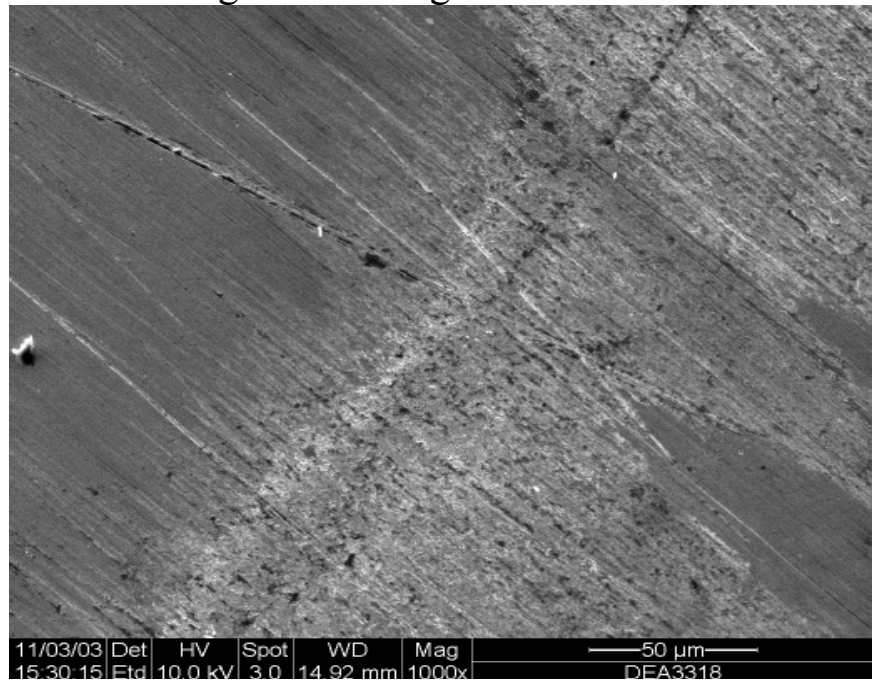

Figure 8b: Magnification-x1000

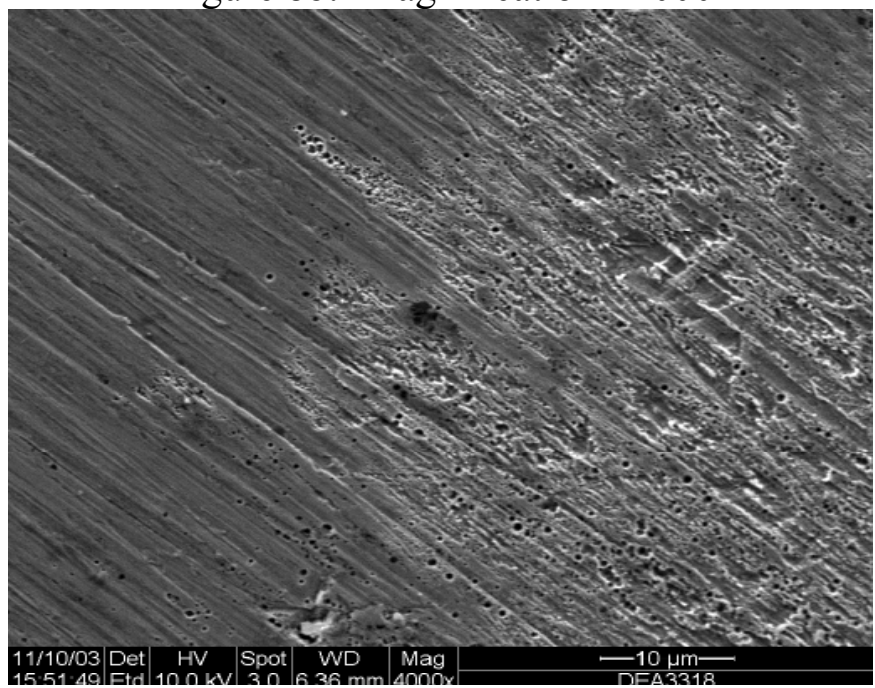

Figure 8c: Magnification- $\mathrm{x} 4000$
Figure 8: SEM images of Alloy 22 after cyclic polarization in $4 \mathrm{M} \mathrm{NaCl}+0.4 \mathrm{M}$ $\mathrm{Na}_{2} \mathrm{SO}_{4}$ at $45^{\circ} \mathrm{C}$, at a sweep rate of 0.1667 $\mathrm{mVs}^{-1}$. Maximum potential attained during polarization on this specimen was about $1.2 \mathrm{~V}$ (SSC). 


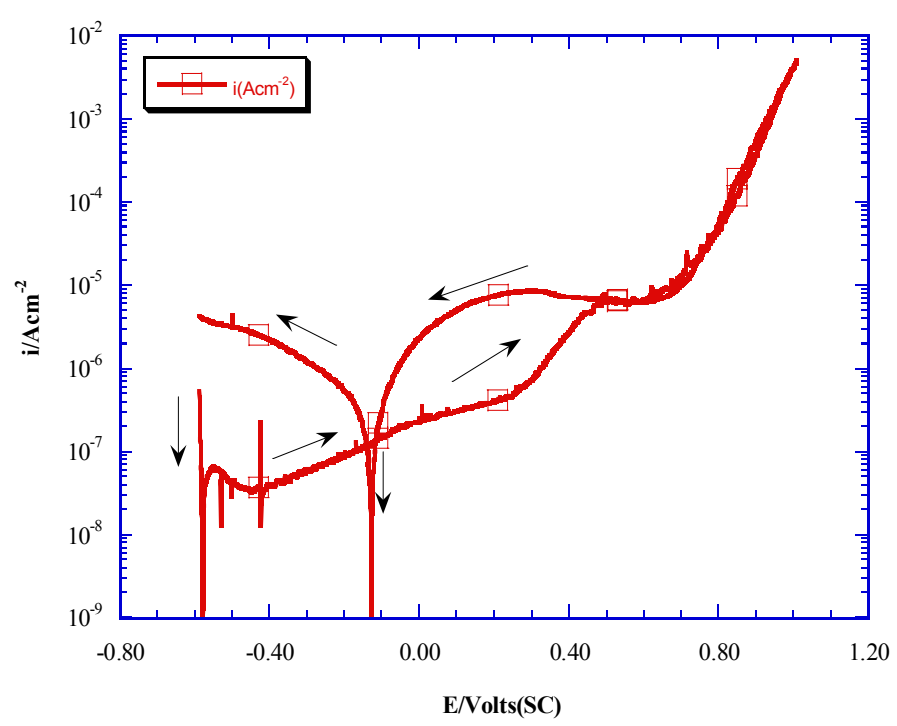

Figure 9a: $4 \mathrm{M} \mathrm{NaCl}$

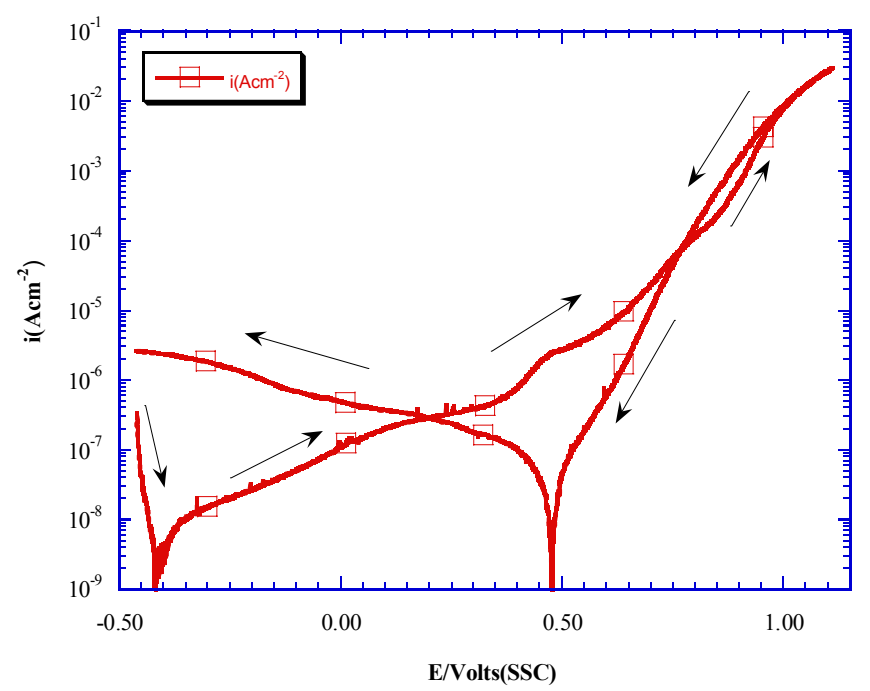

Figure 9c: $4 \mathrm{M} \mathrm{NaCl}+0.4 \mathrm{M} \mathrm{Na}_{2} \mathrm{SO}_{4}$

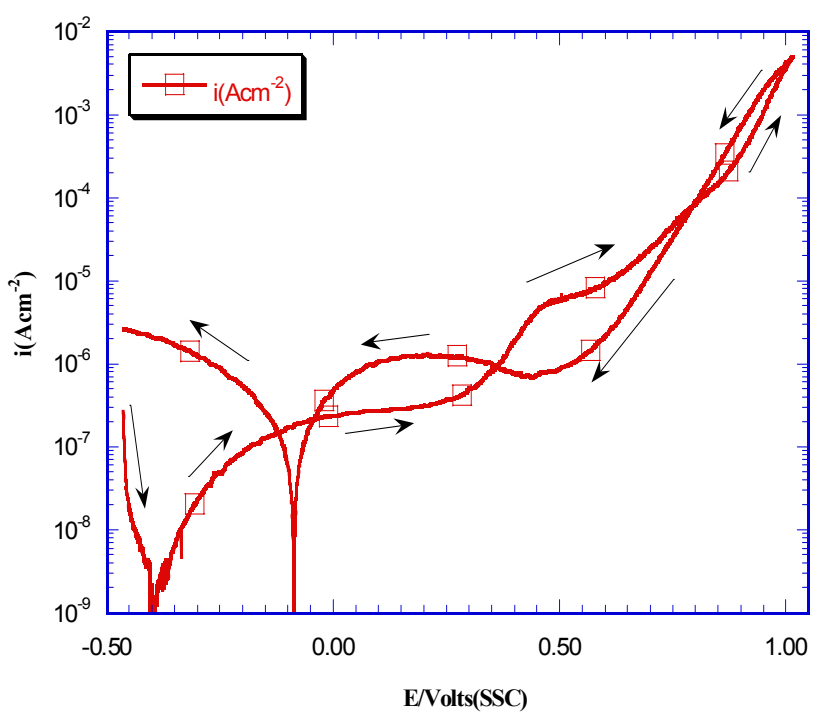

Figure 9b: $4 \mathrm{M} \mathrm{NaCl}+0.04 \mathrm{M} \mathrm{Na}_{2} \mathrm{SO}_{4}$

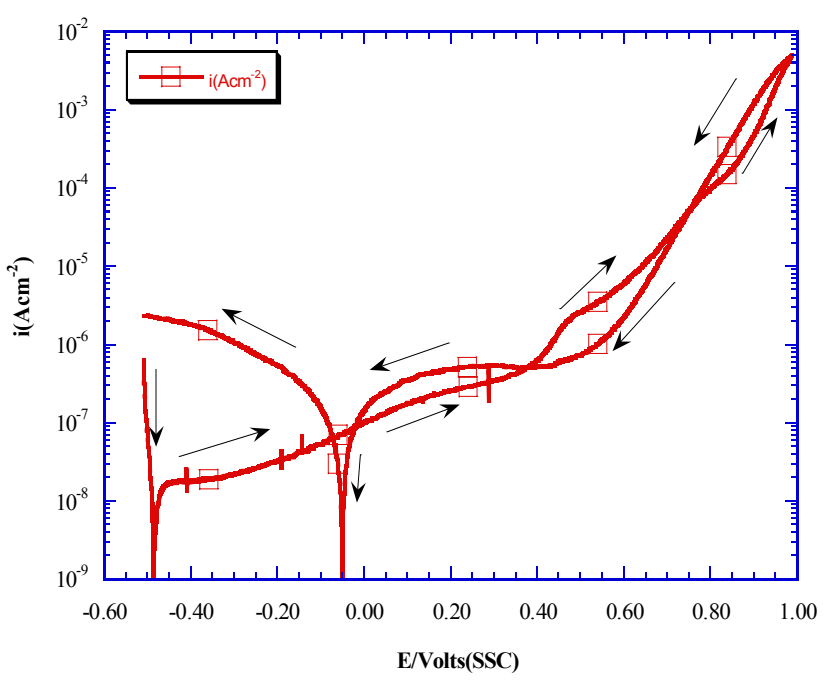

Figure 9d: $4 \mathrm{M} \mathrm{NaCl}+0.4 \mathrm{M} \mathrm{Na}_{2} \mathrm{SO}_{4}$

Figure 9: Polarization curves of Alloy 22 at $60{ }^{\circ} \mathrm{C}$. The polarization curves represent the shapes of the curves generated from all three electrolytes (namely: $4 \mathrm{M} \mathrm{NaCl}, 4 \mathrm{M} \mathrm{NaCl}+0.04 \mathrm{M}$ $\mathrm{Na}_{2} \mathrm{SO}_{4}+$ and $4 \mathrm{M} \mathrm{NaCl}+0.4 \mathrm{M} \mathrm{Na}_{2} \mathrm{SO}_{4}$ ) tested at $60^{\circ} \mathrm{C}$. Sweep rate was $0.1667 \mathrm{mVs}^{-1}$. 


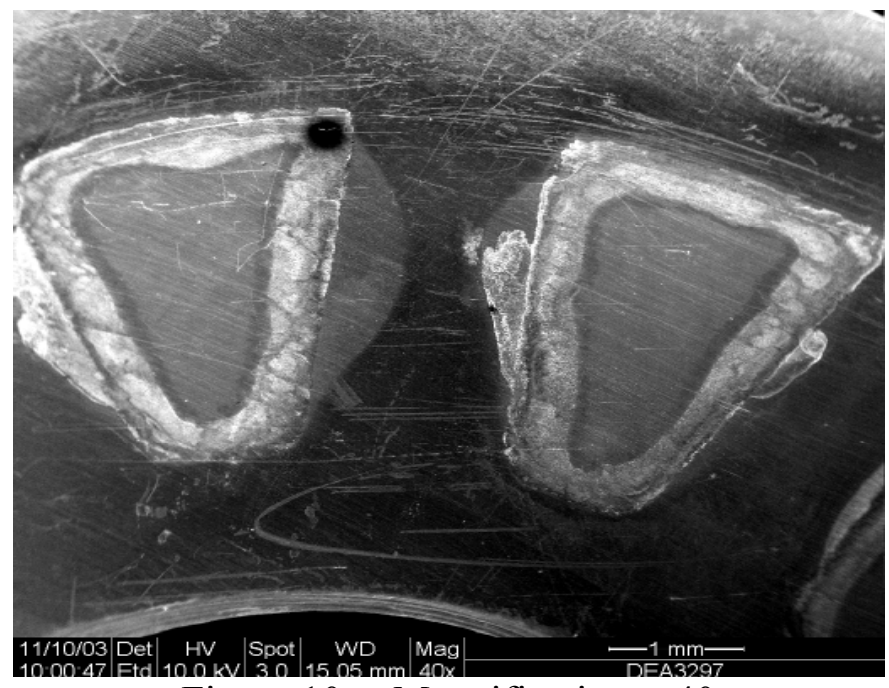

Figure 10a: Magnification- $\mathrm{x} 40$

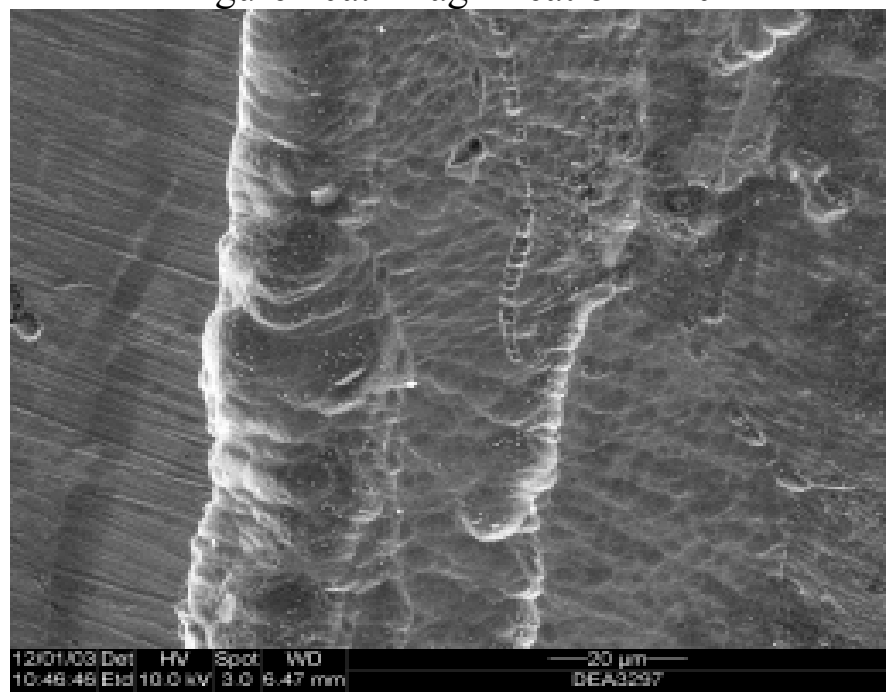

Figure 10b: Magnification- x2000

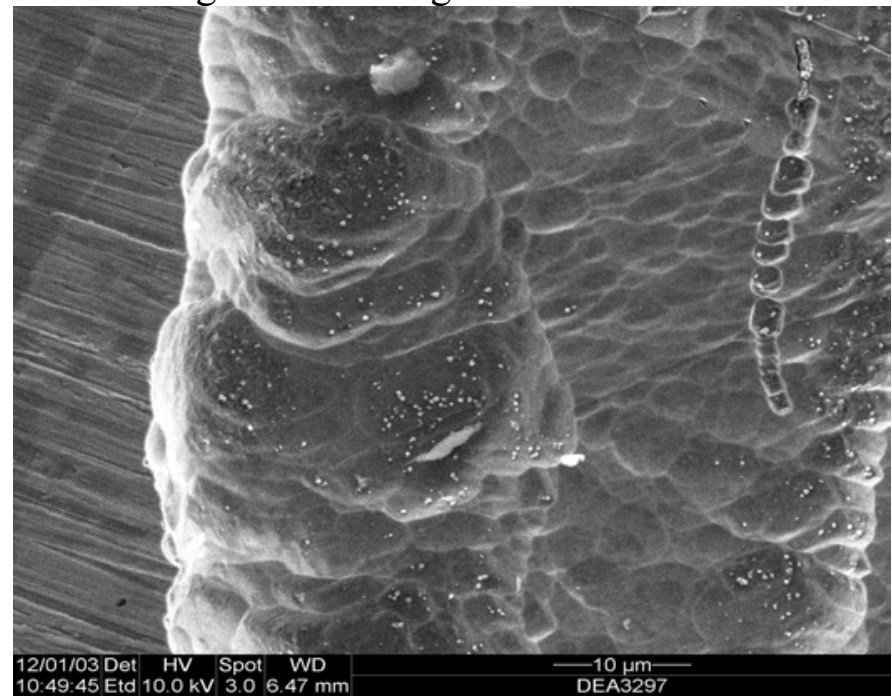

Figure 10c: Magnification- x4000
Figure 10: SEM images of Alloy 22 after cyclic polarization in $4 \mathrm{M} \mathrm{NaCl}$ at $60^{\circ} \mathrm{C}$, at a sweep rate of $0.1667 \mathrm{mVs}^{-1}$. Maximum potential attained during polarization on this specimen was about $1.0 \mathrm{~V}$ (SSC). 


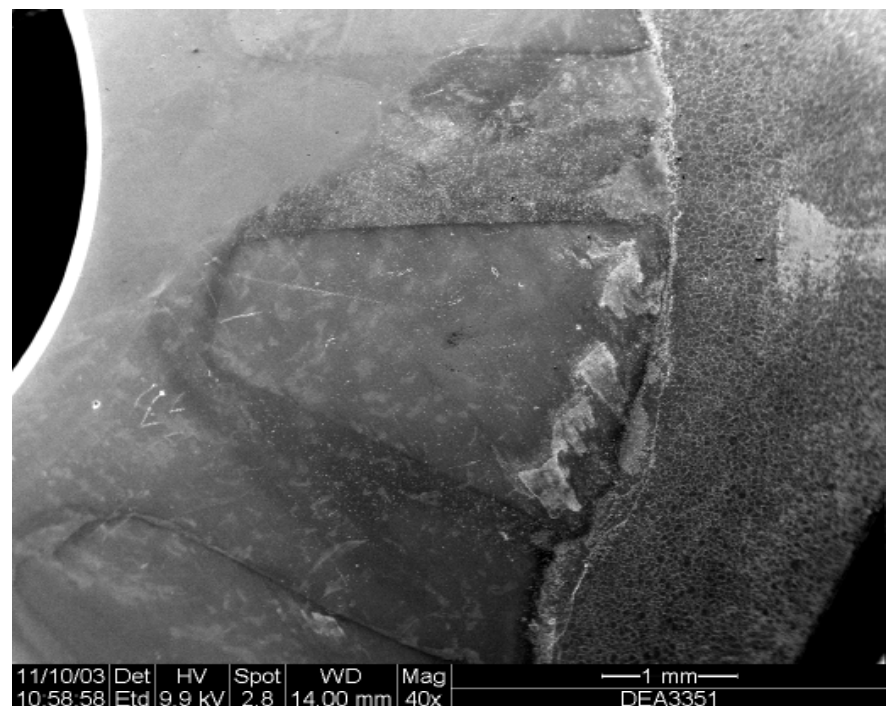

Figure 11a: Magnification- $\mathrm{x} 40$

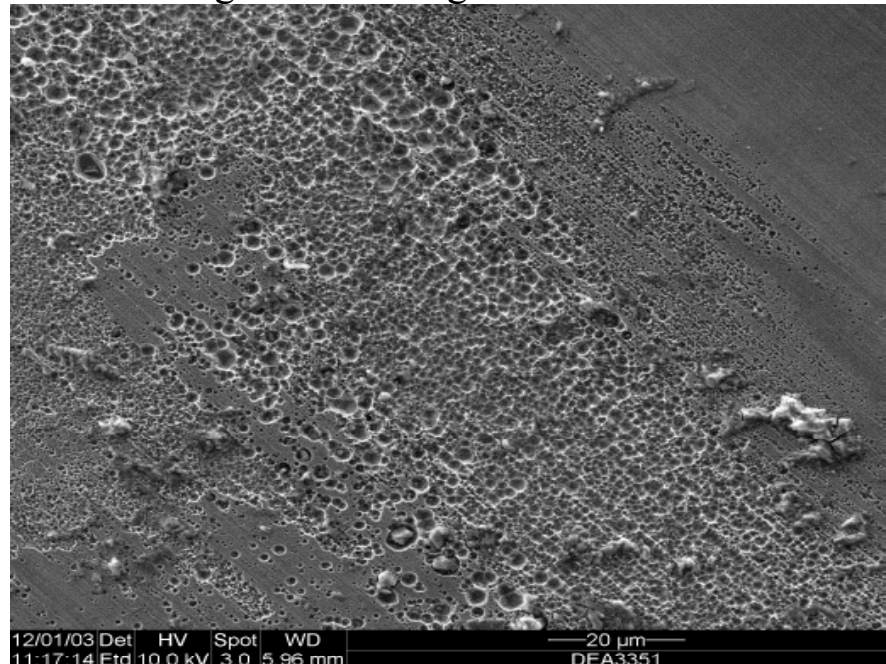

Figure 11b: Magnification- x2000

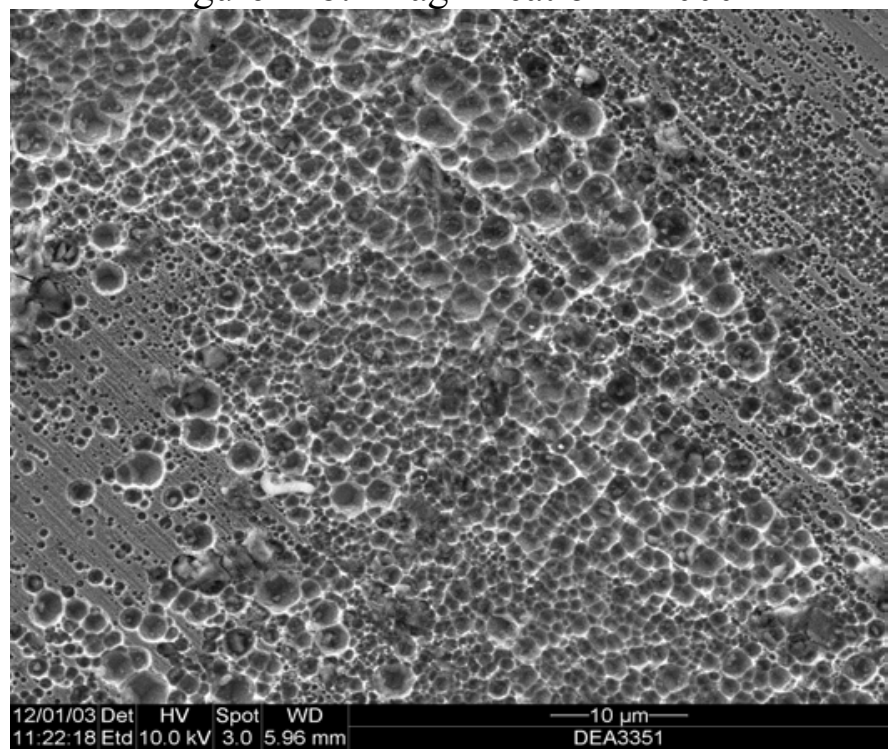

Figure 11c: Magnification- x4000
Figure 11: SEM images of Alloy 22 after cyclic polarization in $4 \mathrm{M} \mathrm{NaCl}+0.04 \mathrm{M}$ $\mathrm{Na}_{2} \mathrm{SO}_{4}$ at $60^{\circ} \mathrm{C}$, at a sweep rate of 0.1667 $\mathrm{mVs}^{-1}$. Maximum potential attained during polarization on this specimen was about $1.2 \mathrm{~V}$ (SSC). 


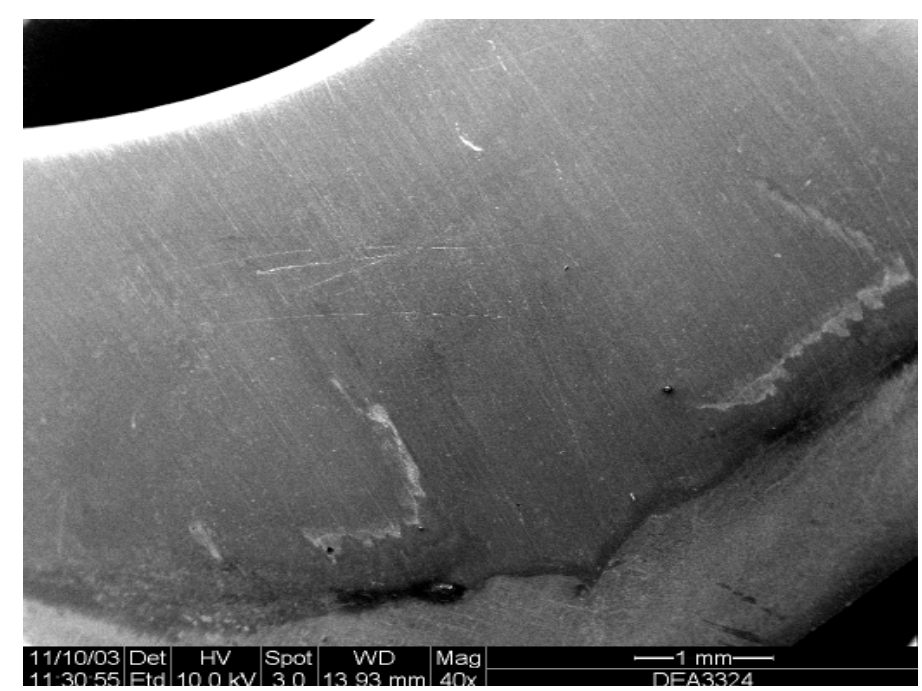

Figure 12a: Magnification- $\mathrm{x} 40$

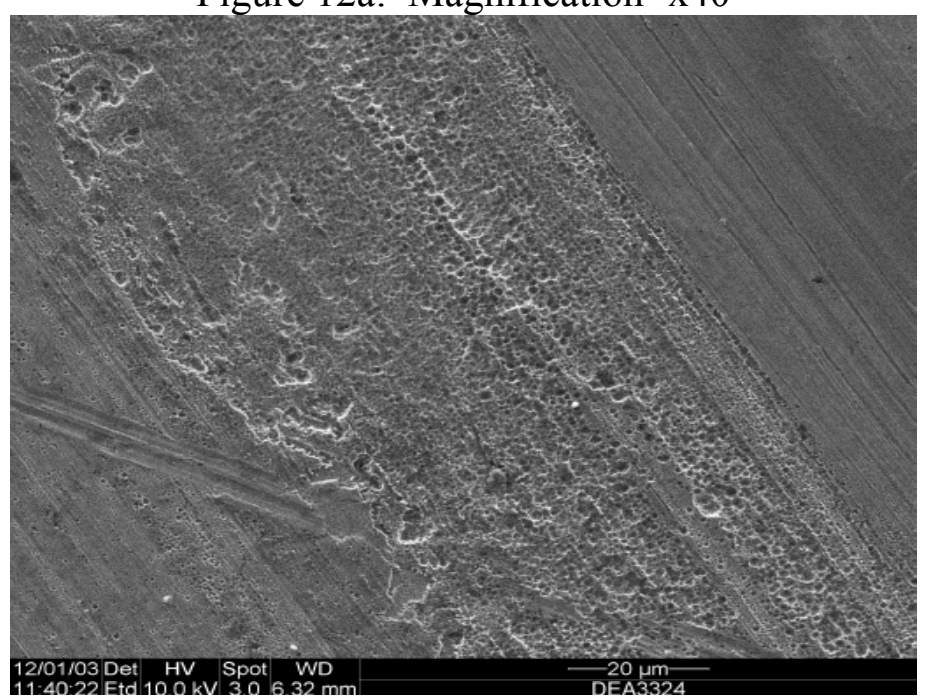

Figure 12b: Magnification- x2000

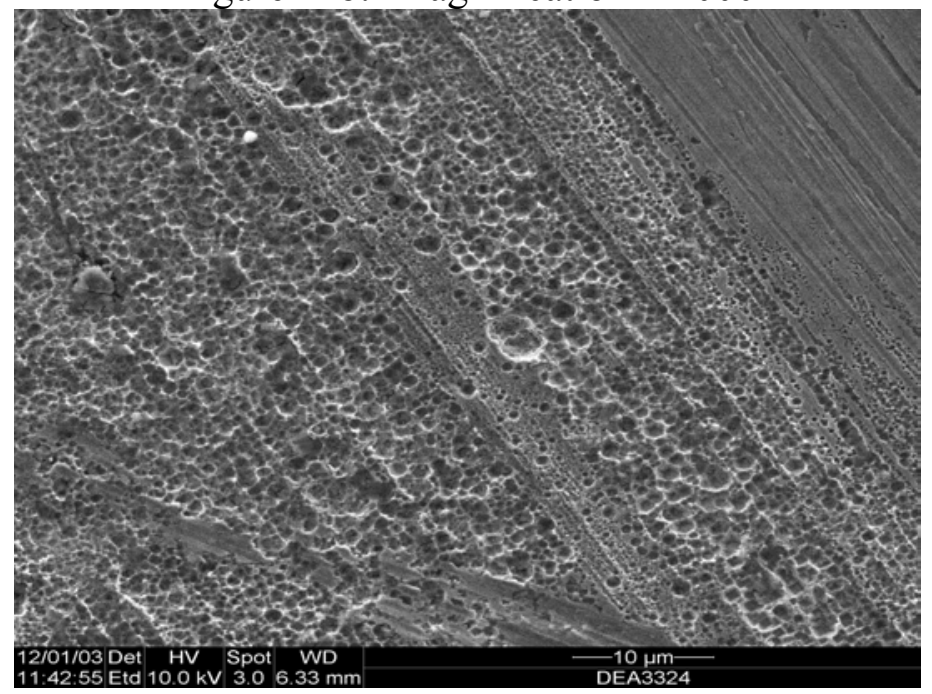

Figure 12c: Magnification- $\mathrm{x} 4000$
Figure 12: SEM images of Alloy 22 after cyclic polarization in $4 \mathrm{M} \mathrm{NaCl}+$ $0.4 \mathrm{M} \mathrm{Na}_{2} \mathrm{SO}_{4}$ at $60^{\circ} \mathrm{C}$, at a sweep rate of $0.1667 \mathrm{mVs}^{-1}$. Maximum potential attained during polarization on this specimen was about 1.0 V (SSC). 


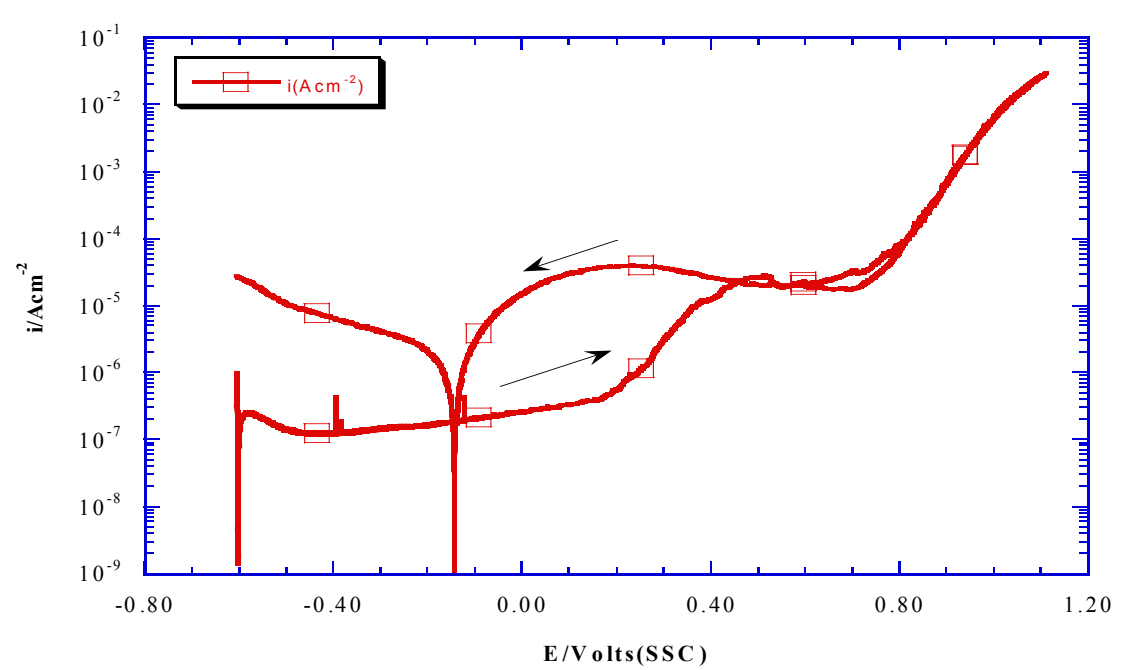

Figure 13a: $4 \mathrm{M} \mathrm{NaCl}$ at $75^{\circ} \mathrm{C}$

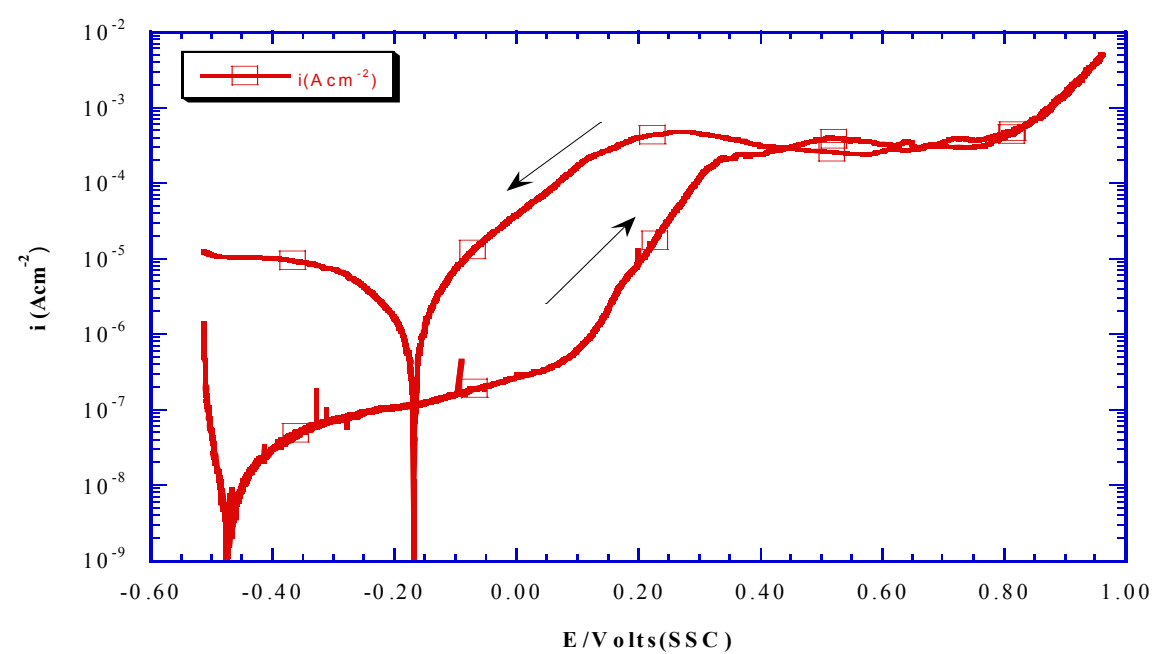

Figure 13:

Polarization curves of Alloy 22 at 75, 90 and $105^{\circ} \mathrm{C}$ in $4 \mathrm{M}$ $\mathrm{NaCl}$. Sweep rate was $0.1667 \mathrm{mVs}^{-1}$

Figure 13b: $4 \mathrm{M} \mathrm{NaCl}$ at $90^{\circ} \mathrm{C}$

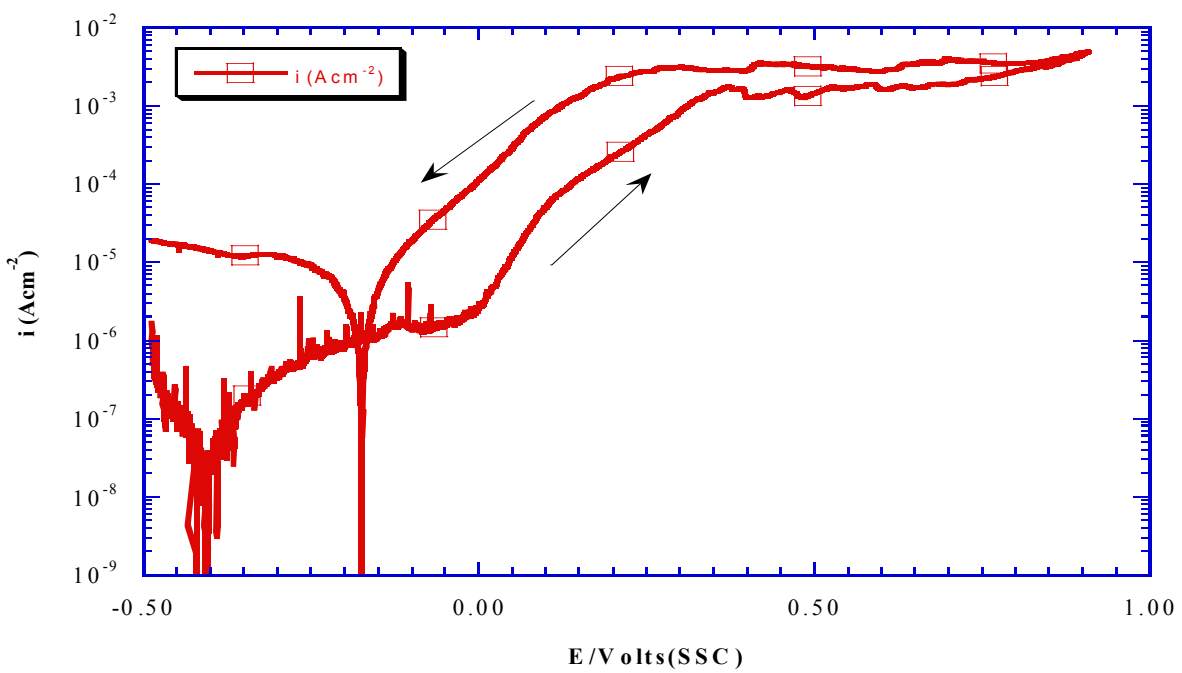

Figure $13 \mathrm{c}: 4 \mathrm{M} \mathrm{NaCl}$ at $105^{\circ} \mathrm{C}$ 


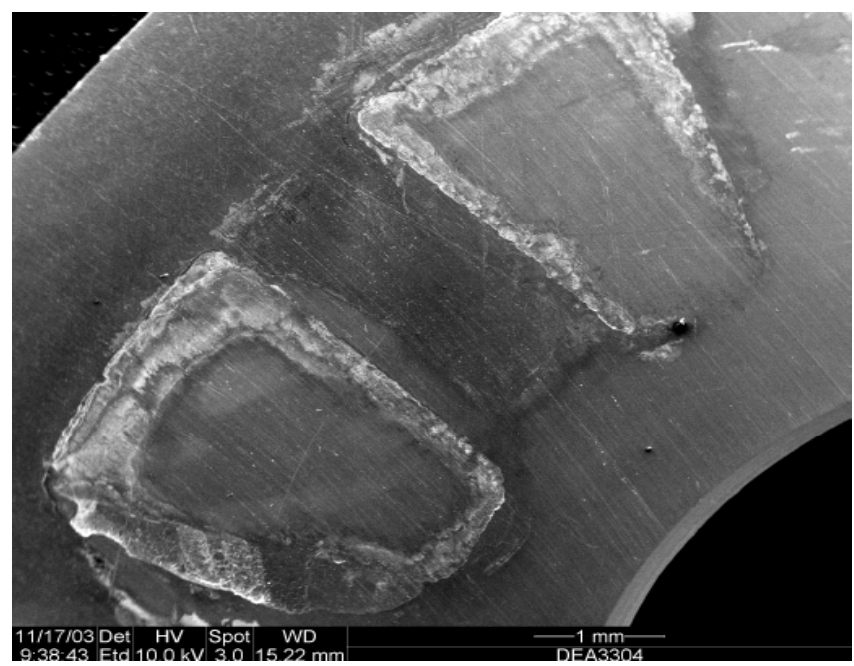

Figure 14a: Magnification- x40

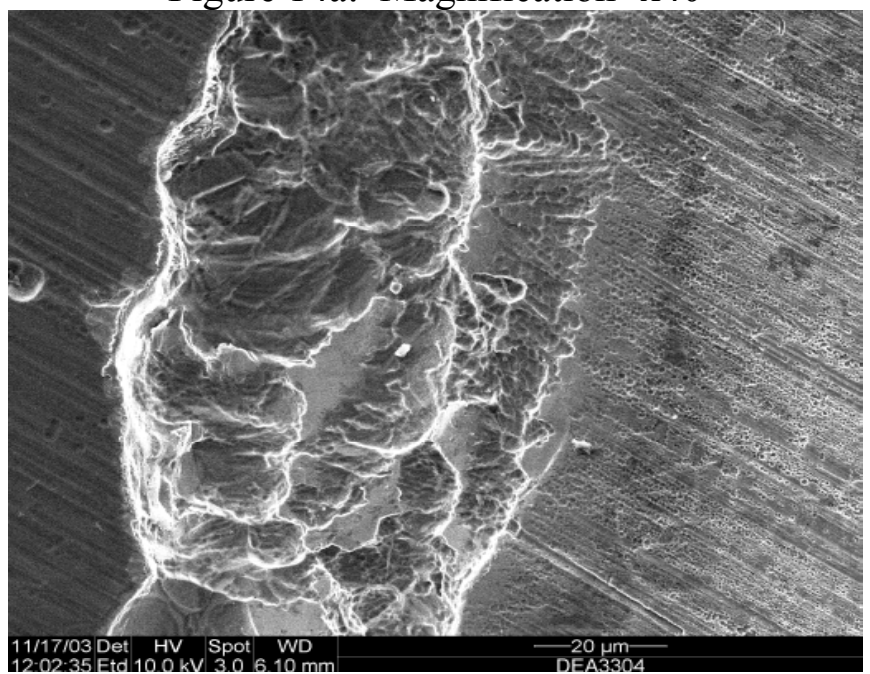

Figure 14b: Magnification- x2000

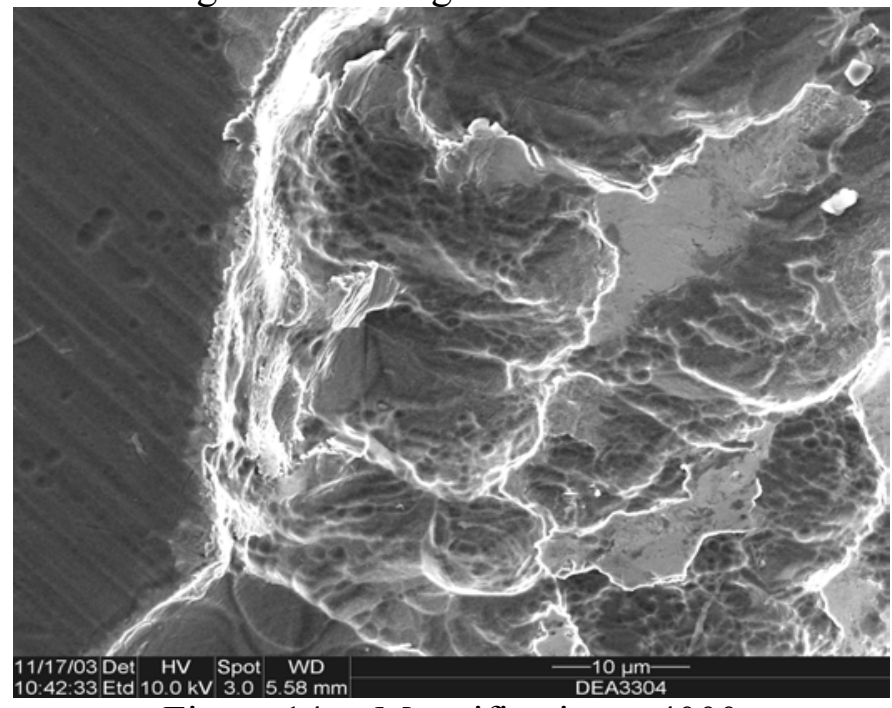

Figure 14c: Magnification- x4000

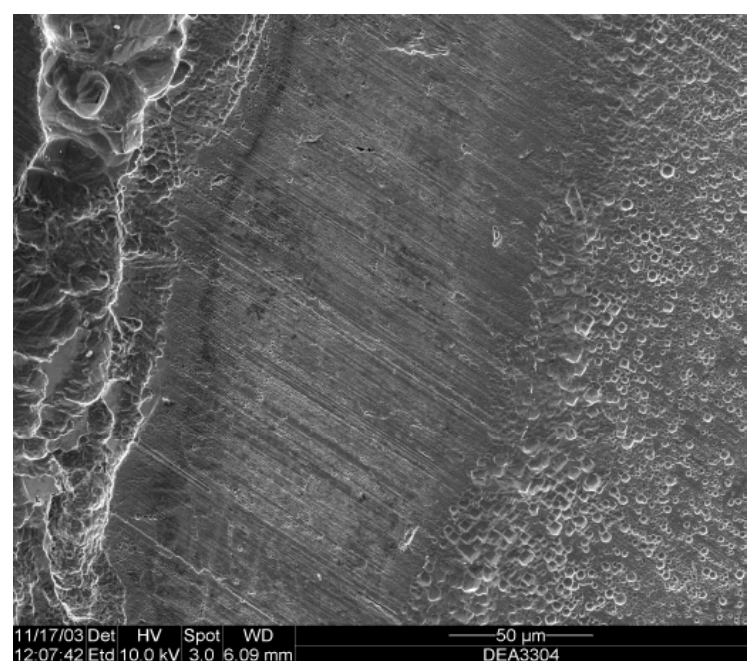

Figure 14d: Magnification -x1000

Figure 14: SEM images of Alloy 22 after cyclic polarization in $4 \mathrm{M} \mathrm{NaCl}$ at $75^{\circ} \mathrm{C}$, at a sweep rate of $0.1667 \mathrm{mVs}^{-1}$. Maximum potential attained during polarization on this specimen was about 1.1 V (SSC). 


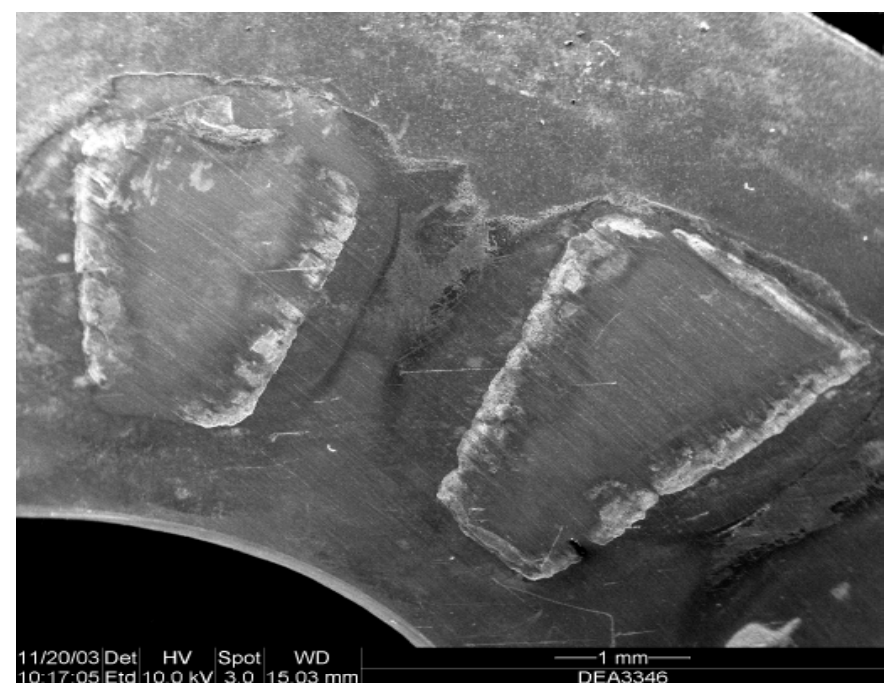

Figure 15a: Magnification- $x 40$

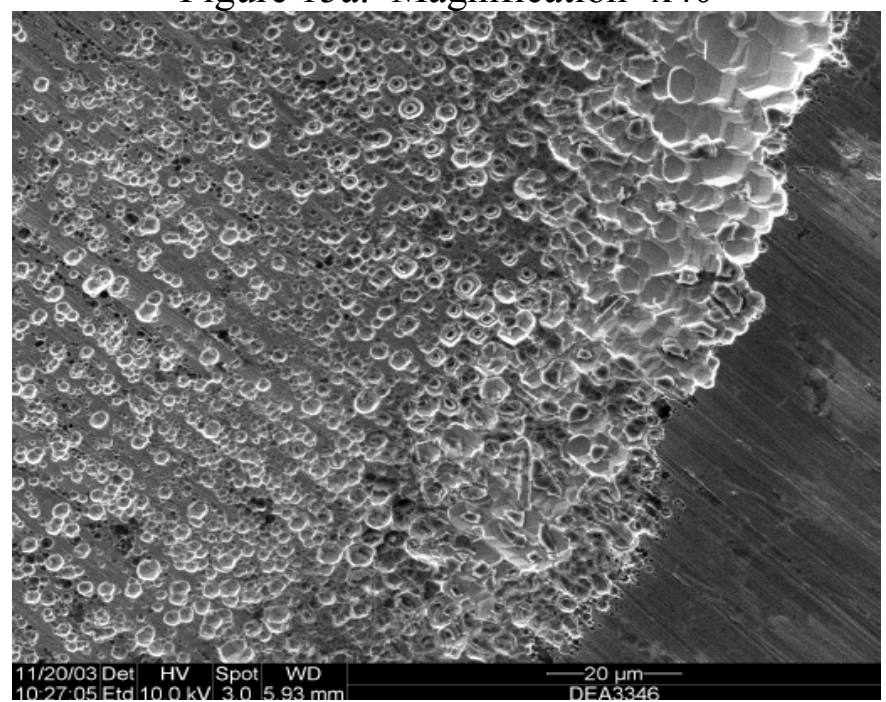

Figure 15b: Magnification- x2000

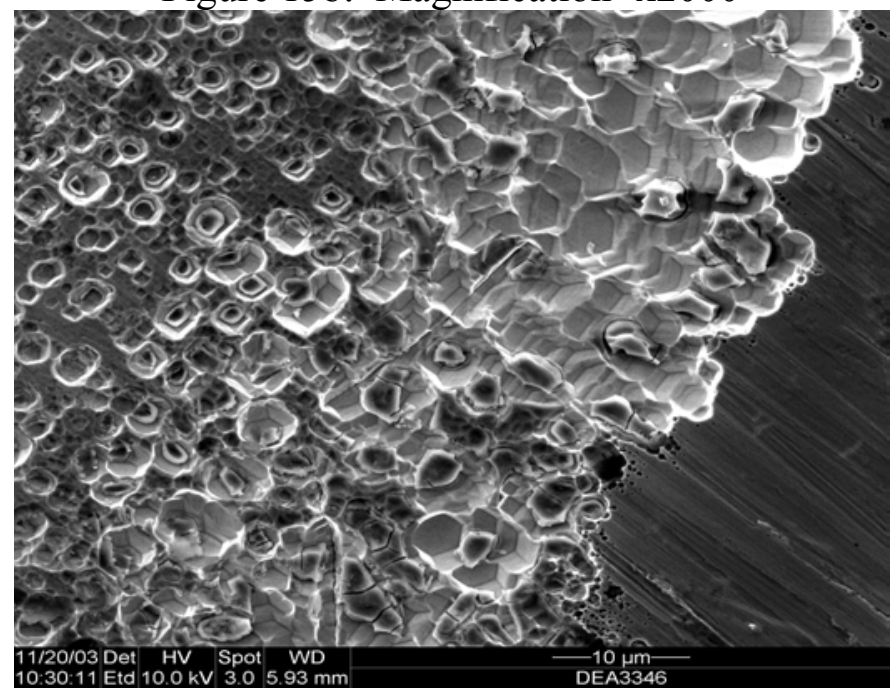

Figure 15c: Magnification- $\mathrm{x} 4000$
Figure 15: SEM images of Alloy 22 after cyclic polarization in $4 \mathrm{M} \mathrm{NaCl}+0.04 \mathrm{M}$ $\mathrm{Na}_{2} \mathrm{SO}_{4}$ at $75^{\circ} \mathrm{C}$, at a sweep rate of 0.1667 $\mathrm{mVs}^{-1}$. Maximum potential attained during polarization on this specimen was about $1.1 \mathrm{~V}$ (SSC). Figures 15a and 15b show under-teeth attack (crevicing). 


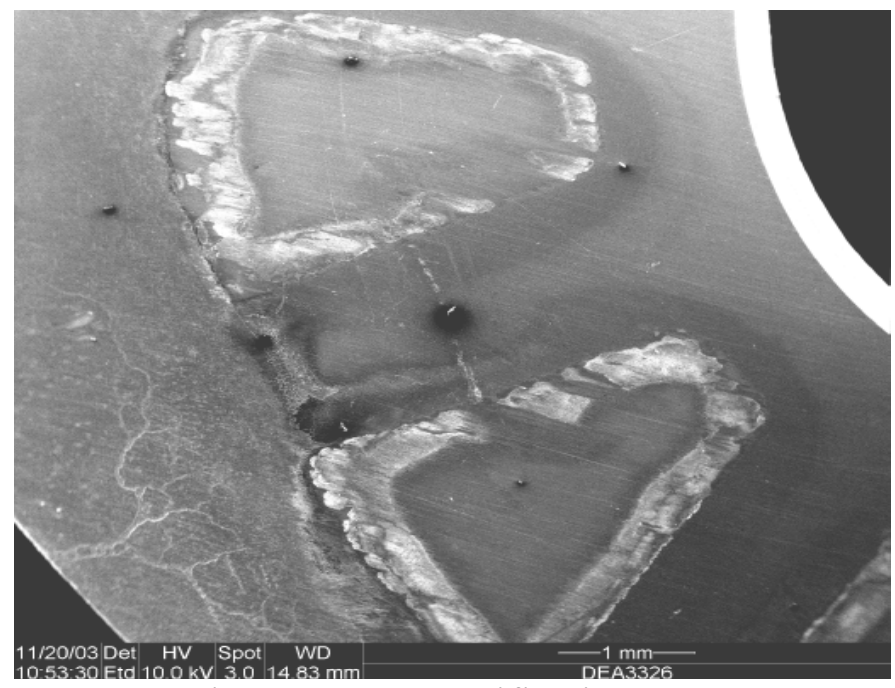

Figure 16a: Magnification- x40

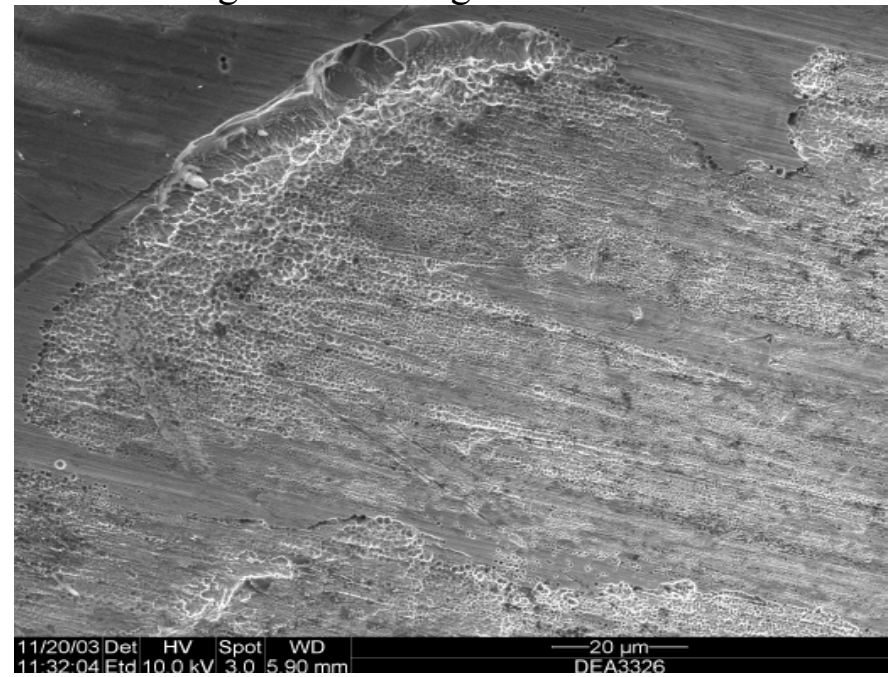

Figure 16b: Magnification- x2000

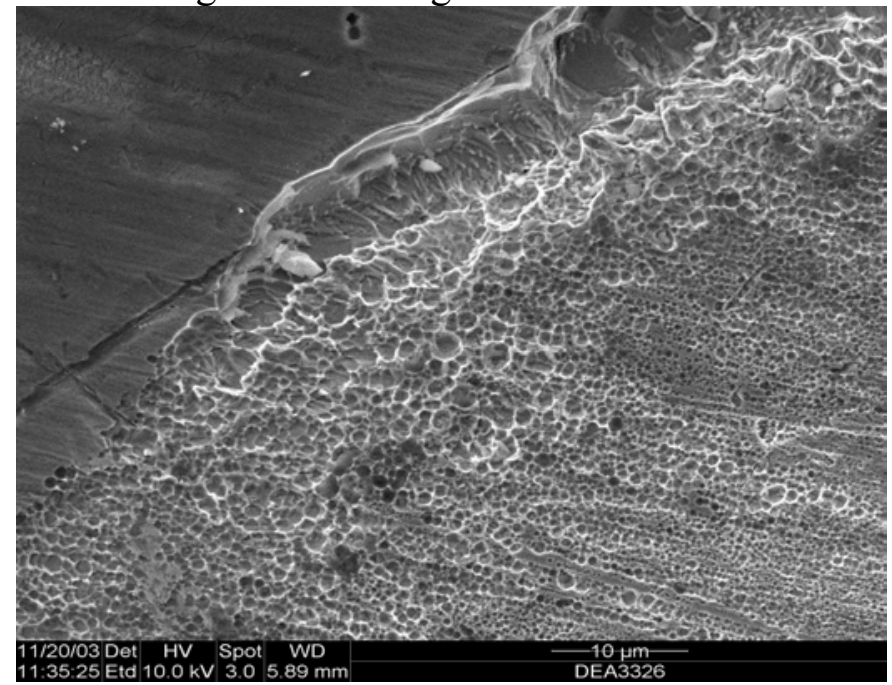

FIGURE 16c: Magnification- x4000
Figure 16: SEM images of Alloy 22 after cyclic polarization in $4 \mathrm{M} \mathrm{NaCl}+$ $0.4 \mathrm{M} \mathrm{Na}_{2} \mathrm{SO}_{4}$ at $75^{\circ} \mathrm{C}$, at a sweep rate of $0.1667 \mathrm{mVs}^{-1}$. Maximum potential attained during polarization on this specimen was about $1.0 \mathrm{~V}$ (SSC). 


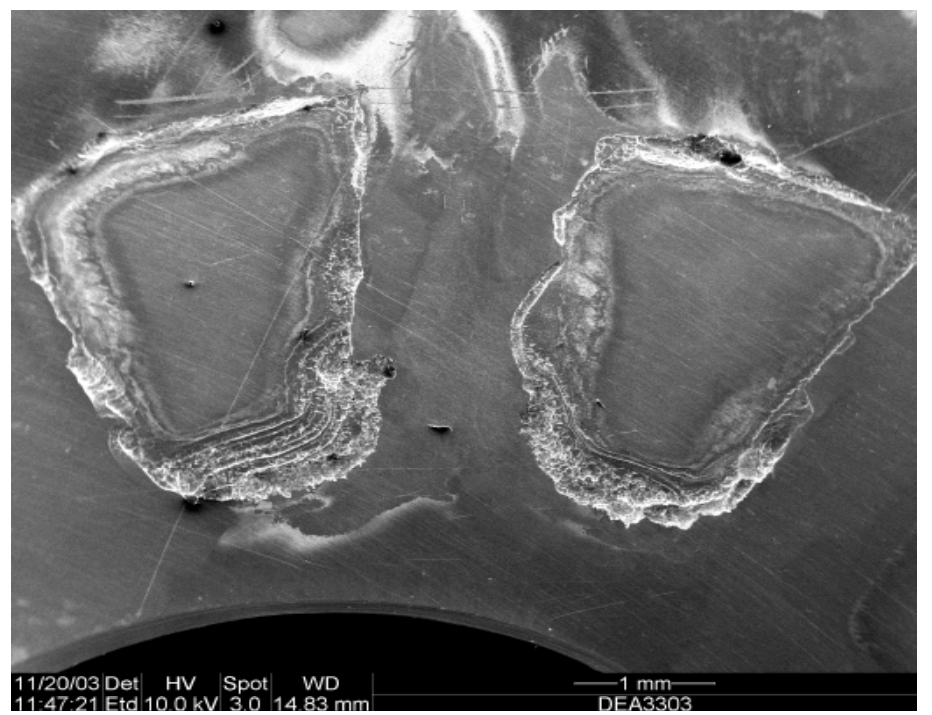

Figure 17a: Magnification- x40

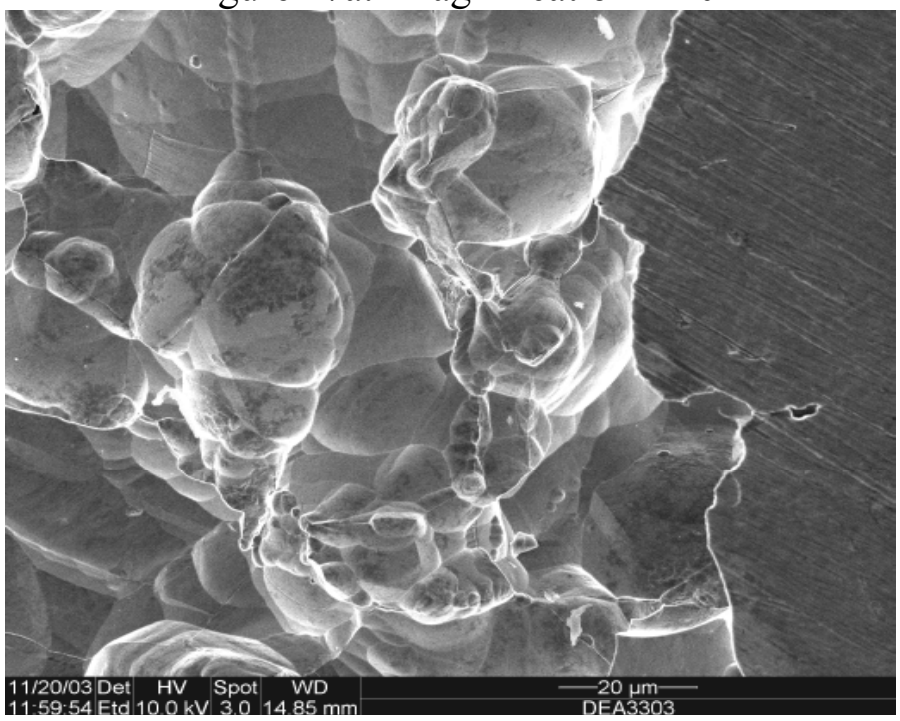

Figure 17b: Magnification- x2000

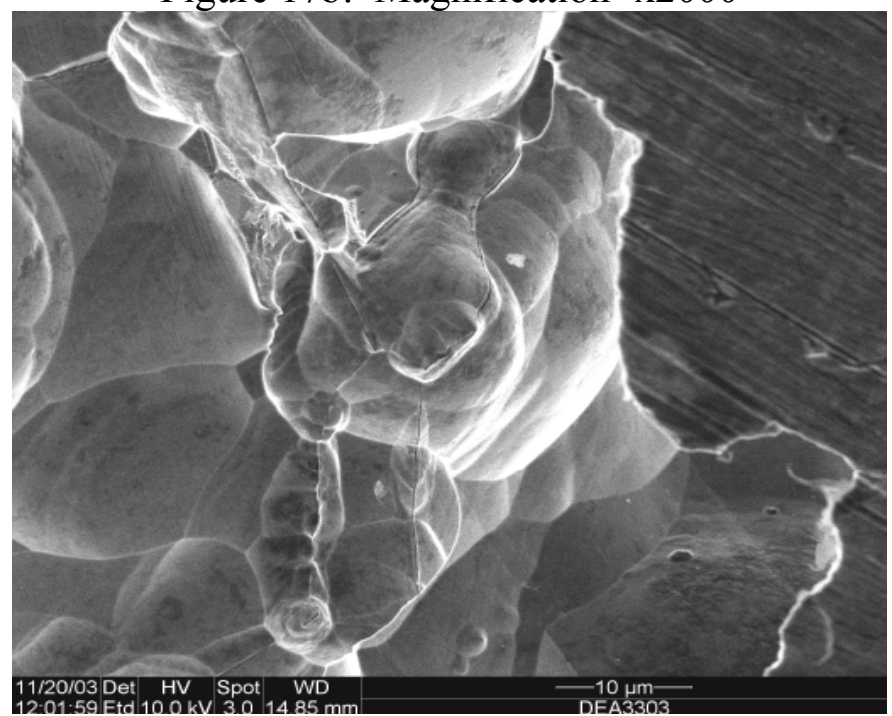

Figure 17c: Magnification- x4000

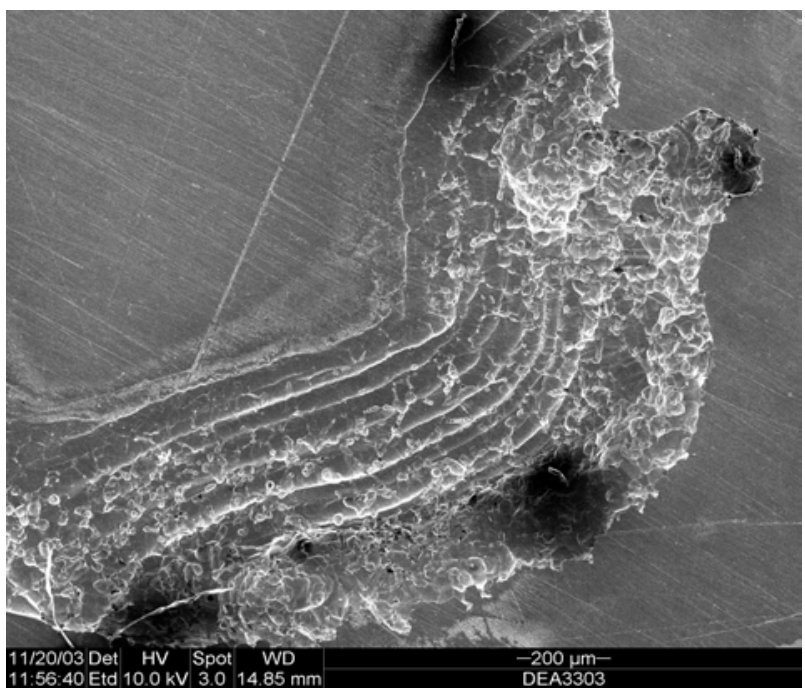

Figure 17d: Magnification- x150

Figure 17: SEM images of Alloy 22 after cyclic polarization in $4 \mathrm{M} \mathrm{NaCl}$ at $90^{\circ} \mathrm{C}$, at a sweep rate of $0.1667 \mathrm{mVs}^{-1}$. Maximum potential attained during polarization on this specimen was about 1.0 V (SSC). 


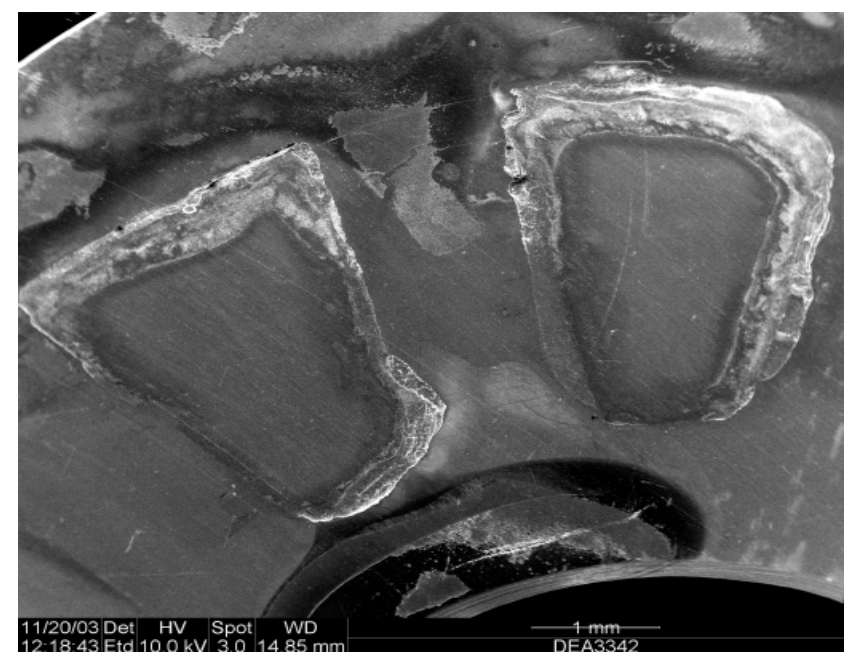

Figure 18a: Magnification- x40

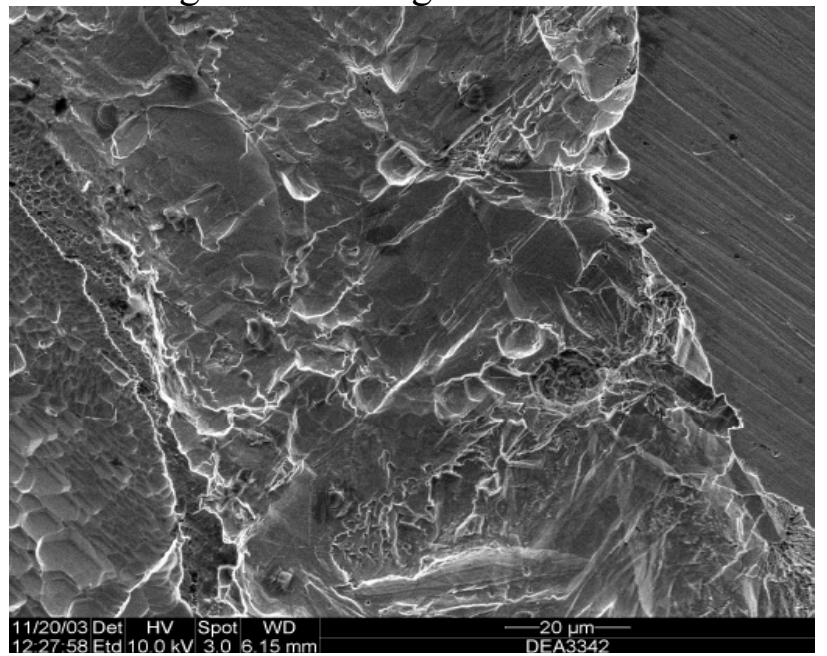

Figure 18b: Magnification- x2000

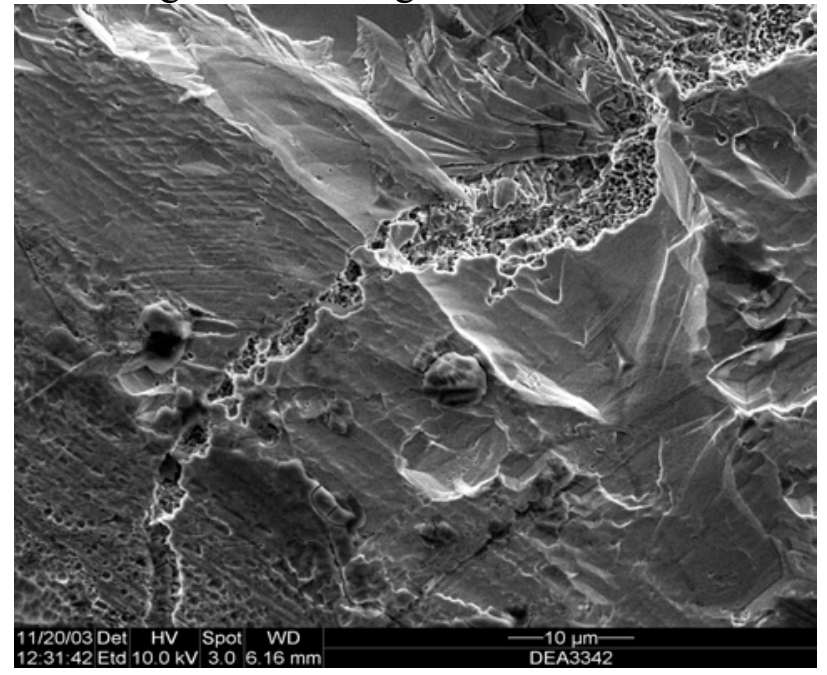

Figure 18c: Magnification- x4000
Figure 18: SEM images of Alloy 22 after cyclic polarization in $4 \mathrm{M} \mathrm{NaCl}+0.04 \mathrm{M}$ $\mathrm{Na}_{2} \mathrm{SO}_{4}$ at $90^{\circ} \mathrm{C}$, at a sweep rate of 0.1667 $\mathrm{mVs}^{-1}$. Maximum potential attained during polarization on this specimen was about $1.1 \mathrm{~V}$ (SSC). 


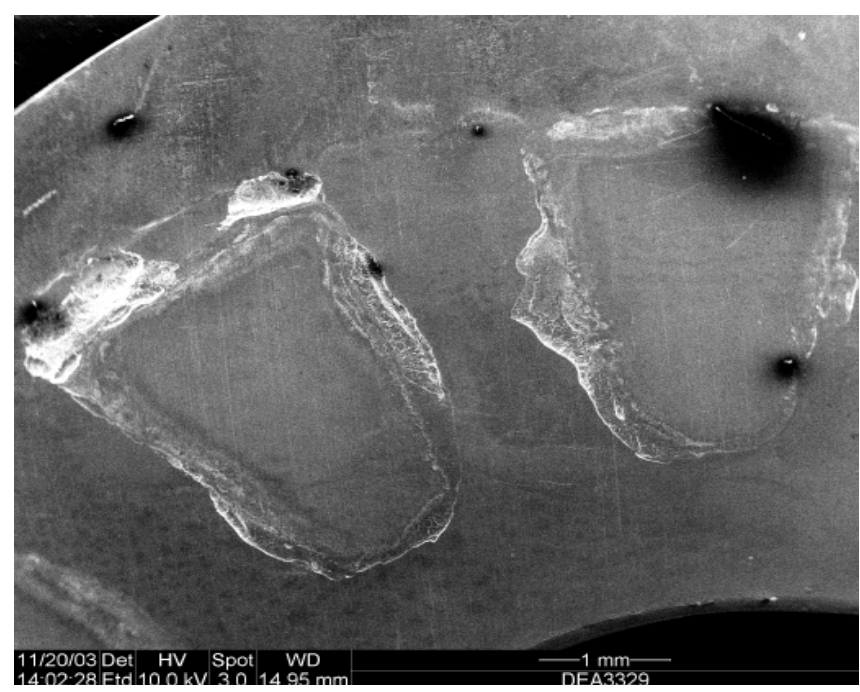

Figure 19a: Magnification- $\mathrm{x} 40$

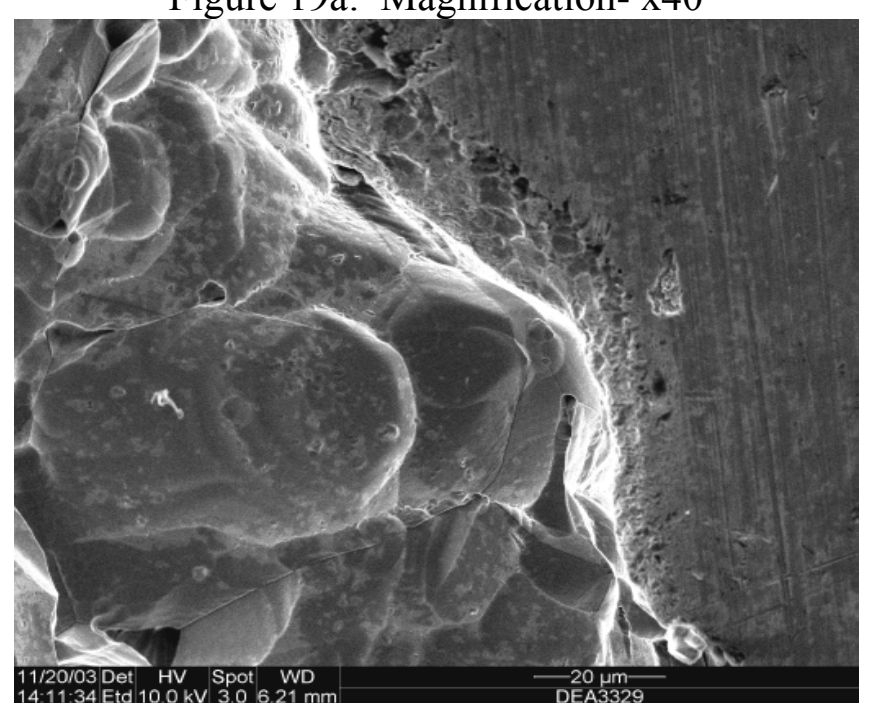

Figure 19b: Magnification- x2000

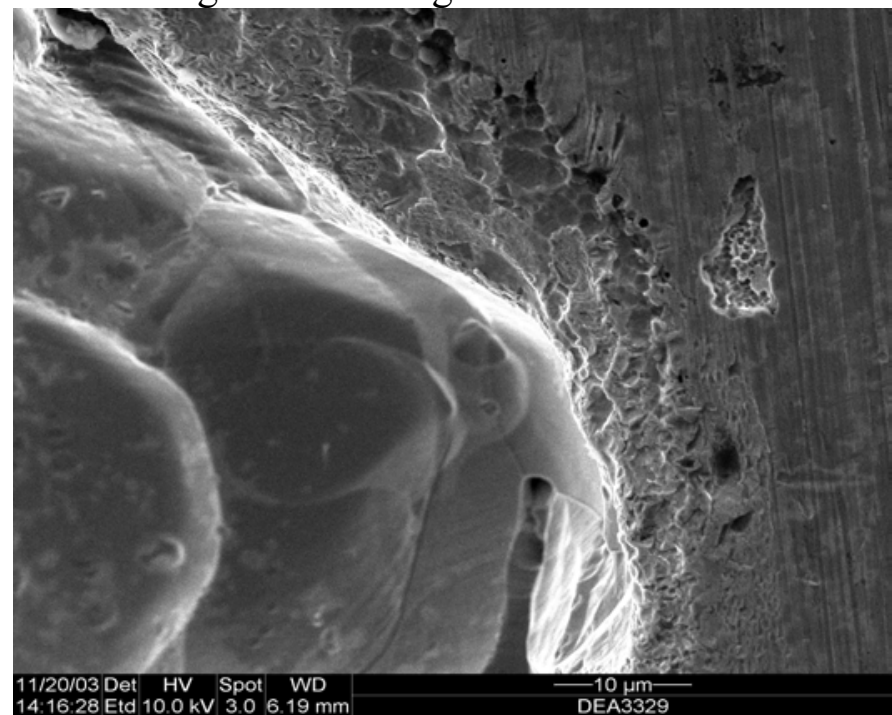

Figure 19c: Magnification- $\mathrm{x} 4000$
Figure 19: SEM images of Alloy 22 after cyclic polarization in $4 \mathrm{M} \mathrm{NaCl}+0.4 \mathrm{M}$ $\mathrm{Na}_{2} \mathrm{SO}_{4}$ at $90^{\circ} \mathrm{C}$, at a sweep rate of 0.1667 $\mathrm{mVs}^{-1}$. Maximum potential attained during polarization on this specimen was about $1.0 \mathrm{~V}$ (SSC). 


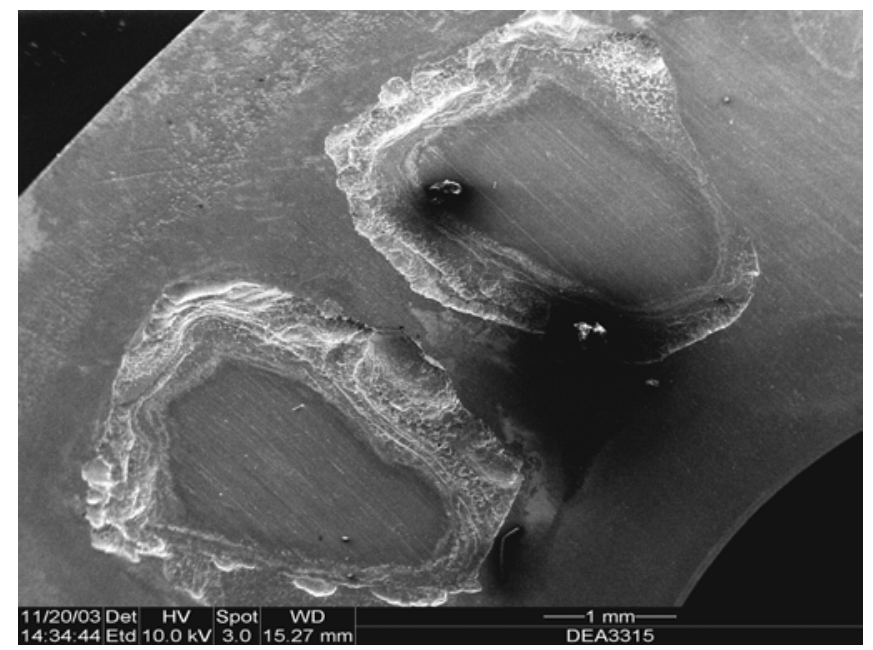

Figure 20a: $4 \mathrm{M} \mathrm{NaCl}$ Magnification: x40

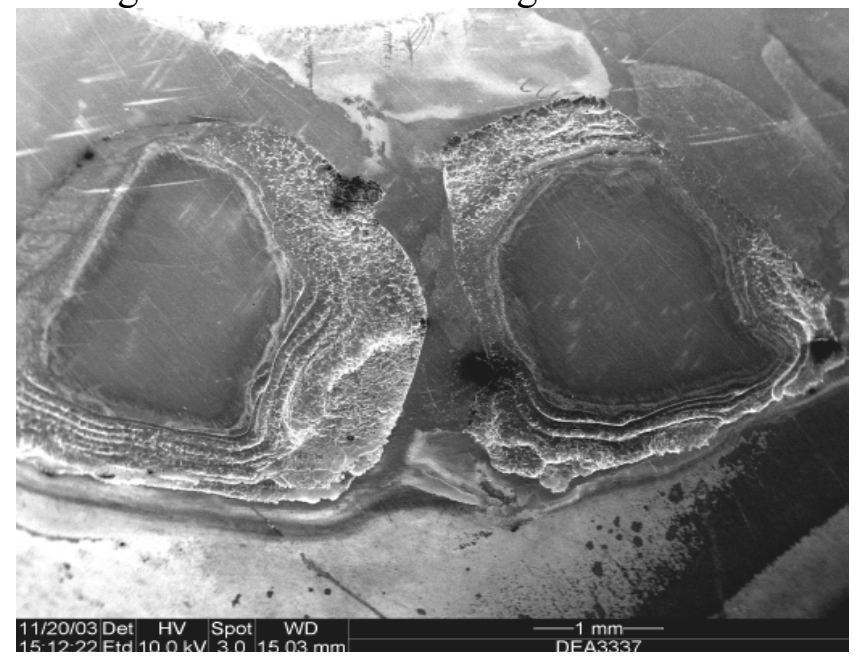

Figure 20b: $4 \mathrm{M} \mathrm{NaCl}+0.04 \mathrm{M} \mathrm{Na}_{2} \mathrm{SO}_{4}$

Magnification: $\mathrm{x} 40$

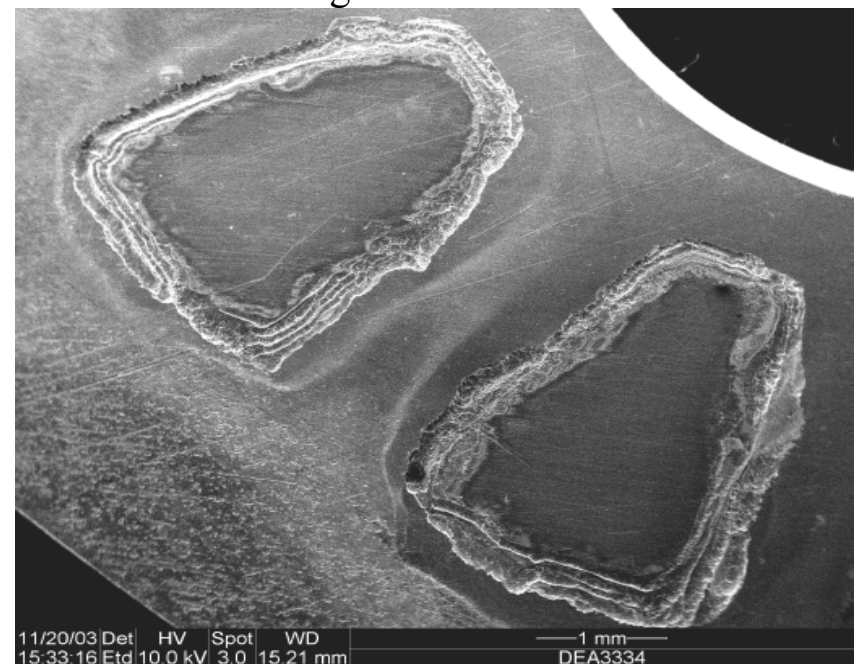

Figure 20c: $4 \mathrm{M} \mathrm{NaCl}+0.4 \mathrm{M} \mathrm{Na}_{2} \mathrm{SO}_{4}$

Magnification: $\mathrm{x} 40$
Figure 20: SEM images of Alloy 22 after cyclic polarization in $4 \mathrm{M} \mathrm{NaCl}$ (20a), $4 \mathrm{M} \mathrm{NaCl}+0.04 \mathrm{M} \mathrm{Na}_{2} \mathrm{SO}_{4}(20 \mathrm{~b})$ and $4 \mathrm{M} \mathrm{NaCl}+0.4 \mathrm{M} \mathrm{Na}_{2} \mathrm{SO}_{4}$ (20c) at $105^{\circ} \mathrm{C}$. Sweep rate was $0.1667 \mathrm{mVs}^{-1}$. Maximum potential attained during polarization on these specimens were about 1.1, 0.9 and 1.0V (SSC) for Figures $20 \mathrm{a}, 20 \mathrm{~b}$ and $20 \mathrm{c}$ respectively. 


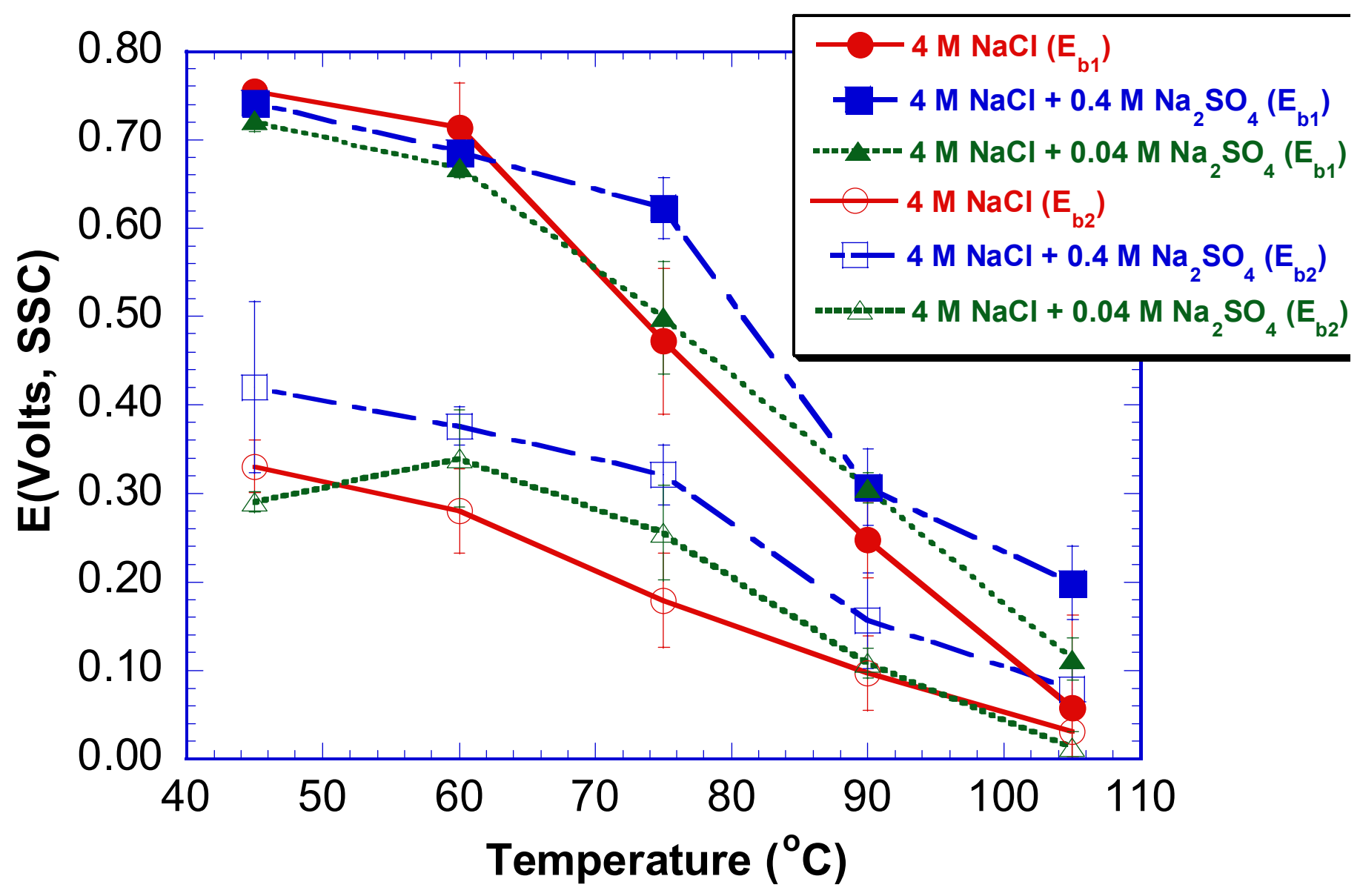

Figure 21. $\mathrm{E}_{\mathrm{b}}$ of MCA wrought specimens as a function of temperature in $4 \mathrm{M} \mathrm{NaCl}, 4 \mathrm{M} \mathrm{NaCl}$ $+0.04 \mathrm{M} \mathrm{Na}_{2} \mathrm{SO}_{4}+$ and $4 \mathrm{M} \mathrm{NaCl}+0.4 \mathrm{M} \mathrm{Na}_{2} \mathrm{SO}_{4}$. " $\mathrm{E}_{\mathrm{b} 1}$ " denotes $\mathrm{E}_{\mathrm{b}}$ values acquired using Method 1 while "E $\mathrm{E}_{\mathrm{b} 2}$ " denotes values acquired using Method 2. 


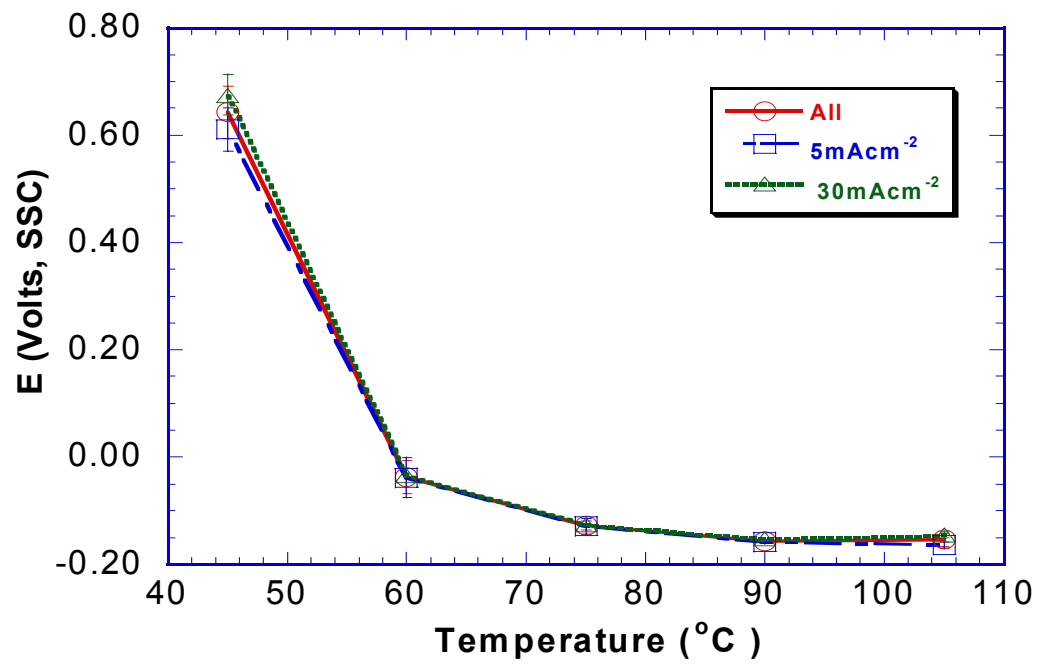

Figure 22a: $4 \mathrm{M} \mathrm{NaCl}$

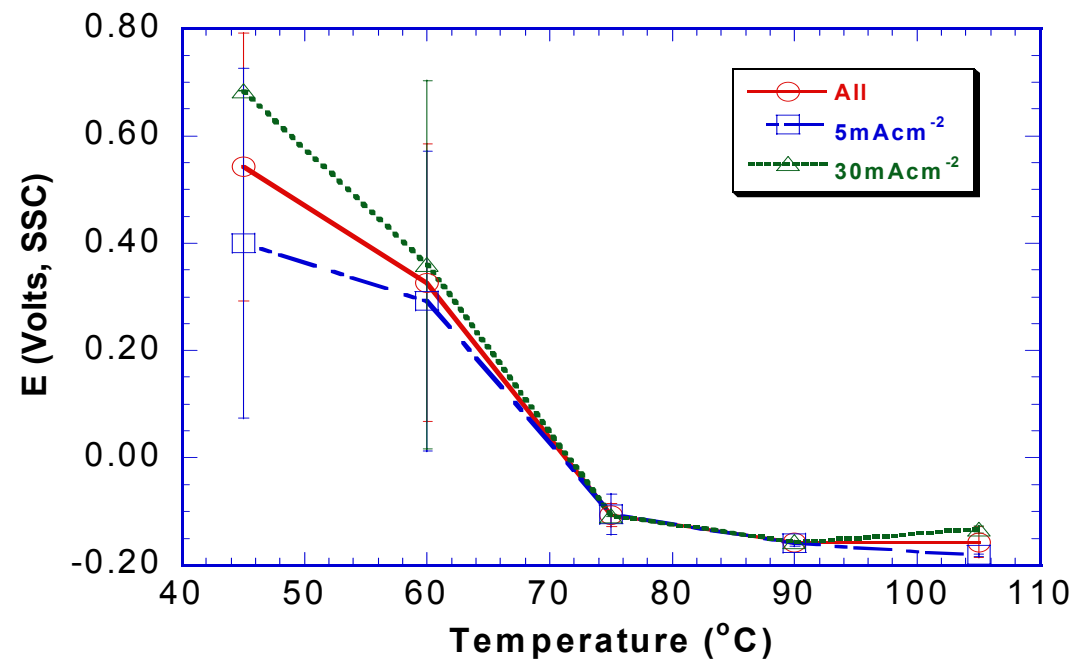

Figure 22b: $4 \mathrm{M} \mathrm{NaCl}+0.04 \mathrm{M} \mathrm{Na}_{2} \mathrm{SO}_{4}$

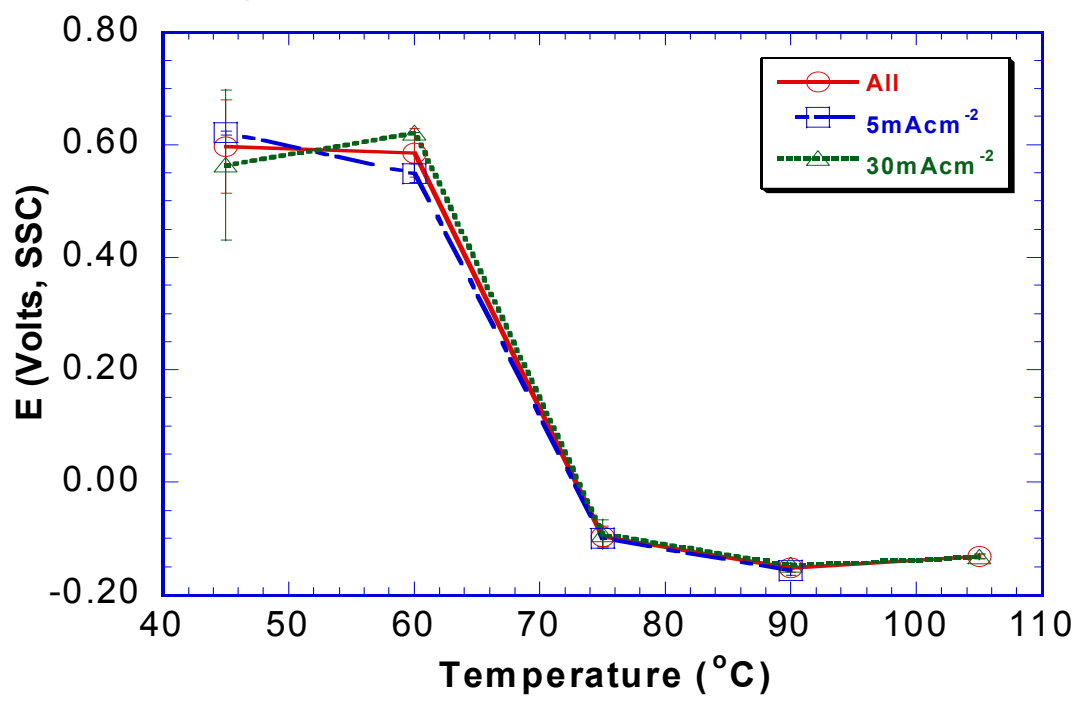

Figure 22c: $4 \mathrm{M} \mathrm{NaCl}+0.4 \mathrm{M} \mathrm{Na}_{2} \mathrm{SO}_{4}$
Figure 22. $\mathrm{E}_{\mathrm{rp}}$ of MCA in 4 $\mathrm{M} \mathrm{NaCl}$ solution measured by Method $1\left(\mathrm{E}_{\mathrm{r} 1}\right)$ comparing values turn-around current densities of 5 and $30 \mathrm{mAcm}^{-2}$ as a function of temperature. Graphs also show data the $\mathrm{E}_{\mathrm{rp}}$, which are a mean of the values derived from curves with a reversal current density of 5 and $30 \mathrm{mAcm}^{-2}$. 


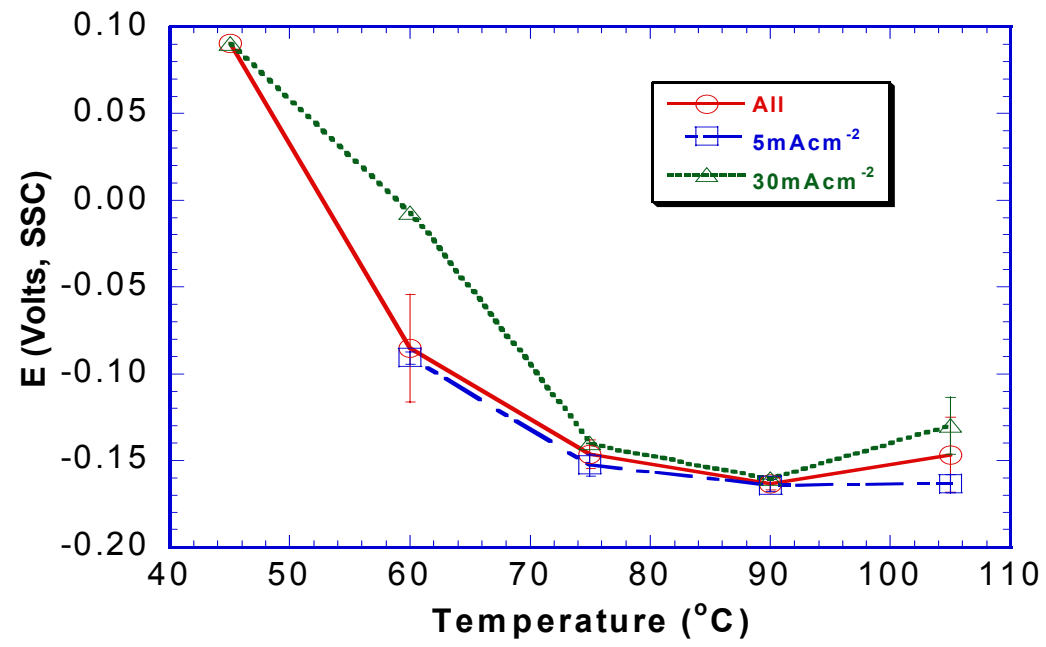

Figure 23a: $4 \mathrm{M} \mathrm{NaCl}$

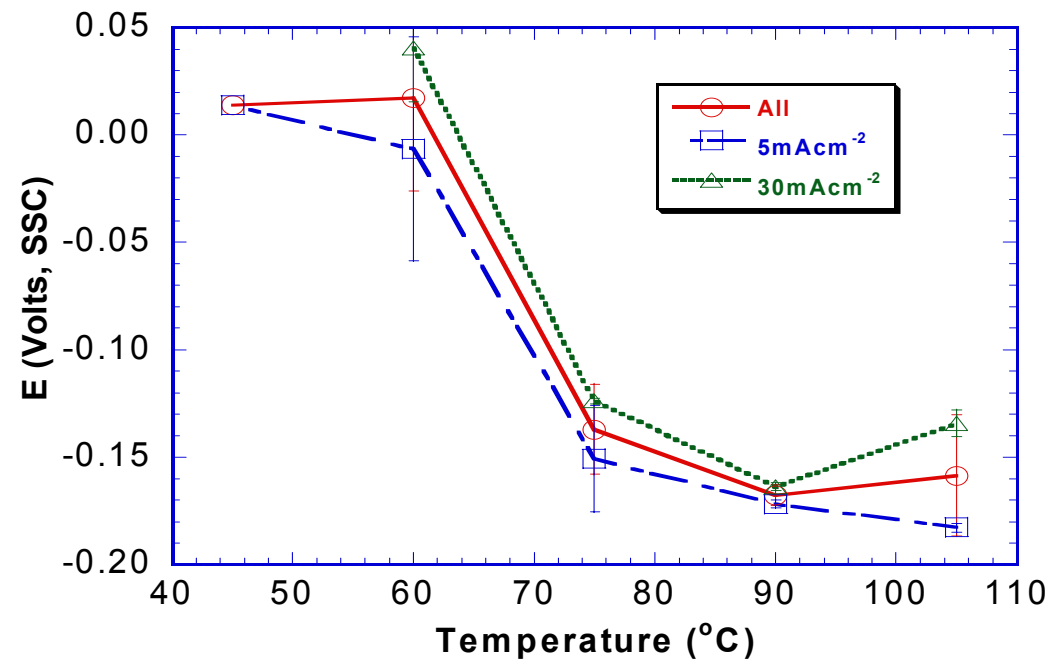

Figure 23b: $4 \mathrm{M} \mathrm{NaCl}+0.04 \mathrm{M} \mathrm{Na}_{2} \mathrm{SO}_{4}$

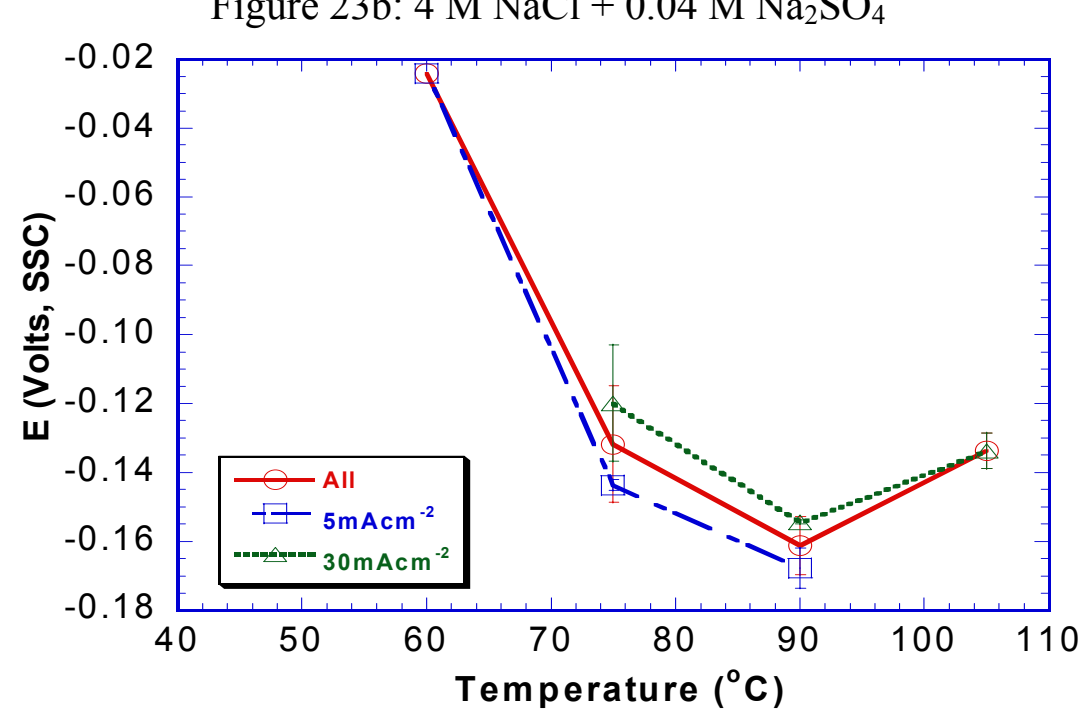

Figure 23c: $4 \mathrm{M} \mathrm{NaCl}+0.4 \mathrm{M} \mathrm{Na}_{2} \mathrm{SO}_{4}$
Figure 23. $\mathrm{E}_{\mathrm{rp}}$ of MCA in $4 \mathrm{M} \mathrm{NaCl}$ solution measured by Method 2 $\left(\mathrm{E}_{\mathrm{r} 2}\right)$ comparing values turn-around current densities of 5 and 30 $\mathrm{mAcm}^{-2}$ as a function of temperature. Graphs also show data the $\mathrm{E}_{\mathrm{rp}}$, which are a mean of the values derived from curves with a reversal current density of 5 and $30 \mathrm{mAcm}^{-2}$. 


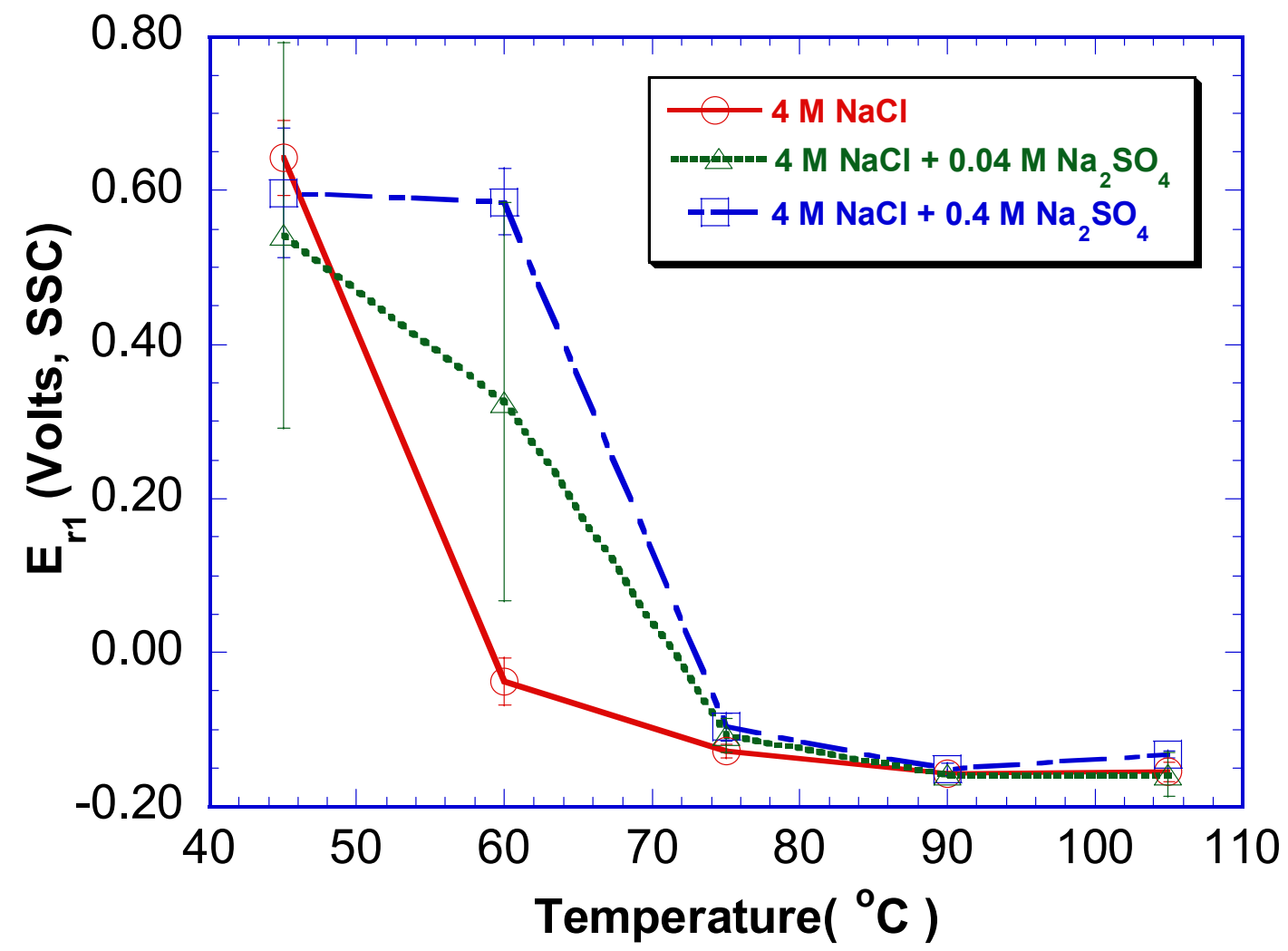

Figure 24: Summary of $\mathrm{E}_{\mathrm{r} 1}$ for $4 \mathrm{M} \mathrm{NaCl}, 4 \mathrm{M} \mathrm{NaCl}+0.4 \mathrm{M} \mathrm{Na}_{2} \mathrm{SO}_{4}$, and $4 \mathrm{M} \mathrm{NaCl}+0.04 \mathrm{M}$ $\mathrm{Na}_{2} \mathrm{SO}_{4}$. 


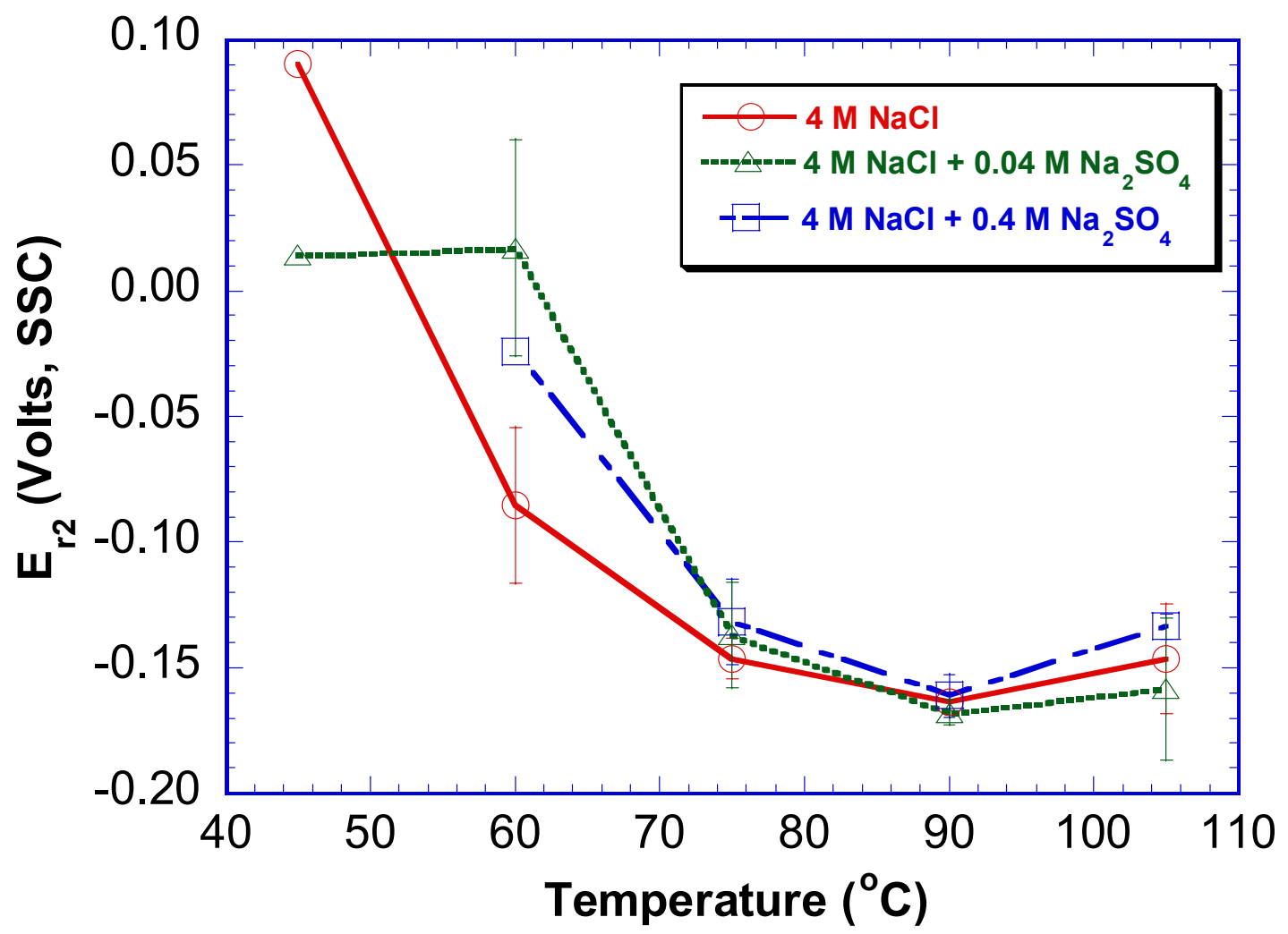

Figure25: Summary of $\mathrm{E}_{\mathrm{r} 2}$ for $4 \mathrm{M} \mathrm{NaCl}, 4 \mathrm{M} \mathrm{NaCl}+0.4 \mathrm{M} \mathrm{Na}_{2} \mathrm{SO}_{4}$, and $4 \mathrm{M} \mathrm{NaCl}+0.04 \mathrm{M}$ $\mathrm{Na}_{2} \mathrm{SO}_{4}$. 


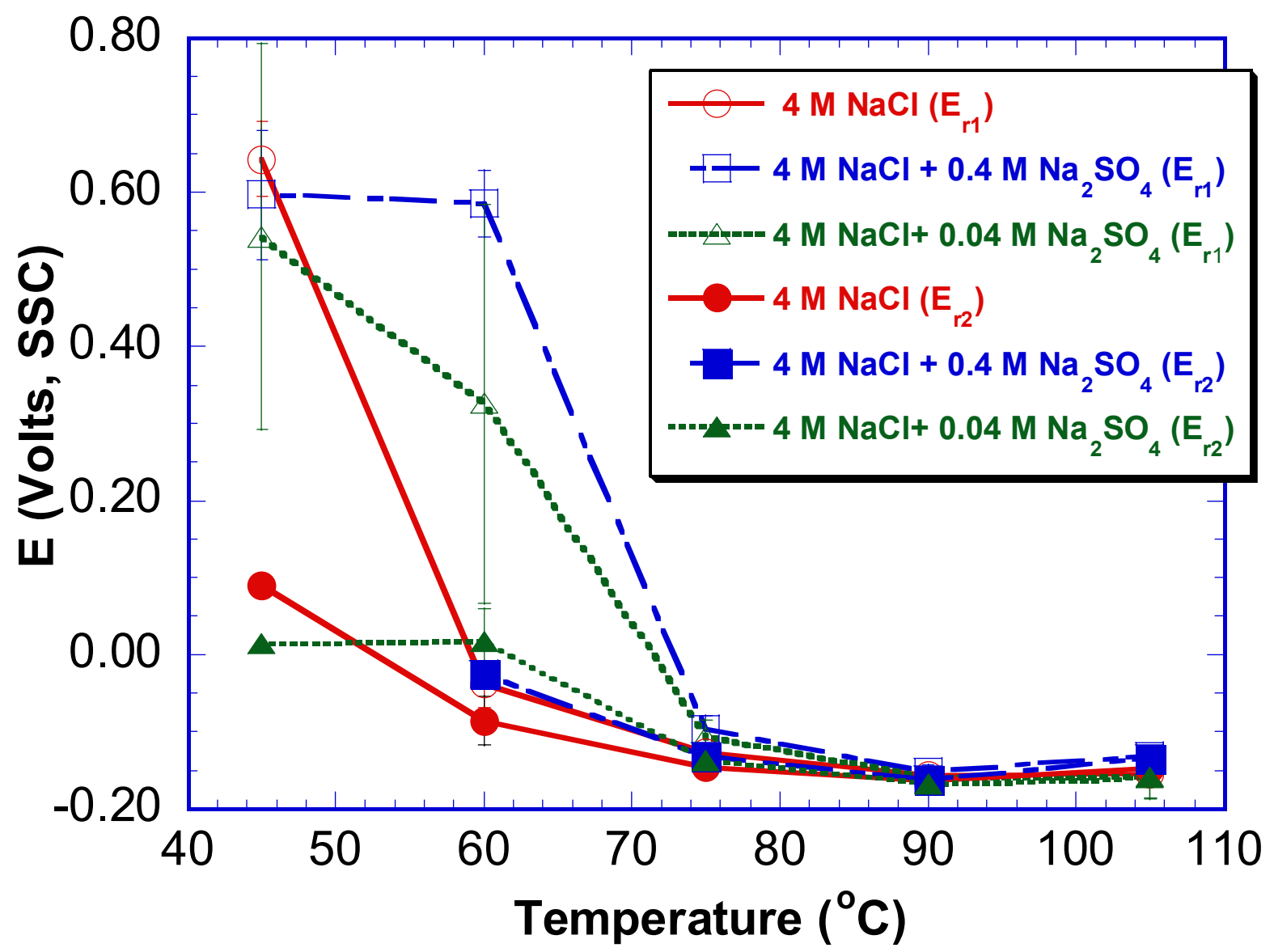

Figure 26: A comparison of $\mathrm{E}_{\mathrm{r} 1}$ and $\mathrm{E}_{\mathrm{r} 2}$ as a function of temperature. 